\title{
REVERSIBILITY \\ AS A SUSTAINABILITY CRITERION \\ FOR PROJECT SELECTION
}

\author{
by \\ Nick Fanai \\ A Thesis \\ presented to the Faculty of Graduate Studies \\ The University of Manitoba \\ in partial fulfillment of \\ the requirements for the degree of \\ Master of Science \\ in the Department of Civil and Geological Engineering
}

() December, 1996 
National Library

of Canada

Acquisitions and Bibliographic Services

395 Wellington Street Ottawa ON K1A ON4 Canada
Bibliothèque nationale du Canada

Acquisitions et services bibliographiques

395, rue Wellington Onewa ON K1A ON4

Canada
The author has granted a nonexclusive licence allowing the National Library of Canada to reproduce, loan, distribute or sell copies of this thesis in microform, paper or electronic formats.
L'auteur a accordé une licence non exclusive permettant à la Bibliothèque nationale du Canada de reproduire, prêter, distribuer ou vendre des copies de cette thèse sous la forme de microfiche/film, de reproduction sur papier ou sur format électronique.

L'auteur conserve la propriété du droit d'auteur qui protège cette thèse. Ni la thèse ni des extraits substantiels de celle-ci ne doivent être imprimés ou autrement reproduits sans son autorisation. 


\title{
THE UNIVERSTTY OF MANITOBA
}

\section{FACULTY OF GRADUATE STUDIES}

COPYRIGHT PERMISSION

\author{
REVERSIBILITY AS A SUSTAIABILITY CRITERIOA \\ FOR PROJECT SELECTIOI
}

BY

MIG FAMAI

A Thesis/Practicum submitted to the Faculty of Graduate Studies of the University of Manitoba in partial fulfillment of the requirements for the degree of

MASTER OF SCIENCE

Nick Panai C 1996

Permission has been granted to the LIBRARY OF THE UNIVERSITY OF MANITOBA to lend or sell copies of this thesis/practicum, to the NATIONAL LIBRARY OF CANADA to microfilm this thesis/practicum and to lend or sell copies of the film, and to UNIVERSITY MICROFILMS INC. to publish an abstract of this thesis/practicum..

This reproduction or copy of this thesis has been made available by authority of the copyright owner solely for the purpose of private study and research, and may only be reproduced and copied as permitted by copyright laws or with express written authorization from the copyright owner. 


\section{ACKNOWLEDGMENTS}

The author would like to express his gratitude to Dr. Bum for his invaluable advice and guidance during this research, and for his suggestions during documentation of this thesis. The author is grateful to Dr. Simonovic and Dr. Lence for their support and guidance during the research related to this thesis, and to Dr. Troutt for her useful comments on the final draft of this thesis. The author would also like to thank Dr. Onyebuchi, Ms. Kristjanson, Mr. Miles, Mr. Surminski, Mr. Wojczynski, and Mr. Raban from Manitoba Hydro for their time and input, and for the interest they have shown in the research related to this thesis. The author is also grateful to Manitoba Hydro for providing the data for the case study, and for accepting to partially support this research so that the author could receive a Natural Sciences and Engineering Research Council of Canada (NSERC) Postgraduate Industrial Scholarship. 


\section{ABSTRACT}

Increasing stress on the environment and current norms of sustainable development have prompted the formalization of new approaches to decision-making. This may be achieved through the integration of sustainability issues into the project selection process. One of the issues of relevance in this context is reversibility. Reversibility in the context of this research is defined as the degree to which the anticipated or unanticipated impacts of a development project can be mitigated. This definition implies consideration of all impacts of a development plan for the purpose of identifying which alternative is "less irreversible," namely more reversible. A framework is proposed for measuring reversibility as one component of a sustainable approach to project selection. Other components include, for example, risk and equity. In the reversibility framework, social, ecological and economic impacts are combined in their respective categories using a distance metric to obtain three category indexes of reversibility for each altemative. Concepts of resilience, time preferences, option value, quasioption value, and cumulative effects, which aid the impact quantification stage, are discussed. The application of the reversibility framework is demonstrated using data from a detailed case study, the North Central Project, which involves construction of approximately 500 kilometers of transmission and distribution lines and related activities to provide electricity for seven northern Manitoba communities that have obtained electricity from local diesel generating plants since 1967. The analysis shows that the degree of irreversibility associated with the North Central Project is less than the irreversibility of maintaining the existing diesel plants. Therefore, the North Central Project is the preferred alternative. The proposed reversibility framework is useful for compiling several sources of information in a single comprehensive form. As the principles of sustainability and sustainable development are inherently used in the framework, it is an appropriate tool for sustainable project selection. 


\section{TABLE OF CONTENTS}

\section{ACKNOWLEDGMENTS}

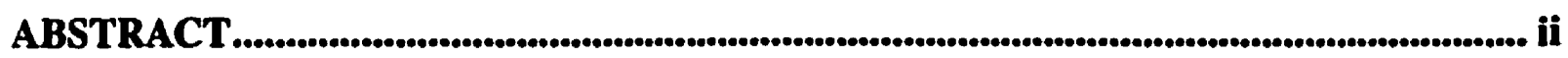

TABLE OF CONTENTS ...................................................................................................... iii

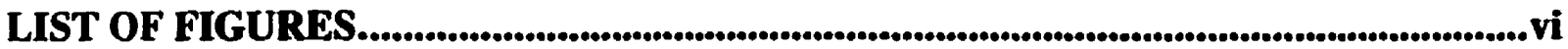

LIST OF TABLES $\ldots \ldots \ldots \ldots \ldots \ldots \ldots \ldots \ldots \ldots \ldots \ldots \ldots \ldots \ldots \ldots \ldots \ldots \ldots \ldots \ldots \ldots \ldots \ldots \ldots \ldots \ldots \ldots \ldots \ldots \ldots \ldots \ldots \ldots \ldots \ldots \ldots \ldots \ldots \ldots \ldots$

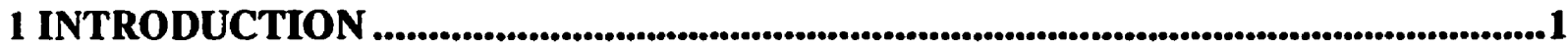

2 LITERATURE REVIEW..............................................................................................................6

2.1 Sustainable Development and Related Issues ...................................................6

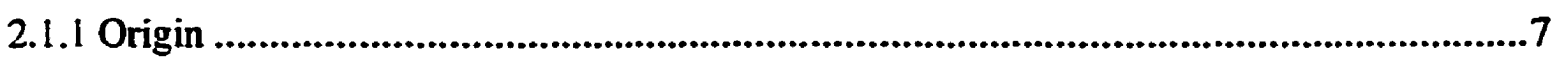

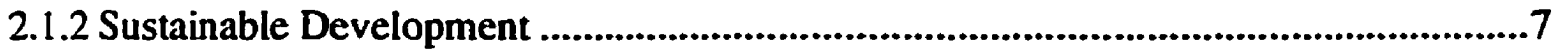

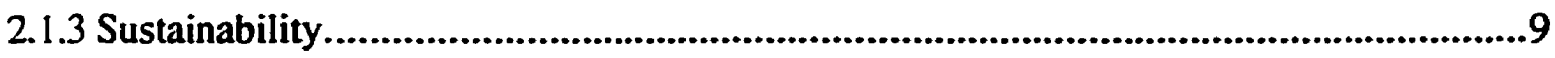

2.1.4 Objectives of Sustainable Development and Sustainability .................................. 13

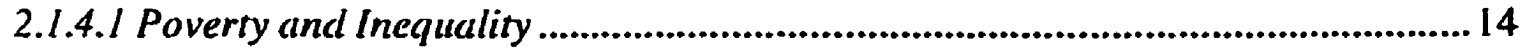

2.1.4.2 Participation .................................................................................. 16

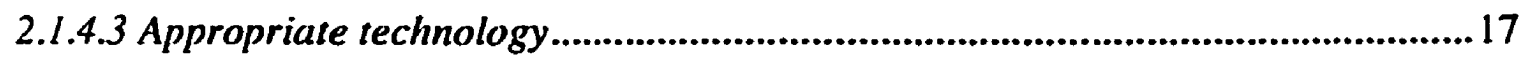

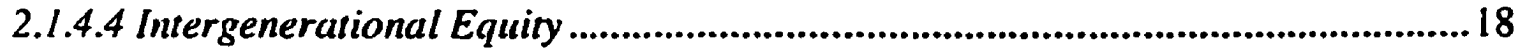

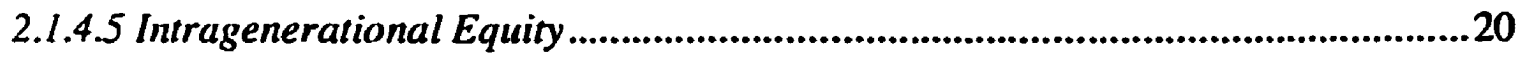

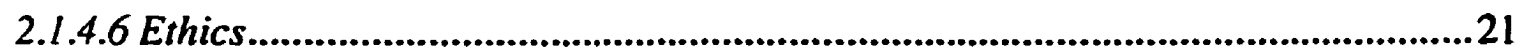

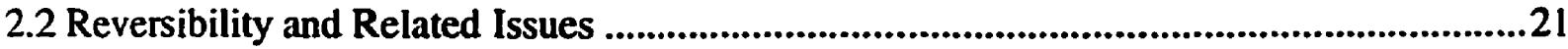

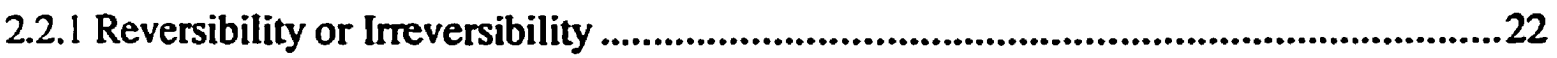

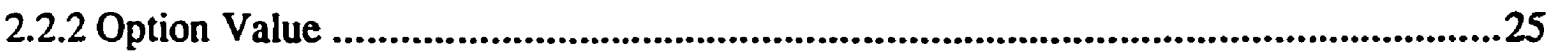

2.2.3 Quasi-Option Value ...................................................................................28

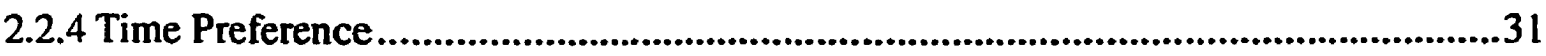

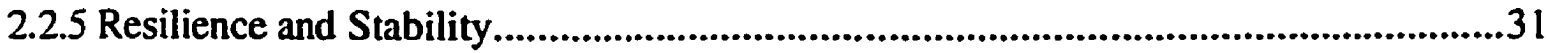


3.1 Reversibility ....................................................................................................................................36

3.2 Framework For Measuring Reversibility......................................................................38

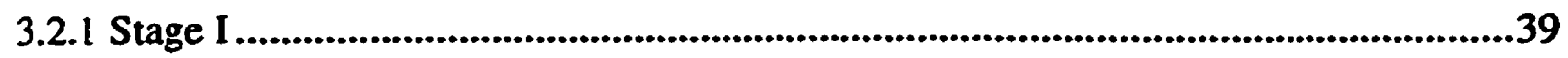

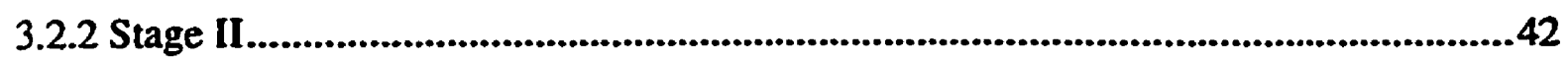

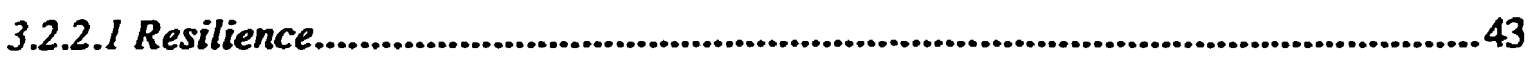

3.2.2.2 Option Value or Quasi-Option Value ...................................................................43

3.2.2.3 Time Preference.......................................................................................................44

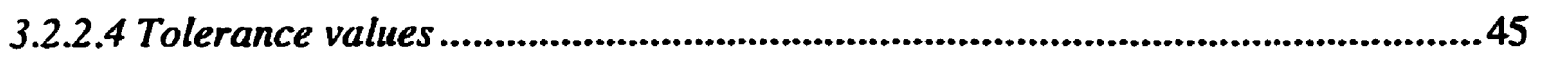

3.2.2.5 Cumulative effects....................................................................................................46

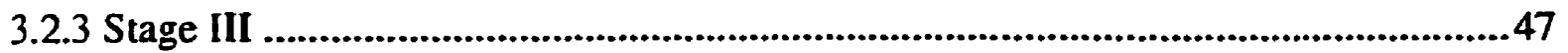

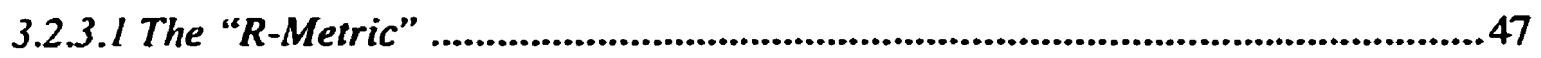

3.2.3.2 Reversibility Thresholds ............................................................................50

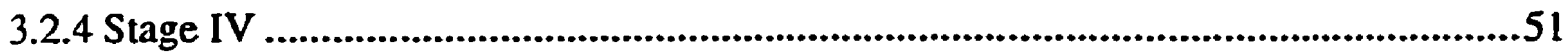

3.2.5 Aggregation of Category Indexes ..........................................................................52

3.3 Utilization of Sustainability Principles ...............................................................................53

4 APPLICATION OF REVERSIBILITY FRAMEWORK................................................54

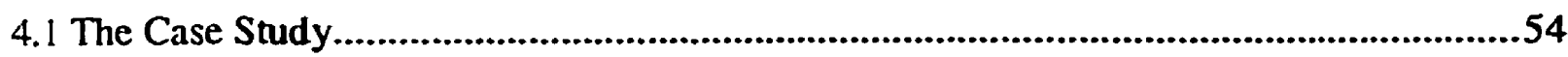

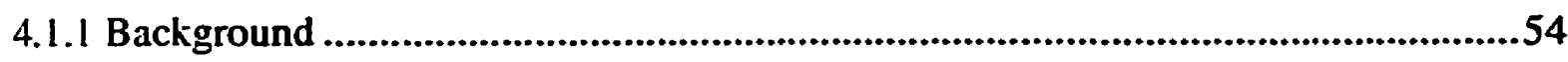

4.1.2 The North Central Project (NCP) .............................................................................57

4.1.3 Community Support and Concerns.................................................................................58

4.2 Application of Reversibility Framework ..........................................................................58

4.2.1 Stage I: Impact Identification ..................................................................................59

4.2.2 Stage II: Impact Quantification ...............................................................................60

4.2.2.I Social Impacts.................................................................................................60

4.2.2.2 Ecological Impacts.......................................................................................68

4.2.2.3 Economic Impacts ..............................................................................................

4.2.3 Stage III: Application of $R$-Metric...........................................................................74

4.2.4 Stage IV: Sensitivity Analysis..................................................................................75 
4.2.4.I Impact Weights ................................................................................................75

4.2.4.2 Impact Values .........................................................................................................77

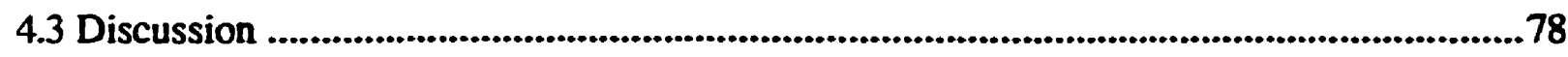

5 CONCLUSION AND RECOMMENDATIONS ..................................................................80

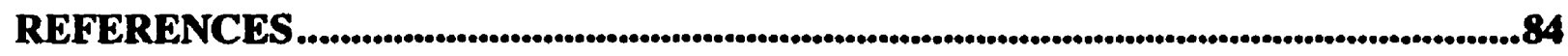

APPENDIX A: Detailed Results of $\boldsymbol{R}$-Metric Application

APPENDIX B: Detailed Results of Sensitivity Analysis 


\section{LIST OF FIGURES}

Figure 3.1 Flowchart of Reversibility Framework.......................................................39

Figure 4.1 NCP Transmission and Distribution Lines........................................................56 


\section{LIST OF TABLES}

Table 3.1 Generic List of Categorized. Impacts ..................................................................40

Table 4.1 List of NCP Impacts and Corresponding Values and Weights .............................59

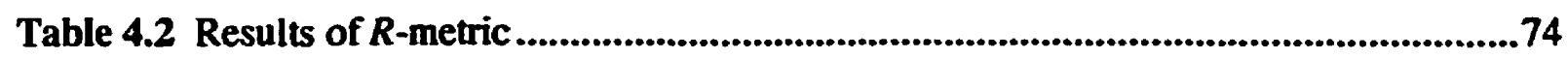

Table 4.3 Category Indexes Calculated for Ten Sets of Randomly Generated Weights........75

Table 4.4 Results of Sensitivity Analysis of Impact values ...................................................76 


\section{INTRODUCTION}

Sustainability is a broad concept that encompasses a wide range of issues conceming social integrity, environmental protection and management, economic development, and the complex linkages between these issues. Sustainable development is the major goal of sustainability with broad objectives involving minimization of damages to social and ecological resources, and supporting economic development. The most recent attempt at enforcing objectives of sustainability and sustainable development has been the incorporation of environmental impact assessment (EIA) guidelines into legislation. In the United States, EIA was incorporated into legislation through the National Environmental Policy Act (NEPA) in 1970 [Dirschl et al. 1993; Pal and Rajappa, 1993]. In Canada, the Environmental Assessment and Review Process (EARP) was established in 1974 to enforce standardized guidelines for carrying out impact assessments of federally proposed development projects [FEARO, 1978]. This process was strengthened through the Environmental Assessment Review Process Guidelines Order by the federal cabinet in 1984. Further actions were taken by the Canadian Parliament in 1993 to establish legislation that requires all development proposals seeking federal funding support or Canadian government approvals to undergo an EIA. This trend towards establishment of legislation for protecting the environment proves that there is general consensus regarding the progressive deterioration of natural resources. This in tum implies that there is a need for appropriate tools for implementing sustainability principles into the decision making process so that decision makers can meet increasingly stringent government regulations for minimizing adverse impacts of development projects. Invariably, there is an implicit requirement to consider impacts of a development project collectively in order to determine which, if any, of the alternatives satisfies regulatory guidelines.

Various methods of coalescing impacts of development plans have been discussed. Pal and Rajappa [1993] discussed environmental impact units, defined as the net difference between the sum of weighted scale values of environmental quality parameters with a project in place and the sum of values without the project, for the purpose of determining the best alternative. Munda et al. [1994] demonstrated the application of fuzzy multi-criteria methods 
for environmental management by means of a land-use problem. They used a fuzzy (qualitative) evaluation matrix containing "linguistic" values of identified criteria (impacts) for each altemative to illustrate a fuzzy conflict analysis of the "sharp conflict between environmental and economic interests." Their procedure also considered a linguistic evaluation of the altematives by affected interest groups. The outcome of their procedure is a ranking of alternatives in order of attractiveness according to the preferences of a decision maker when applied to environmental management problems with conflicting objectives related to social, ecological, and economic impacts.

Sustainable development "indicators" have been developed by a number of countries and international organizations for analyzing the state of natural resources, the pressures exerted on the environment, and the responses of the natural environment to the pressures. The development and use of indicators has been discussed from different perspectives by numerous authors. The Organization for Economic Cooperation and Development (OECD) has identified performance indicators for human "stresses" on the environment, indicators for the state of the environment, and indicators for environmental policy, for example, the amount of protected areas [OECD, 1991]. These indicators are arranged according to seven groups: 1) atmosphere; 2) water; 3) biota; 4) land; 5) waste; 6) natural economic resources; and 7) miscellaneous [from Alfsen and Sabø, 1993]. The set of indicators proposed by the Economic Commission for Europe (ECE) in 1985 are meant to "...assess the current state and development over time of environmental conditions with regard to a broad environmental concem." These indicators are grouped in five main categories: 1) nature; 2) resource; 3) human activities affecting environmental activity; 4) quality of media, species and habitats; and 5) environmental management [from Alfsen and Sæbø, 1993]. Environment Canada [1991] published a preliminary set of indicators covering a wide range of environmental issues grouped under five main headings: 1) atmosphere; 2) water, 3) biota; 4) land; and 5) natural economic resources. The ultimate goal of defining these indicators was to facilitate the development of a "state of the environment index" similar to the economic index GDP [Alfsen, 1991]. Karr et al. [1986] developed the Indicator of Biological Integrity (IBI) for assessing the sustainability of fish populations in streams in midwestern United States. Schaefer et al. [1988] identified eleven criteria for measures of ecosystem health which also 
apply as ecological indicators. Palmer and Rising [1996] developed an environmental sustainability parameter (ESP) for agriculture which rates farm waste management practices relative to a selected set of sample area farms that are identified as being operated at various levels of sustainability, and is adaptable to any farming area.

Typically, there are several alternatives associated with one particular development project. Ultimately one of the alternatives is selected for implementation based on some criteria. A comparison of the altematives is desirable as the type and severity of impacts can vary widely between alternatives. With the exception of EIA guidelines and environmental indicators, comprehensive frameworks that facilitate such comparisons for sustainable project selection are scarce. Traditional decision making approaches for project selection focus mainly on economic objectives that maximize economic benefits, and are based on results of standard benefit-cost analyses. Decision makers who use these approaches are bound only by existing government regulations for minimizing adverse social and ecological impacts. "Architects, engineers, and builders still prefer and use broadly standardized designs and materials rather than work out locally adaptive variants" [Weeden, 1989, p. 44]. Furthermore, sustainable decision making requires changes in substantive and procedural environmental policies [Jordaan et al., 1993]. A consolidation of sustainability principles and traditional objectives of development requires changes in the criteria on which decisions concerning the natural environment are based, environmental policies that enforce sustainability objectives, and most importantly frameworks that comply with the requirements of new environmental policies. "The absence of a clear theoretical and analytical framework...makes it difficult to determine whether the new policies will indeed foster an environmentally sound and socially meaningful form of development" [Lele, 1991, p. 607]. A further requirement for sustainability is the simultaneous consideration of social, ecological, and economic objectives without compromising one for another. Frameworks which are based on sustainability criteria can also increase awareness of the existing state of natural resources and instigate a moral obligation so that protecting natural resources and achieving sustainability become more than a set of government regulations. 
One of the criteria of relevance that can contribute to achieving the broader goal of sustainability is reversibility, identified in an intemational discussion forum under the United Nations Educational, Scientific and Cultural Organization project [UNESCO, 1995]. A framework for measuring reversibility of altemative projects was developed as documented in this thesis. This framework considers the project altemative with the lowest degree of irteversibility (opposite of reversibility) as the most reversible and, therefore, the most desirable. The reversibility framework is proposed as a combined theoretical and analytical tool for implementing reversibility as one of many viable sustainability criteria in the decision making process. The proposed framework also provides an expanded view of development projects that involve use of natural resources and related issues that will assist future research in a similar direction. The ultimate goal of the framework is sustainable project selection.

It is important to note that the reversibility framework is only one of many possible components of a sustainable approach to project selection. It does not replace other methods proposed for identifying and assessing impacts of development such as those discussed earlier. Two other criteria that were identified under the UNESCO project, in addition to reversibility, are risk and equity. Risk, as a component of sustainable project selection, is defined as the possibility of harm and the chance of occurrence as estimated by applicable facts, heuristic knowledge and cultural perception [Kroeger, 1996]. Equity considers the fair distribution of social, ecological, and economic impacts among all affected groups [Matheson, 1996]. A measure of reversibility, or of risk, equity, or other sustainability criteria, supplements a traditional decision making approach, and assists in the evaluation and comparison of project alternatives for sustainable project decision making.

Chapter 2 presents an overview of key sustainability and sustainable development issues that are relevant to this thesis, as well as various topics related to reversibility that have been discussed in the literature. The literature review is sufficiently comprehensive for the purpose of the research presented herein, but is not exhaustive of all issues, particularly those related to sustainable development, as this is beyond the scope of this work.

Chapter 3 contains a description of the reversibility framework and its method of application. Reference to key concepts reviewed in Chapter 2 are made where appropriate in 
order to discuss the theoretical aspects of the framework. The application of the reversibility framework involves four main stages. In Stage I, social, ecological, and economic impacts are identified. Stage II involves the quantification of all impacts. A revised version of a common distance metric is applied in Stage III to obtain reversibility indexes in each category (social, ecological, economic) for all altematives. A sensitivity analysis is carried out in Stage IV. Methods for combining the three category indexes (social, ecological, economic) were not investigated as it is reasonable to assume that the number of feasible alternatives for most development projects are few (less than ten) and, therefore, three indexes per alternative is manageable. Furthermore, decision makers would most likely prefer to observe a measure of performance in each category so that the social, ecological, or economic impacts that are problematic are more easily identified and the appropriate action can be employed. The purpose of the reversibility framework presented in this thesis is not to replace EIA. The reversibility framework is proposed as an additional tool that can assist decision makers in analyzing impacts of development plans in a systematic form for making the project selection process sustainable.

An introduction to the North Central Project and the application of the proposed reversibility framework to data extracted from various documents related to the case study are presented in Chapter 4 . This chapter also contains a discussion of the sensitivity analysis of the reversibility indexes to changes in various parameters.

Chapter 5 contains a discussion of the general proficiency of the framework in terms of the validity of the reversibility indexes and ease of application. The applicability of the reversibility framework in various situations and at various stages of development are discussed. Recommendations for future extensions to the framework are also discussed in this chapter. 


\section{LITERATURE REVIEW}

This chapter is divided into two main sections. Section 2.1 contains a brief overview of sustainable development, sustainability, and several issues of relevance to this thesis that have been addressed in the literature. A complete review of sustainability, sustainable development and all of the related issues is beyond the scope of this research. A clear understanding of the relevant issues, however, is necessary for understanding the proposed framework for measuring reversibility of development decisions. The main motivation in the literature for discussing reversibility or irreversibility coincides with one of the underlying principles of sustainable development, namely the preservation of natural resources. Section 2.2 offers an overview of the topic of reversibility and related issues found in the literature which are used in the proposed framework for measuring reversibility (Chapter 3 ).

\subsection{Sustainable Development and Related Issues}

Definitions of the phrase "sustainable development" have propagated very rapidly since its introduction. A consensus on definitions has not been formed due to the wide range of viewpoints and philosophies that have been discussed. Though a relatively new topic, there are many common issues related to sustainable development that have been discussed by different authors. The definitions of sustainable development and sustainability and their objectives, poverty and participation, intergenerational and intragenerational equity, appropriate technology, and ethics are only a few examples that are of relevance to this thesis. These issues are discussed in this section beginning with the origin of the phrase "sustainable development" as cited by various authors. A complete review of the literature on the topic of sustainable development is beyond the scope of this thesis. 


\subsubsection{Origin}

According to Barbier [1989] the concept of sustainable development (SD) most likely originated at the Paris Biosphere Conference and the Washington DC Conference on the Ecological Aspects of International Development, both held in 1968. However, the 1972 UN conference on the Human Environment, held in Stockholm, is usually credited with popularizing its concept.

Pearce et al. [1993, p. 7] distinguish between two environmental revolutions. The first revolution in attitudes toward the environment occurred in the late 1960s and early 1970s and was characterized by the debate over environmental quality versus economic growth. The late 1980s and early 1990s witnessed a second revolution which continues to expand on the original concepts and arguments. It was during the second revolution that the term "sustainable development" was introduced and began to gain popularity.

The concepts of sustainability and sustainable development received a major impetus from the World Commission on Environment and Development report, Our Common Future. This report is also referred to as the Brundtland Report because the commission, created by the United Nations in 1983, was headed by Mrs. Gro Harlem Brundtland, former Prime Minister of Norway.

\subsubsection{Sustainable Development}

There is no single definition of sustainable development that clearly captures all of its underlying concepts. Many authors have contributed to the literature with their interpretation of the phrase in an attempt to either dispute or concur with the mainstream definitions. For example, while O'Riordan [1985] calls sustainable development a contradiction in terms, Redclift [1987] suggests that it is just another development truism.

The World Commission on Environment and Development [WCED, 1987], in Our Common Future, has defined sustainable development as "development that meets the needs of the present generation without compromising the ability of future generations to meet their own needs" [p. 43]. 
Lele [1991] offers a critical review of conceptual and interpretational weaknesses of the phrase sustainable development. Lele states that there are those who believe that SD should not be defined too rigorously, as the value of the phrase lies in its broad vagueness. But following a full discussion of interpretational problems and conceptual weaknesses contained in the phrase, he suggests that if SD is to have a fundamental impact, its politically expedient vagueness must be replaced by intellectual clarity and rigor. Lele tries to clarify interpretational problems associated with the phrase "sustainable development," which as he claims are ultimately conceptual but have some semantic roots. He defines the concepts of sustainability and development separately and then brings the concepts together to present a general interpretation of sustainable development: sustainable development is achieving traditional objectives of development, for example, meeting basic needs, plus ecological and social sustainability.

From an economic perspective, Pearce et al. [1993, p. 8] state that SD "describes a process in which the natural resource base is not allowed to deteriorate." What they call the second environmental revolution in the 1980s showed that limits to economic change do exist if economies are not managed in an environmentally sensitive way. This change in economic perspective has been captured by the term "sustainable development."

Pearce et al. [1990] claim that "development" is a value word, implying change that is desirable. Therefore there is no consensus as to its meaning. They define development in terms of a "vector of desirable social objectives," a list of attributes which society seeks to achieve or maximize. After discussing a few caveats, they suggest that sustainable development can be defined in its "weak form" as the general requirement that the rate of change of development (the vector of desirable characteristics) over time be püsitive over some selected finite time horizon. In its "strong form" sustainable development requires that the rate of change be increasing.

According to Tolba [1984] most people use the phrase "sustainable development" interchangeably with "ecologically sustainable" or "environmentally sound development" [Tolba, 1984, cited in Lele, 1991].

Mannion [1992] states that the concept of sustainable development promotes the message that resources should be conserved because they are not infinite. It is a term that is 
acknowledged to be more rhetorically than factually valuable. Mannion briefly discusses the spatial and temporal aspects of sustainable development. For example, what is sustainable locally may not be sustainable regionally, and what is sustainable over a decade may not be sustainable over a century.

Pearce and Turner [1990] establish two rules for achieving a sustainable economy. First, use of renewable resources should be carried out such that the rate of use is not greater than the natural regeneration rate. Second, waste flows to the environment must be kept at or below the assimilative capacity of the environment.

Repetto [1986] defines sustainable development as a development strategy that manages all assets, natural resources, and human resources, as well as financial and physical assets, for increasing long-term wealth and well-being. Sustainable development rejects policies and practices that deplete the productive base including natural resources to support living standards and leaves future generations with poorer prospects and greater risks than our own [p. 15].

Sustainable development is viewed as an objective of the much larger goal of sustainability. The distinction has not been clearly addressed in most of the literature, and an attempt to do so is beyond the scope of this thesis. The topic of sustainability is addressed in the next section.

\subsubsection{Sustainability}

A few authors have used mainstream concepts to define sustainability in place of sustainable development. For example, Pearce et al. [1993] (summarized in the previous section) used a maintenance-of-the-natural-resources argument to describe SD, while Field and Olewiler [1995] used a similar argument to define sustainability (see below). The most notable attempt at defining both concepts in a single article appears in Lele [1991]. This article and several other sources that have addressed the concept of sustainability apart from that of SD are summarized in this section.

According to Lele [1991] the concept of sustainability originated in the context of renewable resources such as forests and fisheries, and has formed into a broad slogan 
sanctioned by the environmental movement. Most proponents of sustainability accept the interpretation that it is "the existence of ecological conditions necessary to support human life at a specified level of well-being through future generations" [p. 609]. Lele argues that one cannot deny that humans (as well as animals) depend on ecological resources and conditions for sustenance and well-being. Ecological sustainability is necessary to support human life now and in the future. This means that the ecological or biophysical patterns that respond to human activity must be maintained such that the ability of present and future generations to use the ecological resources does not diminish. This implies a circular relationship between humans and ecological resources. As an example, soil erosion could be caused by excessive farming on marginal lands without allowing for fallow periods. This ecological unsustainability can perpetuate into further degradation of farming conditions thus jeopardizing the ability of those who depend on farming for subsistence, both now and in the future. In reality, however, the problem may be much more complex with social causes being one aspect of ecological unsustainability.

Dovers and Handmer [1993] define sustainability as "the long-term and difficult goal of reaching an ecologically sustainable state." Sustainable development is only a variable process by which we might move towards sustainability. They argue therefore, that sustainable development is an objective of the much larger goal of sustainability.

Jacobs [1993] states that the term sustainability is often used as a general indication of "environmental goodness" but it does have a useful intuitive meaning, namely the capacity to last or continue. Jacobs defines sustainability as the maintenance of environmental capacities at levels which at least avoid future environmental catastrophe and which at most give future generations the opportunity to enjoy a level of environmental consumption at least equal to that of the present generation.

There are different viewpoints regarding the term sustainability when used with the adjectives 'social' or 'ecological.' While some authors consider social issues independent of ecological issues, others consider them complementary. Barbier [1987] considers social sustainability separate from ecological sustainability and defines it as the ability to maintain desired social values, traditions, institutions, cultures, or other social characteristics. Robinson et al. [1990] state that "a sustainable society must be sustainable in both 
environmental and socio-political terms" [p. 38]. Weeden [1989] points out that social issues must be considered if a development project is to be sustainable since a human activity can be sustained only if it is socially acceptable. Lele [1991] maintains that usage of the term 'social sustainability' is not very common but social aspects of sustainability must be considered in order to determine which of the ecological principles of (ecological) sustainability are acceptable. There is no contradiction between social and ecological sustainability, rather they can complement and inform each other.

Tumer [1988] presents two modes of sustainability [from McPeak, 1994]. The first is sustainable growth mode which is defined by a policy where conservation is one of several goals of an overall materials policy that includes waste recycling options and waste reduction strategies. The second is the sustainable development mode which, by contrast, considers conservation and preservation as the sole basis for defining criteria to be used in evaluating policy. In this mode, environmental ethics becomes the key theme for analysis.

To define sustainability, Robinson et al. [1990] use the Brundtland Commission's (WCED) definition of sustainable development, which provides a basis for applying the concept of sustainability both bio-physically and socio-politically, as a starting point. They define sustainability as "the persistence over an apparently indefinite future of certain necessary and desired characteristics of the socio-political system and its natural environment" [p. 39].

Dovers and Handmer [1993] have identified and commented on eight of what they call "most obvious contradictions" of sustainability. The first contradiction is between "technology and culture: cause versus cure" which suggests that technology and cultural preferences are the cause of unsustainability to date but they also provide the only means of moving towards sustainability. The second is "humility versus arrogance" which suggests that despite a continually increasing quantity of information our comprehension of the global environment is characterized by greater and greater uncertainty. While needing humility to acknowledge our non-omniscence and accept new knowledge and experience, we also need arrogance to make decisions in the face of the inevitable ignorance regarding the global environment. The third contradiction considers "intergenerational versus intragenerational equity" to point out that conflicting allocation of resources between present and future 
generations can arise due to the difficulty in selecting appropriate temporal scales. The fourth, "growth versus limits," points out the conflict between, and hence the concem for, economic growth and the limits that must be imposed on that growth in order to achieve sustainability. Fifth, "individual versus collective interests" are in conflict since environmental issues, and sustainability generally, are overwhelmingly collective problems arising from the sum of individual preferences and consumption. Those who consume little and those who consume a great deal bear the same costs of total consumption. Therefore, tensions between individual and broader goals increase. The sixth, "democracy: diversity versus purpose," points out that self-determination and participatory democracy are promoted as basic rights in a world that is structured by a myriad of unconnected, autonomous regional economies, which may contradict the need for purposeful action at the global level. To reconcile with the other extreme of world governance involves measures that might be called "international ecofascism." The seventh is "adaptability versus resistance" which indicates that "change at the margins" in industrialized societies gives the appearance of significant change in response to pressure, while retaining the underlying assumptions and institutional structure, when in fact that change is a form of resistance. To avoid delaying change until it occurs in a painful way, institutions which are flexible and adaptable are required. The last contradiction, "optimization versus spare capacity," questions whether or not optimization is antisustainability since it implies making the best possible use of the environment leaving very little spare capacity to be used when confronted by the need to change [from McPeak, 1994].

Economists Field and Olewiler [1995, p. 434] state that sustainability is fundamentally a matter of renewable resources. A rule to achieving sustainability is to use nonrenewable resources at a rate that is neither too fast nor too slow, and to ensure that the natural wealth that they represent is converted to human-made wealth consisting of physical capital (roads, industry), human capital (education, skills), and institutional capital (efficient legal system, effective public agencies). 


\subsubsection{Objectives of Sustainable Development and Sustainability}

Some of the literature on the topic of SD has tried to capture and summarize objectives of SD within social, ecological, and economic boundaries. Several more clearly stated objectives extracted from selected articles are reviewed in this section.

According to Tolba [1984], the concept of sustainable development put forward by The United Nations Environment Program (UNEP) encompassed the following goals of sustainable development: (i) help for the poor, because they are left with no options but to destroy their environment; (ii) the idea of self-reliant development, within natural resource constraints; (iii) the idea of cost-effective development using nontraditional economic criteria; (iv) issues of health control, appropriate technology, food self-reliance, clean water and shelter for all; and $(v)$ the notion that people-centered initiatives are needed.

Jacobs et al. [1987] summarize the debate at the conference on Conservation and Development (held in Ottawa in 1986) into five broad requirements for sustainable development: ( 1 ) integration of conservation and development; (2) satisfaction of basic human needs; (3) achievement of equity and social justice; (4) provision of social self-determination and cultural diversity; and (5) maintenance of ecological integrity.

Serageldin [1993] suggests that the principles of SD require that the ecological, social, and economic criteria have equal importance, and that the mainstream economic objectives be replaced by a combination of the three criteria. These SD criteria occupy the three comers of the SD triad. Therefore, the objectives of SD can be categorized into three components: (1) social objectives, including social cohesion, institutional setting, empowerment, social identity, and participation; (2) ecological objectives, including ecosystem integrity, maintenance of environmental carrying capacity, and biodiversity; and (3) economic objectives, including growth (for example, growth in GDP), equity, and efficiency.

WCED [1987] lists eight operational objectives of sustainable development: (1) reviving growth; (2) changing the quality of growth; (3) meeting essential needs for jobs, food, energy, water, and sanitation; (4) ensuring a sustainable level of population; (5) conserving and enhancing the resource base; (6) reorienting technology and managing risk; (7) merging environment and economics in decision making; and (8) reorienting international 
economic relations [p. 49].

Palmer [1992, p. 183] offers twelve priorities for achieving sustainable development: (1) slow population growth; (2) reduce poverty, inequality and Third World debt; (3) make agriculture sustainable; (4) protect forests and habitats; (5) maintain water quality; (6) increase energy efficiency; (7) develop renewable sources of energy; (8) limit air pollutants especially greenhouse gases; (9) reduce waste generation and increase recycling; (10) protect the ozone layer, (11) protect ocean and coastal resources; and (12) shift military spending to sustainable development.

Several themes are common to the objectives of sustainable development and sustainability. A clear representation of all themes is a daunting task as they are interrelated and can bifurcate into many subcomponents. The common themes considered in this literature review include poverty and inequality, participation, appropriate technology, intergenerational equity (or intergenerational faimess), intragenerational equity, and ethics. Segments from selected articles that have addressed these themes are respectively summarized in the subsections that follow.

\subsubsection{Poverty and Inequality}

Singh and Titi [1995, p. 6] defined poverty as "...a condition of lack of access to options and entitlements which are social, political, economic, cultural and ecological." They listed three conditions that characterize the poor: (1) isolation due to distance from centers of trade and information; (2) vulnerability to physical incapacity and exploitation; and (3) powerlessness because of ignorance of their rights and lack of access to employment. They defined impoverishment, in relation to poverty, as "...an active process that leads to diminished access to options and entitlements" [p. 6].

Serageldin [1993] points out that the poor suffer the most from environmental degradation and they are the least well-equipped to protect themselves, yet they are the cause of much of the damage as a result of short term necessity, ignorance, and lack of resources. In particular, the poor are the most vulnerable in terms of exposure to certain types of 
pollution. They also suffer disproportionately from indoor air pollution that results from buming unclean, but affordable, bio-fuels [p. 8].

Pearce and Warford [1993] relate poverty to the level of environmental degradation especially in the poorer economies that heavily depend on natural resources. As poverty increases, natural environments are degraded to obtain immediate subsistence supplies. As environments degrade, the prospects for future livelihood decrease, and environmental degradation generates more poverty. Thus, the cycle accelerates and the "trap of environmental degradation and poverty" worsens [page 48].

Reddy [1994], in his discussion of technology and development, argues that povertystricken inhabitants of developing countries are more adversely affected by environmental pollution because of their much lower level of nutrition and health. The under-privileged in poor countries, therefore, can afford pollution less than the healthier and better nourished people in rich countries.

Bartelmus [1986] also points out the link between poverty, development and environmental problems in developing countries. Bartelmus states that "...many environmental problems in developing countries originate from the lack of development, that is from the struggle to overcome extreme conditions of poverty" [p. 18].

Boyce [ 1994] extends two hypotheses that relate environmentally degrading economic activity to the balance of 'power' and wealth. First, the extent of an environmentally degrading activity depends on the balance of power between the winners, who derive net benefits from the activity, and the losers, who bear net costs. Second, greater inequalities of power and wealth lead to more environmental degradation. Environmentally degrading activities often generate relatively small short term benefits and high long-run costs.

Reddy [1994] suggests that inequalities grow with increasing industrialization in developing countries on the basis of modem technology [p. 330]. The gap between the rich and the poor increases as a result of unemployment caused by introducing capital-intensive modern technology into developing countries where only labour is found in abundance.

Repetto [1986] argues that most would agree that consigning a large segment of the world's population to deprivation and poverty is unfair since poverty is the underlying reason for the deterioration of resources and the population growth in much of the world. 


\subsubsection{Participation}

The concept of participation is related to poverty in terms of sustainable development in that participation is a necessary condition for 'empowerment' defined as the process of removing poverty. Participation can occur at different levels with respect to sustainable development. For example, Cohen and Uphoff [1980] identified four types of participation: in decision making, implementation, benefit distribution and their evaluation. This section is generally concerned with the role of participation, at any level, for achieving sustainable development.

Lele [1991] identifies participation as one of the conceptual weaknesses of sustainable development. The term 'local participation' is beginning to gain as much emphasis as equity and social justice. There are three problems with this shift. First, the term participation should not be used interchangeably with the terms equity or decentralization since participation is necessary but not sufficient for maintaining equity and social justice. Second, mainstream SD literature assumes that involvement of non-government organizations in project management and implementation ensures project success. Third, there is an assumption that participation automatically reinforces ecological sustainability.

In a discussion paper on the topic of participation, Vivian [1991, p.18] stated that “...struggles for greater participation are essential elements of the foundation of an endurable basis for sustainable development. This process can only be helped by the growing recognition of the importance of the environment for the future well-being of the entire planet."

Serageldin [1993] argues that people are the instruments, beneficiaries, and victims of all development activities. Their active involvement in various stages of development are crucial to achieving success. Therefore, "the challenge is to make participation more than an empty catchword" [p. 10]. Those potentially affected by development projects should participate at the design stage. Local knowledge should be better incorporated in design and implementation of projects.

Cernea [1993], in his discussion on the sociologists' approach to achieving sustainable development, identifies "social management tools" that can be used to integrate social resources with development programs. These tools range from creating public awareness to 
investing in human capital, and from simple consultations to fostering participatory comanagement. With respect to technology, creating and strengthening socially adequate organizational structures, and involving users of the technology, is no less important than the technology itself.

Ghai [1992] points out that local communities should be given the power to protect themselves against adverse impacts of development. This can only be achieved by allowing them to participate in the decision-making process. Locals have a greater interest in the health and integrity of the environment than any outside parties for their very existence and way of life are at stake. The knowledge and understanding possessed by local communities of the indigenous ecology characterized by incredible complexity, diversity and specificity gained out of constant interaction with the environment are invaluable. Local communities are in a good position to evaluate the relevance and validity of solutions to environmental problems devised by external agencies.

\subsubsection{Appropriate technology}

Reddy [1994] offers criticisms of modern technology classified into three broad categories: environmental; economic; and social. His environmental criticisms focus on exploitation of natural resources and urban gigantism in developed countries, and high levels of pollution caused by high concentrations of modern technology in industrialized regions of developing countries. With respect to economics, Reddy argues that the capital-intensive and labor-saving nature of modern technology when introduced into developing countries, where labour is abundant but capital is scarce, results in increased unemployment. Unemployment aggravates poverty, and since the market of luxury goods produced by modem industry is only accessible to those employed at the higher levels of the capital-intensive modern sector, the gap between the affluent and the poor increases. This can also occur within different regions of developed countries. Reddy's social criticisms of modern technology center on commercialism in developed countries which causes dispossession of the under-privileged and social stresses between the rich and the poor leading to possible acts of aggression. In developing countries, the disintegration of traditional social forms of organization and ancient modes of production, and the generation of a dual society, are the main social criticisms. 
Hogendorn [1992] defines technology as the application of art, craft, or skill to a product or process. He discusses technological change in industry, in agriculture, in forming "human capital," in planning and markets, and in relation to economies of scale from an economic viewpoint. Hogendom considers five economic arguments that are used to justify high capital intensity in the modem sector of a labor-abundant country: (1) low labor productivity, most often a result of malnutrition and illness in the work force; (2) artificially high prices for labor or low prices for capital; (3) factor substitution is difficult if the capitallabor ratio is largely fixed and unalterable; (4) designing and servicing labor-intensive equipment; and (5) technology that is used as a competitive device.

Mannion [1992] argues that biotechnology can contribute to achieving sustainable development. Resource recovery and recycling, and hazardous waste disposal are environmentally beneficial facets of biotechnology. These are pertinent to sustainable development because they extend the resource base.

Krutilla and Fisher [1972] discuss some economic implications of technological change. When a decision is made to invest in a development project, the corresponding technology is locked in during the life of the investment. Considering a number of development alternatives (for example, all possible means of producing electricity such as hydro, thermal, wind, etc.), the shorter the life of the facility, the shorter is the time over which each alternative is locked in by the state of technology existing at the time of investment. In other words, the shorter the life, the more frequently will the capacity of hydropower generation of the alternative be updated by new technology, and, other things remaining equal, the more efficient will the shorter lived altemative grow relative to the longer lived technologically fixed alternative. In short, technological improvements of alternative sources of electricity occur at different rates, therefore the relative technological advancements must be considered.

\subsubsection{Intergenerational Equity}

Page $[1977 \mathrm{a}, \mathrm{b}]$ argues that in order to achieve a state of "permanent livability," a state of economy that is sustainable through time, there must be "equal access" to the natural resource base. This will ensure that the least advantaged generation is supplied with the 
maximum amount of primary goods (goods which people rationally prefer more of than less of). Thus, in the context of intergenerational faimess, the general requirement is that the stock of natural capital be increasing, or at least held constant, through time.

Solow [1986] also uses the constancy of total capital stock argument to set out conditions for intergenerational faimess. From an ethical perspective, this means an equitable rate of depletion of non-renewable resources from one generation to another, and a constant flow of consumption over time. To achieve intergenerational faimess, therefore, it is necessary to invest the entire economic return from a non-renewable resource in reproducible (natural) capital. Field and Olewiler [1995] agree with this point, and state that when nonrenewable resources are used they become unavailable to future generations.

Pearce et al. [1989] say that the intragenerational equity aspect of sustainable development places emphasis on providing for the needs of the least advantaged in society. They suggest as a general principle that future generations should be compensated for reductions in resources caused by the actions of the present generation. Pearce et al. [1990] use Rawls' [1972] principle of justice as a moral basis for arguing that the next generation should have a level of access to the natural resource base at least equal to that of the previous generation. Since individuals are under a "veil of ignorance" about where in society they would be allocated, decision-makers would avoid disadvantaging certain groups for fear that they themselves would be allocated to those groups. The intergenerational variant of the Rawls principle extends the veil of ignorance to the intertemporal context in which each generation is ignorant of the time period to which it will be allocated.

Tisdell [ 1993] also uses Rawls' theory of justice as a basis for argument. Tisdell states that "given that every individual could have been bom into the situation of any other, and that everyone in a hypothetical original position involving 'a veil of ignorance' would be uncertain of when and in what situation they would be born, they would opt for equality of 'income' unless inequality was to the advantage of all" [p. 132].

Jacobs [1993] defines two interpretations of sustainability. A "weak" or "minimal" version of sustainability would require that present generations sustain the environment to the extent that future generations are guaranteed at least the avoidance of environmental catastrophe. The "strong" or "maximal" version by contrast would demand that future 
generations be given the opportunity to experience a level of environmental consumption at least equal to that of the present generation.

According to Batie [1989], the main concem regarding intergenerational equity is central among advocates of SD. He identifies two general definitions common to most interpretations. These are "constrained economic growth" and "maintenance of the resources." The constrained economic growth definition involves first a formalization of rules that incorporate ecological principles and environmental ethics, and second allowance for traditional economic maximization within the framework. Conversely, the maintenance of the resource definition is a maximization concept that implies minimizing the use of the natural environment.

Dovers and Handmer [1993] state that intergenerational equity, or justice between generations, is the ultimate principle behind the notion of sustainability.

\subsubsection{Intragenerational Equity}

Rawls [1972], from a moral perspective, proposed a "maximin" strategy for fair distribution of the resource base. This strategy suggests that to ensure justice, the least advantaged in a given society must be favored. Justice is to be equated with a bias in resource allocation to the least advantaged in society.

Pearce et al. [1990] define and discuss the key necessary (but not sufficient) condition for sustainable development as "constancy of the natural capital stock." They point out that a constant or increasing natural capital stock serves the goal of intragenerational faimess, which is justice to the socially disadvantaged both within any one country and between countries at a given point in time. Pearce and Warford [1993] agree with this argument. Achieving faimess within a generation is equivalent to achieving justice for the socially disadvantaged both within a single country and between different countries at any point in time. The authors give examples of intragenerational equity including reliance on biomass fuels such as animal waste and fuelwood; untreated water supplies; natural fertilizers to maintain soil quality; and fodder from natural vegetation for livestock [p. 45]. 


\subsubsection{Ethics}

Jacobs [1993] discusses valuation methods for determining environmental costs of projects in order to point out the ethical premise of sustainability. He explains that valuation methods of determining environmental consequences of projects are seen by economists to be examples of a 'positive' concept, one which relies on objectively measurable desires and interests of those affected. This is a descriptive approach that determines an 'optimal' level of environmental protection based on what is, not on what should be. Sustainability, on the other hand, is a 'normative' concept which goes beyond what is to what should be. The traditional economics is a positive discipline which is not based on value judgments. In other words, it only determines the optimal level but does not indicate whether it is ethical to apply it. SD, however, has value judgments integrated into its principles. This forces one to ask what should the 'morally optimal' level of environmental protection be. Environmental valuation attempts to place monetary values on natural and environmental resources. SD implies that while it may be acceptable to discount one's own future, it is ethically unacceptable to do so with the lives of other people. Basically, there is a general refusal to treat others as if they are morally less significant.

Other authors have contributed to the literature on ethics, theology and value theory, though with little emphasis on these topics in the context of sustainable development. See, for example, Gray [1994], Cobb [1993], and Bedau [1991].

\subsection{Reversibility and Related Issues}

The topic of reversibility of development of natural resources has mainly appeared in the environmental economics literature, where the main focus has been the irreversibility of decisions regarding allocation of natural resources to development instead of preservation. Typically, the approach taken is to consider any amount of development to be irreversible, and to analyze the consequences of the development (or preservation) decision, including benefits and costs, information gained or forgone, flexibility, and the effects on environmental policies. The underlying basis in the literature for discussing reversibility or irreversibility, therefore, is 
the preservation of natural resources, a central theme of sustainability and sustainable development. This is where the concept of reversibility is strongly associated with sustainable development. Reversibility has also been discussed in other contexts. For example, Ryding [1981] discussed the reversibility of man-induced eutrophication based on results of a lake recovery study of thirty lakes. Haimes and Hall [1977] proposed a multiobjective framework that considered irreversibility, defined as "the degree of difficulty involved in restoring previous states or conditions once the system has been altered by a decision" [p. 72], as one objective function in water resource management models. Several articles from the economics literature that have directly addressed irreversibility of development decisions are reviewed in the following subsection. Other issues that are significant to this thesis, including option value, quasi-option value, time preference, and resilience are reviewed in subsequent subsections.

\subsubsection{Reversibility or Irreversibility}

Henry [1974a] defined an irreversible decision as a decision which "...significantly reduces for a long time the variety of choices that would be possible in the future." He considered a problem of sequential decisions under irreversibility and uncertainty, where irreversible decisions may be made and where the information structure pertaining to the state of nature improves with time. The problem was related to a cost-benefit analysis of the destruction of public forests to build a circumferential highway around Paris at the time. This initial uncertain problem could be converted to a riskless problem if every random return or cost were replaced by its expected value before application of any decision criterion. In a multi-period information structure, at each individual time period two possible situations exist: 1) there is a choice as to whether or not an irreversible decision is made; and, 2) no choice remains open. Henry proved that there is a relationship between the level of risk (or uncertainty) and irreversibility for sequential decision problems, and that a risk neutral decision maker will, more often than not, adopt an irreversible decision. That is, if the solution to the riskless problem, solved by a risk-neutral decision maker, does not imply an immediate irreversible decision, then the solution to the initial random problem does not 
either. However, a situation may occur in which the solution to the riskless problem requires an immediate irreversible decision, whereas the solution to the initial random problem does not.

Arrow and Fisher [1974] were primarily concerned with the effect of uncertainty on decision criteria for a binary choice between preservation and development, two broad alternative uses of natural environments. The expected value (under uncertainty) of benefits of development are considered to be less than the value of benefits under certainty. A useful interpretation of this point is that if uncertainty exists about the benefits of investment in development, underinvestment is more appropriate than overinvestment as development is irreversible. In other words, underinvestment in the first period can be remedied in the second period when new information and experience has been gained, whereas consequences of overinvestment persist and cannot be reversed. In general, less development should take place initially so as not to foreclose future options when making sequential decisions under uncertainty. This result is true whenever there is a chance that future disinvestment will be warranted; demonstrated for the continuous choice case by Henry [1974b] and for the discrete case by Bernanke [1983].

Miller and Lad [1984] applied a Bayesian decision theoretic framework to a twoperiod decision problem similar to Arrow and Fisher's [1974] framework. They explicitly stated the assumption that development is irreversible and that expectations about benefits and costs during the second period vary with results of the first-period action. The amount and type of leaming (information gained about consequences of development) achieved depend upon the action taken in the first period. In their model of a general decision problem, the irreversibility of development is represented by the assumption that the amount of development undertaken in the second period cannot be negative; the proportion of resources developed in the first period cannot be retumed to a preserved state. Miller and Lad disagreed with the general consensus in the literature [Henry, 1974, Arrow and Fisher, 1978] that in the presence of irreversibility flexible decisions that allow leaming should entail less development than fixed long-term development decisions. If less or no development takes place in the first period, more is learned about preservation. Conversely, if more is developed in the first period, less is learned about preservation but more information about the 
consequences of development will become available. Therefore, optimal use of the information accumulated through sequential decisions even in the face of irreversibility does not necessarily favor preservation over development.

Viscusi [1985] discussed the effects of irreversibility on levels of investment decisions in environmental policies or in development of natural areas. Viscusi examined the influence of uncertainty regarding the irreversible effects for a series of models that encompass the usual concerns raised in the literature, such as the uncertainty regarding benefit values. The most common type of framework [Arrow and Fisher, 1974; Henry, 1974; Usategui, 1990] considers downward irreversibility in which the level of environmental policy choice variable cannot be reduced over time, as in the case of development of a scenic area. Viscusi identified two other types of irreversibilities: upward irreversibility and complete irreversibility. In environmental situations in which not investing is the irreversible decision, as pointed out by Miller and Lad [1984], there is irreversibility in the upward direction. For upward irreversibility to occur, there must be a constraint that limits the ability to increase the level of environmental policy choice variable. The application of the framework for this type of irreversibility is demonstrated in the case of pollution abatement expenditures that are needed to prevent irreversible environmental damage. Complete irreversibility occurs when part or all of a development project cannot be altered in either direction, as in the case of the height of a completed dam. In general, Viscusi concluded that an uncertain chance of irreversibility leads to lower levels of investment than in the reversible case if there is downward irreversibility, higher levels of investment if there is upward irreversibility, and an effect in either direction if there is complete irreversibility.

Viscusi [1988] examined the consequences of not considering costs of changing the allocation in the second period but did not include uncertainty of irreversibility that was introduced in his earlier work [Viscusi, 1985]. Usategui [1990], on the other hand, presented a two period model which considers initial uncertainty not only on the irreversibility of development but also on the benefits of the two uses (development and preservation) in the second period, the arrival of information at the end of the first period, and costs of changing the allocation of the resource in the second period. 
Pindyck [1991] also discussed the effects of irreversibility and uncertainty on investment expenditures. Pindyck pointed out two important characteristics of most investment expenditures ignored by existing econometric models. First, investment expenditures are mostly sunk costs that are irrecoverable, thus irreversible. Investment expenditures are considered to be sunk costs, thus irreversible, because of the fact that the capital is usually firm or industry specific, and cannot be used by a different firm. In addition, irreversibilities can arise because of government regulations or institutional arrangements. For example, capital controls may make it impossible for foreign or domestic investors to sell assets and reallocate their funds. Investments in new workers may be partly irreversible because of high costs of hiring, training, and firing. Second, investments can be delayed in order to gain information about prices, costs and other market conditions before committing resources. In the context of natural resources and the environment, for example, if future values of wilderness areas and parking lots are uncertain, it may be better to wait before irreversibly paving over a wilderness area.

Other authors have developed and discussed analyses of irreversible investments, including Arrow [1968], Fisher et al. [1972], Fisher et al. [1974], Cummings and Norton [1974], and Fisher and Krutilla [1974]. The central theme of all these analyses has been the unique and irreplaceable resources that may be affected by investment decisions to develop, and the irreversible impacts on the environment.

\subsubsection{Option Value}

The concept of option value is only indirectly related to the concept of reversibility as defined in the context of the research presented in this thesis. It is, however, useful for providing insight into various methods and theories that have been put forward in the last three decades for assigning monetary values to potential non-monetary benefits that can be derived from various goods and services including natural environmental resources. In economic terms, option value has been commonly defined as the difference between option price and consumer surplus. Option price of a resource is an amount potential users of a resource are willing to pay in order to retain the option of using that resource in the future. 
Consumer surplus accounts for the amount actual consumers of a resource are willing to pay to continue using that resource (equivalent variation), or the amount of compensation they will accept to forego its use (compensating variation), in addition to the market price of that resource [Young, 1992]. Option value, therefore, is one measure of non-user benefits. The concept has evolved in the economics literature as a means for evaluating non-user benefits to be used in conventional benefit-cost analyses. Several relevant articles are reviewed below.

The concept of option value was introduced by Weisbrod [1964]. Weisbrod pointed out that it is customary to distinguish individual-consumption (private) goods from collectiveconsumption (public) goods. A number of significant commodities appear to be of the private variety but also possess characteristics of public goods. Even if a privately produced good or service, such as visiting a national park, is not profitable it may serve the social welfare to subsidize its production, as opposed to allocating the resources to other uses such as lumbering or mining as would be dictated by conventional economic reasoning. Weisbrod pointed out the existence of those who anticipate purchasing such a commodity (visiting the park) at some time in the future, and who are willing to pay something for the option to consume the commodity in the future. This "option value" should be integrated into the decision of whether the park should remain open, or be closed so that its resources can be allocated to altemative uses. Another example is hospitals. A hospital is utilized infrequently by most persons and not at all by some, and like the national park provides a valuable stand-by service. Therefore, the value of the hospital cannot be measured by the number of its users or the fees collectable from them alone. The value of the hospital must also include the option value of its use. This option value may be large enough to justify the existence of the hospital even when its operation is economically unprofitable.

Long [1967] challenged Weisbrod's definition of option value and argued that it was simply a different name for user benefits that were already being counted using standard techniques of benefit-cost analysis. A potential user of a national park would not be willing to pay for an option to visit the park unless there was a good chance of actually using the option. Long suggested that option value of a national park is "...exactly the expected consumer surplus from consuming the goods at the terms specified in the option." A rebuttal was offered by Lindsay [1969], who asserted that Long had neglected a key element in Weisbrod's 
condition for evaluating option value, namely uncertainty. Lindsay evaluated an amount that potential 1983 users of a national park (Weisbrod's example) would be willing to pay for options purchased in 1982. In agreement with Weisbrod, this additional payment for each option in excess of consumer surplus was Lindsay's concept of option value.

Cicchetti and Freeman [1971] tried to incorporate uncertainty into the concept of option value. They argued that option value arises from two types of uncertainty. First, there may be uncertainty regarding future demand for a natural resource (such as a national park). They defined option price as the maximum sum one would be willing to pay to preserve the option to use a natural resource (visiting a national park) before one's demand uncertainty was resolved. They proved that option value is the difference between option price and consumer surplus, and is positive since option price exceeds consumer surplus. This is especially the case for risk averse individuals. Second, there may be uncertainty about the future availability of the resource. Cicchetti and Freeman mentioned but did not develop the connection between supply uncertainty and option value.

Schmalensee [1972], Bohm [1975], Anderson [1981], Bishop [1982], and Freeman [1984b] all agree that Cicchetti and Freeman's conclusion that option value is positive for risk averse individuals was wrong, and that option value can be either positive or negative depending on the circumstances.

Smith [1984] extended Schmalensee's [1972] original framework for analyzing option value in an attempt to provide an analytical bound for option value. The bound derived from this framework suggests that the magnitude of option value relative to the expected consumer surplus will depend on the degree of uniqueness of the good or service of interest measured using Cook and Graham's [1977] uniqueness index, and the nature of demand uncertainty. As the uniqueness of an environmental resource increases, indicating a more irreplaceable good or service, the bound for option value also increases. Thus the relationship between option value and expected consumer surplus will vary with the character of the environmental resource of interest.

According to Hanemann [1989], two broad interpretations of option value have emerged from the literature since its introduction. The first interpretation is time-independent and is primarily concerned with uncertainty in demand or supply of a resource. This 
interpretation views option value as a risk premium and is the most common. The second interpretation focuses on the intertemporal aspects of decisions concerning allocation of resources to altemative uses (for example, preservation of a national park or the allocation of its resources to mining or lumbering). Hanemann focused on this time-dependent concept to analyze properties of option value. He discussed the relationship of option value to the value of information, and the effects of an increase in uncertainty concerning the future costs and benefits of development on both types (time dependent and time independent) of option value. In contrast to Conrad's [1980] assertion that option value is equivalent to the value of perfect information (see below), Hanemann shows that option value is distinct from, but bounded by, the value of information in the overall decision problem.

The general consensus among these and other authors [Brookshire et al., 1983; Smith, 1983; and Freeman, 1985] who have since contributed to the literature on the topic of option value has been its relevance when making decisions concerning natural resources. A general agreement is that the analysis of option value should be expanded to include "supply-side" uncertainty in addition to the inherent uncertainty in demand.

\subsubsection{Quasi-Option Value}

The concept of quasi-option value is similar to that of option value but is more relevant when development of a natural resource (the alternative to its preservation) is considered to be irreversible, and the passage of time (time-dependent development decisions) is taken into account. This is the source of the confusion between option value and quasioption value. Bishop [1982] briefly pointed out that these are separate concepts and should not be confused but did not discuss the issue further. Henry [1974] referred to the concept of quasi-option value introduced by Arrow and Fisher [1974] as simply option value. Such discrepancies continue to appear in more recent literature, for example, in Hanemann [1989], but will not be explored here. A discussion of the nature of quasi-option value in relation to option value is beyond the scope of this research. Several key publications in the last two decades that have discussed the concept of quasi-option value are reviewed below. 
Arrow and Fisher [1974] originally introduced the concept of quasi-option value. They considered a framework in which information about the consequences of development would arrive with time independently of the development decision itself. Within this framework, they showed that there is a positive quasi-option value of preservation. Further, Arrow and Fisher showed that quasi-option value is not dependent on risk aversion; it could be present even when decision makers made choices based on the expected value of uncertain variables. The effect of quasi-option value is similar to risk aversion which would also result in a reduction in the value of expected benefits, thus less of an area would be developed.

Conrad [1980] reached a similar conclusion as the one advanced by Arrow and Fisher [1974]: that there is a quasi-option value benefit to preserving a natural area or to delaying its development. Using a simple intergenerational growth model containing a stochastic environmental degradation variable, Conrad showed that quasi-option value is equivalent to a more fundamental concept, namely the expected value of information. Conrad also suggested that option value could be interpreted as the expected value of perfect information but did not discuss the idea.

Freeman [1984a], on the other hand, appeared to disagree with the Arrow and Fisher [1974] conclusion that consideration of quasi-option value would lead to relatively less irreversible development and relatively more preservation of natural environments. Freeman showed that quasi-option value is a neutral concept. It does not inherently favor either preservation or development. In short, the existence of quasi-option value and whether it is positive or negative for preservation depends on the nature of the uncertainty regarding the benefits of preservation, the opportunities for reducing uncertainty by gaining information, and the structure of the decision problem. Quasi-option value of preservation will be larger the larger is the possible loss due to preserving a natural area, the more likely is its occurrence, and the smailer is the opportunity cost of preserving the option to develop. Conversely, the quasi-option value of development is larger, the larger is the possible loss due to full development, the more likely the loss is to occur, and the smaller are the benefits. A lack of information about preservation benefits creates uncertainty. This type of uncertainty can be resolved by waiting and carrying out the appropriate research in order to gain information. In this case it is the waiting and researching that creates quasi-option value. But if the 
uncertainty is due to lack of information about benefits and costs of development, then this uncertainty might be reduced by experimenting with a little development while preserving the option to undertake full development if the experimental development yields undesirable results. In this case, it is the experimental development which produces quasi-option value. Therefore, consideration of quasi-option value is likely to result in relatively less development only when the uncertainty is generated by the lack of information regarding preservation benefits.

Fisher and Hanemann [1987] pointed out that the Arrow and Fisher [1974] conclusions are correct. They explained that the source of the difference in Freeman's [1984a] model is a confusion between quasi-option value which is always positive, and the net benefits of preservation which does not hold the same restriction. Fisher and Hanemann conclude by showing that even if information is provided by development, as in Freeman's "dependent learning" framework, full development may not be indicated. If information is provided by an arbitrarily small amount of development, then the choice is between an arbitrarily small amount and full development. The arbitrarily small amount of development in Freeman's model becomes equivalent to "full preservation" in their model as well as in Arrow and Fisher's. In that case, the arbitrarily small amount of development yields a positive quasioption value. A further complication is that the amount of development required to obtain information is unknown.

Miller and Lad [1984] defined quasi-option value in terms of the flexibility of decisions involving development or preservation of a natural area. Quasi-option value is the expected value of remaining flexible and committing less of a resource to development as opposed to being committed to a longer course of action. It is called quasi-option value as opposed to option value since development decisions are assumed to be irreversible. Under the assumption of costly flexibility, quasi-option value can be negative. This is because a sequential (flexible) decision may entail higher costs than a fixed (inflexible) decision, due to, for example, higher wages demanded because of the uncertainty of work in the next period, quantity discounts on construction material as larger amounts would be purchased for a fixed decision, and political costs if changing one's mind is viewed as a weakness. 


\subsubsection{Time Preference}

The concept of 'time preference' is vaguely related to quasi-option value through the temporal aspect of reversibility [Arrow and Fisher, 1974]. Field [1994] stated that any person who normally will prefer a dollar today to a dollar in 10 years will have a positive rate of time preference. Boyce [1994] describes the rate of time preference as the willingness to trade present benefits for future benefits. People with a higher rate of time preference place greater weight on the present. They prefer the combination of short-run benefits and long-run costs over short-run costs that result in long-run benefits. Boyce distinguishes between rate of time preference that refers to financial savings and the rate of environmental time preference that is applied to environmental resources, including clean air, clean water, soils, and other "natural capital" in their useable form.

The concept of time preference has also been associated with discount rates used in cost-benefit analyses. Feldstein [1964, p. 369] wrote "because society cannot redistribute the consumption of outputs of the public investment through time, any test or measure of the desirability of a public investment is inadequate if it does not take into account the social time preference function, i.e., the relative weights society places on consumption at different times in the future."

\subsubsection{Resilience and Stability}

The concept of resilience, even though it was not referred to by that name, was introduced in water resources as early as the 1960s with the main concern being a water system's ability to recover from an undesirable state of performance [Fiering, 1967; Fiering 1969]. Attempts at connecting resilience to ecological events have also been made [Holling, 1973; Pearce et al., 1990]. Typically, measures of resilience require a basic knowledge of the type, possible magnitude, and possible duration of a failure event. These are generally known for physical systems such as water supply (reservoir) systems but unknown for some natural systems. The concept of resilience is better understood when discussed in relation to other concepts such as reliability, stability, vulnerability, or sensitivity. Several publications that 
addressed these concepts are reviewed below with emphasis placed on the concept of resilience.

For a given system a measure of system resilience based on an estimate of time of recovery from system failure was introduced by Fiering and Holling [1974]. This requires a knowledge of the mechanics and costs of system failure and recovery. Recovery time is dictated independently by the extent of system damage and by the level of resources available for system restoration.

Fiering [1982a] defined resilience as "...the ability of a system to accommodate surprise and to survive or even to recover and thrive under unanticipated perturbation." $\mathrm{He}$ argued that activities or measures designed to protect people and the natural environment from hazards (such as flood control works) tend to drive the respective system toward stability or low variability, and tend to make the system (consisting of flood control structures and the people and environment affected) more brittle or vulnerable to surprise. Fiering showed that classical optimization procedures, used to identify the optimum scheme to meet some system performance criteria and constraints, tend to overlook a valuable characteristic of system performance and, therefore, lead to a "brittle" (inverse of resilient) system which is more susceptible to system perturbations. He demonstrated this point by applying a simple didactic model based on a simple screening analysis to a system of eight reservoirs. The releases from the reservoirs are additive and serve a downstream demand at a single point. For example, when two out of eight reservoirs are to be used simultaneously to meet downstream demand, 28 choices, mathematically calculated as $8 ! /[2 !(8-2) !]$, exist, whereas if all eight are used only one combination is possible. The number of combinations increases until half the number of potential reservoirs are used and decreases thereafter. Fiering concluded that the resilience of a system of reservoirs increases with increasing number of options and greater redundancy, namely the size of the system. One measure of system brittleness (inverse of resilience) is the average percent improvement in system performance in meeting target levels (at the same targets and with the same number of reservoirs) per million dollars of reservoir system cost. Another measure of resilience is obtained by plotting the system performance index (percent of target actually delivered) against changes in target for various system sizes (number of reservoirs in the system). 
Fiering [1982b] examined the concept of resilience of a water resources system further. He suggested and compared a few definitions that are based on the time required to pass from one system state of acceptable performance to another and the passage to or from a state defined as failure, as well as the probability of recovery from failure to some acceptable state within a specified time interval. Considering a system whose state space consists of a best, a worst (failure), and intermediate states that characterize progressively deteriorating system performance from best to worst, definitions of resilience that are surrogate indices of resilience include: 1) residence time in nonfailure state; 2) expected outcome involving a cost (resilience index to be minimized) or a benefit (resilience index to be maximized); 3) steady state probability of not being in a state of failure; 4) system mean first passage time to failure state; 5) mean first passage time from nonfailure to failure; 6) mean passage time between successive failures; and 7) mean passage time to failure from complete recovery. All of these indices are related to time in that all contain probabilities of being in a particular state and most contain mean transfer times from one state to another.

Hashimoto et al. [1982a] discussed resilience and vulnerability as two risk criteria that can be used in addition to the traditional reliability criterion for evaluating the performance of water resource systems. The reliability of a system is described by the frequency or probability that a system is in a satisfactory state. Vulnerability represents the likely magnitude of failure. Resilience describes how quickly a system is likely to recover or bounce back from failure once failure has occurred. A system may be characterized by low resilience if failures are prolonged events and system recovery is slow. This may significantly complicate a system design that attempts to increase resilience. High resilience indicated by the ability to recover rapidly from an adverse state of operation is a desirable characteristic of system design. Hashimoto et al. defined resilience as the inverse of the expected value of the length of time a system's output remains unsatisfactory after a failure, and derived a mathematical expression for that expected value. They concluded that tradeoffs exist among expected benefits, reliability, resilience, and vulnerability. In a companion paper, Hashimoto et al. [1982b] proposed measures of robustness, a concept that is similar to resilience, that describe the overall economic performance of a water resource project. They stated that $\because$...some project designs may be sufficiently flexible to permit their adaptation to a wide range 
of possible demand conditions at little additional cost. Such systems can be called robust" [p. 21].

Moy et al. [1986] expanded on the analysis of risk related criteria carried out by Hashimoto et al. [1982a]. Moy et al. examined tradeoffs between reliability, vulnerability and resilience of a water resource supply reservoir using multiobjective mixed integer linear programming, and confirmed the hypothesized relationships between these performance criteria. In contrast to Hashimoto et al., Moy et al. define reliability in water supply reservoir operation as the probability of failing to achieve some target releases from the reservoir to satisfy downstream demand. In their model, Moy et al. used the number of deficit periods divided by the total number of periods, a measure of the frequency of failure, as a measure of reliability. Vulnerability is a measure of the significance or extent of failure; the magnitude of the largest deficit during the period of operation. Resilience is the probability of recovering from failure to some acceptable state within a specified time interval. The resilience concept was developed with an emphasis on the time element to ease its quantification and incorporation in the mathematical model. For a single reservoir, the maximum number of consecutive periods of shortages that occur prior to recovery was used as a measure of resilience; the larger the number, the less resilient the reservoir. Moy et al. concluded that the vulnerability of a water supply reservoir increases as the reliability of operation is increased or as the resilience is increased.

Holling [1973] discussed the concepts of resilience and stability of ecological systems. With respect to a population in nature, stability is characterized by low fluctuations in population density, whereas resilience is characterized by high fluctuations that allow the population to take advantage of transient periods of favorable conditions in order to persist. Resilience, therefore, determines the persistence of relationships within a system and is a measure of the ability of the system to absorb changes and still persevere. Thus resilience is the property of the system and persistence or the probability of extinction is the result or measure. Stability is the ability of a system to return to an equilibrium state after a temporary disorder. Stability is the property of the system and the degree of fluctuation around a specific state, typically equilibrium, is the measure. Holling concluded that the resilience and stability viewpoints suggest different approaches to the management of natural resources. The 
resilience view emphasizes the need for persistence and heterogeneity. The resilience framework advocates the assumption that future events are unexpected rather than expected and the recognition of ignorance rather than the presumption of sufficient knowledge. A management approach based on resilience would emphasize the need to keep options open, and to view events in a regional rather than a local context.

In their discussion on the relationship between natural capital and resilience, Pearce et al. [1990, p. 16] write: "The resilience justification for conserving the natural capital stock is [thus] based on the idea that diverse ecological and economic systems are more resilient to shocks and stress. In turn, to maintain diversity it is essential to avoid irreversible choices. Since knowledge is rarely lost for ever, economic irreversibility is likely to be rare-a discontinued machine can be re-created, towns can be rebuilt, and so on. But ecological irreversibility is not unusua! natural species are lost..., unique ecosystems are destroyed and environmental functions are irreparably damaged."

Barbier [1987] viewed sustainability of systems as a form of resilience, the ability to recover when subjected to economic or environmental shocks. Tisdell [1993] briefly discussed the role of resilience of production and economic systems. He wrote "as the amount of biodiversity is reduced, as variety of all types is reduced in the world and as the environment is degraded by economic processes, economic activity may become less resilient when subjected to environmental and other shocks. Thus desirable production and economic states may no longer be sustainable in the long term given the possibilities of stresses on the system or shocks to it. Systems may become subject to jumps and irreversibilities" [p. 135].

Several authors have discussed connections between resilience and technology. "Some of the sustainable development literature stresses that resilience requires the adoption of 'ecologically sensitive' technologies adapted to agro-ecological conditions (see especially Brown, 1981; WCED, 1987; IUCN, 1980)" [Pearce et al., 1990, p. 15]. 


\section{REVERSIBILITY FRAMEWORK}

The concept of reversibility and its possible application for achieving sustainable development were discussed in Chapter 1. The method of application within a defined framework is the focus of this chapter. The proposed reversibility framework is a combination of theoretical and analytical tools. Some theoretical concepts are derived from the literature on the topic of reversibility reviewed in Chapter 2, while other concepts are generally developed for the reversibility framework. An analytical formula for calculating reversibility indexes is developed and presented. The principles of sustainability and sustainable development are inherent in the proposed framework as preservation of natural environments through sustainable project selection is the ultimate goal of the framework. Consideration of some of the sustainable development principles reviewed in Chapter 2 is discussed in the last section of this chapter.

\subsection{Reversibility}

Reversibility, in the context of this thesis, can be viewed as a measure of the degree to which the anticipated and unanticipated impacts of a project can be mitigated. Development projects that are highly reversible should allow users of the affected system to continue their normal use, if their normal use does not have irreversible effects. In that case, a high degree of reversibility requires that the least amount of disturbance be imposed on the natural environment where development is to take place. On the other hand, the "normal use" of a natural system can cause significant irreversible impacts, for example in the case of farming of marginal land which leads to loss of soil fertility [Pearce et al., 1993]. In that case, a reversible decision is one that minimizes the adverse impacts, such as loss of soil fertility, by altering the rate of use or by providing alternate means of using the system, rather than allowing the normal use to continue. Reversibility does not necessarily imply the ability to reverse a process that causes irreversible impacts. In most cases the reversal of adverse 
effects is not possible, but mitigation plans or the provision of substitute resources help reduce the negative effects. Furthermore, a process that is technically reversible, such as forest regeneration, is considered practically irreversible as the time span required for complete reversal is large. Therefore, in most cases the degree of irreversibility is more comprehensible and unequivocal than the degree of reversibility associated with impacts of development projects. This point is clarified further in the discussion of the application of the reversibility framework to the selected case study, contained in Chapter 4. Invariably, the central focus of the concept of reversibility (irreversibility) as defined here is the effects or impacts of development projects involving use of natural resources.

Impacts are identified under three broad categories found in sustainable development literature: social, ecological, and economic impacts. A possible quantification of reversibility can be obtained by considering impacts of a development project on the social and ecological environment, and possible economic impacts on the surrounding region. It is useful to note that all development plans have impacts of varying spatial and temporal scales although some of the impacts are not immediately apparent. Therefore, some degree of irreversibility should be expected. This is consistent with the point made earlier that irreversibility is, in most cases, more comprehensible, hence more quantifiable, than reversibility. The reversibility framework considers all alternatives of the development project of interest and determines the degree of irreversibility of each. An alternative that is less irreversible is superior to alternatives that have a higher degree of irreversibility.

There is a distinction between the reversibility of project-related impacts and the reversibility of the project itself. Impact reversibility refers to the degree to which the inevitable and possibly unanticipated impacts of a development plan can be alleviated at any time during project implementation or after project completion. A project with a high degree of reversibility exerts minimal impacts on the social, ecological and economic environment, or is designed to reverse an existing unsustainable process with irreversible effects. Furthermore, reversibility implicitly requires that impacts not exceed the assimilative capacity of the social, ecological and economic environment surrounding the development project. Project reversibility is determined by the ease with which the project can be altered or terminated in order to mitigate some unanticipated impacts. The degree of reversibility of a project is 
dependent on factors such as the type of development (production type, physical characteristics, level of capital investment, etc.) and the size of the project. Project alteration or postponement may be required if unanticipated impacts occur, or if the severity of some impacts exceed the assimilative capacity of the social, ecological, or economic environment.

The main focus in the literature is project irreversibility and development is considered to be irreversible. The reversibility framework defined herein is primarily concerned with impact reversibility for the purpose of selecting the least irreversible alternative, although project reversibility is also considered. For example, in the extreme case, due to complicating factors such as strong public objections and highly irreversible unanticipated impacts, it may be necessary to terminate the irreversible project or continue with a more reversible alternative.

\subsection{Framework For Measuring Reversibility}

The framework for measuring reversibility developed in this research involves several tasks. These tasks include the following: identifying and categorizing impacts; classifying the impacts if necessary; specifying units of measure for the purpose of quantifying each impact; specifying weights for each impact; and applying a formula to obtain indexes of reversibility. These main tasks are grouped into four stages as shown in Figure 3.1 and discussed in detail in the subsections that follow. Stage II, involving quantification and weight assignment, uses concepts of resilience, time preferences, option value or quasi-option value, reviewed in Chapter 2, and considers the concept of cumulative effects. 


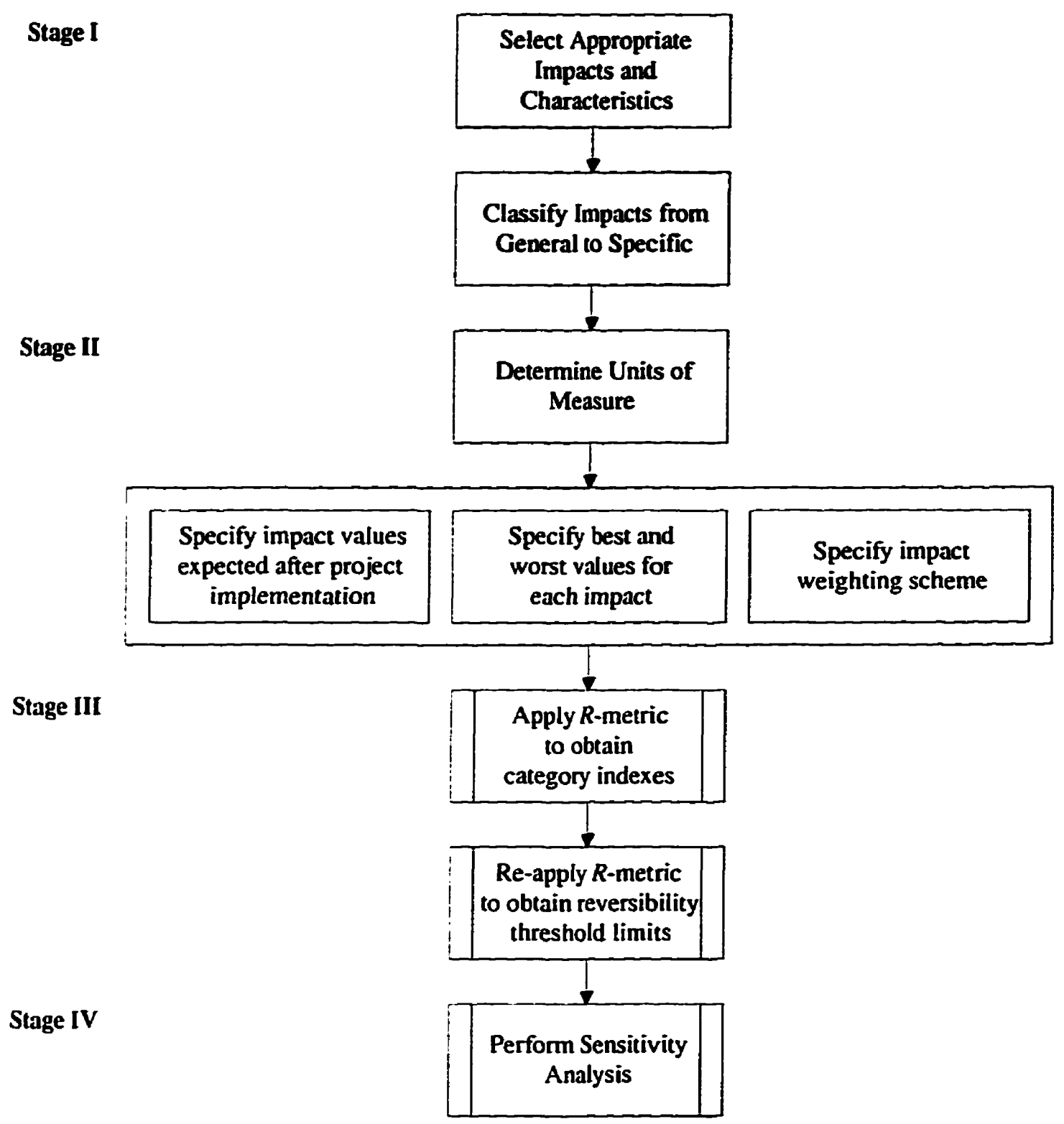

Figure 3.1 Flowchart of Reversibility Framework

\subsubsection{Stage I}

The main step in the framework for measuring reversibility is to identify impacts of the development project of interest and categorize them as social, ecological or economic impacts. This stage also involves classifying the impacts from general to less general (specific), and identifying them as true impacts or characteristics of impacts. Table 3.1 contains a generic list of categorized impacts which are classified from general to specific 
where applicable as indicated by the level of indentation. For example, in the social category health and safety is identified as one of the less-general impacts (one level of indentation) under the most general classification of community impacts. Health and safery impacts are further classified as physical and physiological, and psychological. It may be difficult to measure either the level of physical and physiological well-being of a community prior to, or the severity of such impacts during or following, project implementation. In that case the provision of emergency plans by the project being considered can be used as a characteristic to indicate the degree of reversibility of physical and physiological impacts.

Table 3.1 Generic List of Categorized Impacts

\begin{tabular}{|c|c|c|}
\hline Social & Ecological & Economic \\
\hline $\begin{array}{l}\text { Personal } \\
\text { Quality of life } \\
\text { Social distance } \\
\text { Community } \\
\text { Aesthetic Amenities } \\
\text { Education } \\
\text { Health and Safety } \\
\text { Psychological well-being } \\
\text { Physical well-being } \\
\text { Emergency plans } \\
\text { Disturbance } \\
\text { Noise } \\
\text { Property value } \\
\text { Land use pattern } \\
\text { Institutional } \\
\text { Power } \\
\text { Participation } \\
\text { Technological advancement }\end{array}$ & $\begin{array}{l}\text { Flora } \\
\text { Vegetation cover } \\
\text { Aquatic habitat } \\
\text { Wildlife habitat } \\
\text { Fauna } \\
\text { Animal populations } \\
\text { Biological characteristics } \\
\text { Seasonal characteristics } \\
\text { Fish populations } \\
\text { Land } \\
\text { Geology } \\
\text { Physiography } \\
\text { Drainage } \\
\text { Water logging } \\
\text { Water quality } \\
\text { Water quality parameters } \\
\text { Air quality } \\
\text { Air quality parameters }\end{array}$ & $\begin{array}{l}\text { Incentives and policies } \\
\text { Agricultural programs } \\
\text { Land tenure policies } \\
\text { Proprietary rights } \\
\text { Business opportunity } \\
\text { Consumer costs } \\
\text { Direct billings } \\
\text { Upgrading costs } \\
\text { Development costs } \\
\text { Capital } \\
\quad \text { Industry-specific } \\
\quad \text { Training } \\
\text { Type of Development } \\
\text { Physical characteristics } \\
\text { Production type } \\
\text { Flexibility } \\
\text { Volume } \\
\text { Modification } \\
\text { Material }\end{array}$ \\
\hline
\end{tabular}

The classification process can simplify the execution of subsequent steps especially if the list of identified impacts is large. In general, the impact categorization and classification process aids the decision maker in identifying as many impacts as possible that are anticipated to result from undertaking a project. It is important to note that the list of impacts in Table $3 . \mathrm{l}$ is generic, and is used herein only for demonstrating the idea of generating project-specific impacts. 
Ecological impacts and characteristics (Table 3.1) are classified under flora, fauna, land, water, and air at the most general level. The flora category accounts for all vegetation and wildlife habitat affected by a particular project. Route selection for a hydroelectric transmission line, for example, may require cutting a section of forest. A direct measure of the area that must be cut can be used (relative to the total available area) as one of the ecological impacts of transmission line construction. The economic category includes incentives, costs, type of development, and flexibility of the project as most general economic impacts. A specific project can provide business opportunities for the local communities affected by the project, therefore positive economic impacts are also considered. An extensive economic analysis of altemative projects is typically carried out, and economic irreversibility is likely to be rare [Pearce et al., 1990]. Therefore, less emphasis is placed on the economic category of impacts within the reversibility framework.

There could be dependence between some of the impacts in any one category. For example, in the generic list of impacts contained in Table 3.1, there is a strong connection between aquatic habitat (flora) and fish populations (fauna). However, these two types of impacts address different aspects of an ecological effect conceming aquatic resources: fish populations addresses the direct effect of the project of interest on fish resources while aquatic habitat concerns aquatic vegetation which sustain other species equally important to the ecosystem. For example, construction of a dam on a river could increase fish mortality as a result of fish passing through turbines (for hydropower generation) inside the dam or as a result of disturbance of spawning and migration patterns. Aquatic habitat could be damaged or destroyed as a result of dredging in the reservoir behind the dam or inundation of the river channel.

Dependence could also occur between two or more impacts in different categories. For example, quality of life in the social category could depend on business opportunities listed in the economic category. An increase in business opportunities as a direct result of the project of interest could also improve the quality of life in the affected area. However, quality of life represents the social aspect, the sense of well-being that is generated in the affected community, whereas business opportunities only consider the economic aspect, namely the opportunities for improving income. Dependence is discussed further in Section 4.3. 
Once again it should be noted that the generic list contained in Table 3.1 is not specific to any development project, and is used for discussion purposes only. Different development projects have different effects on the social, ecological, and economic surroundings. Successful application of the reversibility framework requires that a specific list of impacts is assembled for the particular development project under consideration.

Environmental impact statements (EIS) are a reliable source of data pertaining to social, ecological, and economic impacts. An EIS is a written document of an environmental impact assessment (EIA) generally defined as "an activity designed to predict impacts of a proposed action or a development proposal on human health and the well-being of the ecosystem upon which human survival depends" [Dirschl et al., 1993, p. 545]. As stated in Chapter I, EIA has been incorporated into legislation both in the United States and in Canada. Since the early 1970s, "EIA has proven its usefulness to decision makers for promoting the concept of integrated planning, where environmental and social factors are considered on an equal footing with economic and engineering factors" [Dirschl et al., 1993, p. 546]. Therefore, EISs provide a reliable starting point for the application of Stage I of the reversibility framework.

Other sources of information include expert consultants in each of the three categories. For example, ecologists and engineers can provide information for a number of ecological impacts, social scientists or psychologists can identify and assess social impacts, and economists can be consulted for evaluating economic impacts. Previous projects that have similar characteristics and are of the same scale as the project of interest can provide valuable information regarding the measurable severity of various impacts.

\subsubsection{Stage II}

When all potential impacts have been identified, the next step in the framework is to specify units of measure and quantify each impact. Often a subjective scale may be required as most impacts are intangible and cannot take on specific units of measure. Using the specified scale or units of measure, the best, the worst and the expected values are assigned for each impact. The "best value" represents the value of the identified impact when all 
conditions are favourable. The "worst value" indicates the highest severity of the impact that can be expected to occur. The "expected value" is a known (unit) or subjectively assessed (scale) value that can be expected for an impact after implementation of the project of interest. For example, on a subjective scale of 0 to 10,0 can represent the best value, 10 the worst value, and 6 the expected value. The need for quantifying these three values will be clarified further in the discussion of the analytical formula used for measuring reversibility (section 3.2.3). In this stage of the reversibility framework several concepts provide assistance for quantifying impact values and weights. The concepts are resilience, option value or quasioption value, time preferences, and cumulative effects, discussed in the following subsections.

\subsubsection{Resilience}

The concept of resilience of a natural system can be used to measure the ability of the system to recover from undesirable impacts of development. The notion of resilience is evident in the impact identification step described above. The characteristic of an impact, when used as the criterion to be measured, can indicate a source of resilience that is added to the existing environment (social, ecological, or economic) affected by the impact. For example, an emergency plan designed as part of a hydropower development project to respond to flooding is a good indication of the potential resilience of the system or its ability to recover from potential flood-related health and safety impacts. This is one type of resilience which is referred to as "artificial resilience." Alternatively, the resilience of a natural system can be adversely affected by a particular impact. For example, users of an existing unstable or unreliable power source are better prepared for frequent power failures by maintaining wood stoves and heaters, whereas users of a new reliable power source will not possess this resilience. This type of "natural resilience" is compromised by an increase in stability of the existing natural system, namely a more reliable power source.

\subsubsection{Option Value or Quasi-Option Value}

Concepts of option value and quasi-option value have been associated in the environmental economics literature with irreversibility of development projects that involve natural environments (Chapter 2). Methods for evaluating option value or quasi-option value, 
such as analyzing data obtained from public questionnaires (contingent valuation), have been developed and discussed in the economics literature, but are not considered in the reversibility framework. However, the underlying theories that favor natural social and ecological resources, though from an economic viewpoint, are useful as they enable systematic perspectives for quantification of some impacts. For example, if local hunters in an area affected by a project indicate a significant level of option value for future hunting opportunities, the impact on hunting, such as disturbance of movement patterns of animals and loss of critical habitat, can be weighted heavily. If, on the other hand, hunting is not an important part of the traditional lifestyle and, accordingly, the value for maintaining the option to have hunting opportunities in the future are low, then a lower weight can be assigned. However, the concept of option value should only be used as a guide, and other circumstances that affect hunting should not be ignored. For example, if hunting of a wildlife population is exerting irreversible pressure on that population thus threatening their existence, a reduction in hunting as a direct result of a localized project can be viewed as a positive ecological impact, even though the social or economic effects may be negative if, for example, subsistence heavily depends on hunting.

\subsubsection{Time Preference}

The concept of "time preference" has been associated with option value and quasioption value in environmental economics, as observed in the economics literature reviewed in Chapter 2. A modification of the concept of time preferences presented by Boyce [1994] is used here. Instead of considering tradeoffs between present benefits and costs, only potential benefits are considered. The importance of the impact under consideration can then be gauged based on these preferences for benefits; a high rate indicates a more significant impact than a low rate. This concept can aid the impact quantification stage in the reversibility framework where applicable, particularly for impacts that must be subjectively evaluated. For example, a high positive rate of time preference can be typically expected for employment opportunities as residents of a community affected by a project that provides employment opportunities will prefer to have them at the present rather than, say, five years later. In the unlikely event that employment opportunities are already abundant in the affected community, 
the rate of time preference could be lower as most residents are employed and are indifferent towards jobs created by a project at the present or five years in the future. Similarly, if the choice is between a land fill site or tuming the piece of land into a scenic golf course, a high rate of time preference for the golf course can be expected as people in general would prefer a scenic view to the unpleasant sight and odor of a land fill. Analytical methods for measuring the rate of time preferences are beyond the scope of this research. Only the concept is employed here to aid the impact quantification process.

\subsubsection{Tolerance values}

The concept of tolerance values was developed in this research for application in the reversibility framework. Tolerance values define the acceptable range for the impacts being considered and can be used to quantify the worst possible values for each impact. A tolerance value for an impact represents the level beyond which the severity of the impact is unacceptable. Bishop [1978, p. 10] stated that some "[flow] resources are renewable within limits but have a threshold or critical zone such that once the critical zone is reached, further depletion is irreversible." In order to maintain sufficient base population and habitat to assure survival of a particular species, the critical zone must be avoided. The maximum tolerance value refers to the edge of the critical zone. For a resource of interest, the maximum tolerance value is the amount which can be consumed after each growth period without depleting the base population of that resource. If the base population is reduced in one period, the maximum amount of that resource which can be harvested in the next period decreases.

Consideration of tolerance values may not be so simple in some cases. Sustainable utilization of natural resources is a complex issue. Consider, for example, the tolerance limits for sustainable harvesting of natural forests. The selective cutting and removing of dead or dying trees is often necessary in order to ensure optimal growth and regeneration rates. The base population of forest species could decrease if the amount of selectively harvested trees is less than some lower tolerance limit. If the base population of some forest species decreases in one period, less of the species must be harvested in the next period. Therefore, if a development project requires clearing sections of a natural forest, it would be useful to 
consider the lower tolerance limit for the cutting of trees so as not to overestimate the severity of the impact of the project on the base population of forest species.

This type of theorizing is useful for quantifying impacts that are complex. The intent here is to maintain simplicity so as to clarify the role of tolerance values, where applicable, in identifying the worst value of an impact. The best impact value is simple to identify as the desirable level for most impacts, especially negative impacts, is equivalent to their minimum possible value (units or scale). When a lower tolerance limit is specified for the use of a certain natural resource, this value can be used to represent the "best" value of the impact of the development project under consideration. The need to quantify best and worst values for each impact is clarified in the discussion of the application of an analytical formula for measuring reversibility (Section 3.2.3).

\subsubsection{Cumulative effects}

Cumulative effects result from a combination of various impacts and compounding factors. These can be used to determine weighting schemes for impacts, or for each category (social, ecological, or economic) relative to the other two. The notion of cumulative effects involves issues such as: the availability of substitute resources; the assimilative or carrying capacity of ecological systems; the level of poverty within the social setting; the size and duration of the project; and, mitigative measures provided by the project.

Cumulative effects are of two basic types: simply additive and synergistic [Erickson, 19941. A simply additive cumulative impact is essentially an arithmetic summation of incremental occurrences of the same type of impact. For example, incremental losses in forest acreage due to successive development projects could result in the total loss of the forest. Simply additive cumulative impacts include those that result from gradual increases in ambient concentrations of toxic or injurious chemicals in air, water, and soil and eventually result in significant health risks to people and their natural environment. These impacts also include those that result from gradual depletion of resources, including wildlife species and their respective habitat, human recreational and educational resources, historic sites, and aesthetic

resources. A cumulative impact that is greater than the simple arithmetic total of the incremental contributions made by subsequent projects may be described as synergistic. For 
example, a population of large mammals, such as deer, may successively decrease in proportion to the amount of critical habitat removed each time a development project takes place in the area. However, the total population could be lost long before all the critical habitat is removed as population density also depends on other factors including a minimum density required for successful reproduction. Similarly, successive projects may reduce the density of a thick forest creating semi-open or open stands that become susceptible to the effects of windthrow from sudden exposure, resulting in synergistic loss of acreage. Furthermore, when two or more projects are implemented simultaneously the cumulative effects could be synergistic rather than simply additive.

The concept of cumulative effects is related to resilience. If the resilience of a natural resource is high, a small shock created by some form of development will not threaten its survival or the biodiversity of the affected area. Then, successive shocks following the initial development are considered to be additive only. Simultaneous shocks are more complicated, but may be only additive (as opposed to synergistic) if the resilience of the system is not affected.

\subsubsection{Stage III}

\subsubsection{The "R-Metric"}

Stage III of the reversibility framework involves the application of an analytical formulation to the set of quantified impact values and weights. To reiterate, the characteristics of some impacts and a direct measure of the severity of other impacts are used as metrics to be combined so as to obtain a measure of reversibility. The impacts and characteristics have noncommensurate units by which they can be measured. This necessitates a method for converting the metrics into one commensurate unit or into dimensionless numbers. A further requirement is the selection of a weighting scheme to represent the importance of the impacts and characteristics relative to each other. The commensuration and weighting of impacts may be accomplished through the use of what is referred to as the distance metric. 
The distance metric formulation, also referred to as the $L_{p}$-metric, is used in multiobjective analysis for the ranking of altematives based on a set of objectives by representing the relative importance of each objective as well as preferences of decision makers [Simonovic, 1989; Duckstein and Opricovic, 1980; Zeleny, 1973]. A common version of the formula [Zeleny, 1982] is

$$
L_{p}(j)=\left(\sum_{i=1}^{N} w_{i}^{p} \frac{\left|f_{i}^{*}-f_{i j}\right|^{p}}{\left|M_{i}-m_{i}\right|^{p}}\right)^{\frac{1}{p}}
$$

where

$$
\begin{aligned}
& j=\text { index for alternative project } \\
& i=\text { index for objective or criterion } \\
& N=\text { total number objectives or criteria } \\
& w_{i}=\text { weighting factor for objective or criterion } i \\
& M_{i}=\text { maximum value for objective or criterion } i \\
& m_{i}=\text { minimum value for objective or criterion } i \\
& f_{i}^{*}=\text { ideal or preferred value for objective or criterion } i \\
& f_{i j}=\text { value of objective or criterion } i \text { attained by implementing alternative } j \\
& p=\text { parameter reflecting the attitude of the decision maker }
\end{aligned}
$$

The ideal or preferred value for criterion $i, f_{i}^{*}$, is in most cases equivalent to the maximum value, $M_{i}$, of the criterion. The $L_{p}$-metric calculates the absolute value of the distance from the ideal value raised to exponent $p$, divided by the absolute value of the difference between the maximum and the minimum possible values $M_{i}$ and $m_{i}$, respectively, also raised to exponent $p$, for criterion $i$. Thus a set of $N$ weighted dimensionless numbers are obtained, which are multiplied by their respective weights, $w_{i}^{p}$, then summed up and raised to the exponent $\frac{1}{p}$ to obtain one $L_{p}$ value for each alternative $j$. The choice of the parameter $p$ reflects the importance of the deviations from ideal values of the criteria to the decision maker. Typically, three values for $p, 1,2$, and $\infty$, are examined [Simonovic, 1989; Goicoechea et al., 1982]. For $p=1$ all distances are weighted equally. For $p=2$, the 
deviations are weighted in proportion to their magnitude. For $p=\infty$, larger deviations receive larger weights relative to smaller deviations. The larger the value of $p$, the greater the concern regarding the maximal deviation.

For application in the reversibility framework, a simplified version of the distance metric is used. The parameter $p$ is fixed at a value of 2 , the ideal value, $f_{i}^{*}$, is replaced by $M_{i}$, and the subscript $c$ is added. The resulting $R$-metric is:

$$
R_{c j}=\left(\sum_{i=1}^{N_{c}} w_{c i}^{2}\left|\frac{M_{c i}-f_{c i j}}{M_{c i}-m_{c i}}\right|^{2}\right)^{\frac{1}{2}}
$$

where

$c=$ index for category ( $c=1$ for social, $c=2$ for ecological, $c=3$ for economic)

$j=$ index for alternative project

$R_{c j}=$ Reversibility index in category $c$ for alternative $j$

$i=$ index for impact or characteristic

$N_{c}=$ total number of impacts in category $c$

$w_{c i}=$ assigned weight between 0 and $\mathrm{I}$ for impact $i$ in category $c$

$M_{c i}=$ best value for impact $i$ in category $c$

$m_{c i}=$ worst value for impact $i$ in category $c$

$f_{c i j}=$ expected value of impact $i$ from implementing alternative $j$ in category $c$

Recall that $M_{c i}, m_{c i}$, and $f_{c i j}$ were quantified in Stage II of the framework. The $R$-metric considers the ratio of the distance from the best value, $M_{c i}-f_{c i j}$, to the difference between the best and the worst values, $M_{c i}-m_{c i}$, for impact $i$. This ratio is squared and multiplied by the square of a preselected weight, $w_{c i}{ }^{2}$. The result is a weighted, dimensionless number for each impact. Each category may contain as many impacts as are expected to result from undertaking a project. The square root of the sum of the dimensionless numbers in each of the three categories (social, ecological, and economic) yields a category index. The process is repeated for all project altematives, thus yielding three indexes for each alternative.

The advantage of using the distance metric formulation is that the resulting category indexes of alternative projects are also dimensionless (commensurate) and therefore facilitate 
their comparison. The project altemative with the lowest category index is the most reversible, or least irreversible, alternative in that particular category. The three category indexes can be combined to obtain a single reversibility index for each project alternative. A weighted average of the three indexes is a reliable method for combining the indexes, but there is significant subjectivity associated with specifying category weights. As discussed in Chapter 1, methods for combining the three indexes would not significantly affect the application of the proposed reversibility framework and, therefore, were not investigated.

The "raw" indexes calculated by the $\boldsymbol{R}$-metric could be meaningless without having a reference point or a range of threshold values to scale the indexes. Derivation of the simple equations from the $R$-metric for calculating reversibility thresholds is discussed in the following subsection.

\subsubsection{Reversibility Thresholds}

Determining the reversibility thresholds for a particular project is a relatively simple task when all impacts have been identified and their expected, best, and worst values, as well as respective weights, quantified. The minimum threshold limit, $T c_{m i n}$ indicating the most desirable degree of irreversibility is simply equal to zero. This is confirmed by observing that when the impact values, $f_{c i j}$, are assigned their best values, $M_{c i}$, the value of the distance ratio in the $R$-metric is equal to zero for all $i$. To obtain the maximum threshold limit, $T \mathrm{c}_{\max }$, the impact values, $f_{c i j}$, are assigned their worst values, $m_{i}$, and the distance metric is applied; note that in this case the absolute value ratio is equal to $\mathrm{I}$ for all $i$, such that $T \mathrm{c}_{\max }$ is simply the sum of $w_{i}{ }^{2}$, the square of impact $i$, for all $i$ in each of the three categories. Therefore, the $R$-metric simplifies to the following equations for calculating the minimum and maximum threshold values, respectively:

$$
\begin{aligned}
& T c_{\min }=0 \\
& T c_{\max }=\left(\sum_{i=1}^{N c} w_{c i}^{2}\right)^{\frac{1}{2}}
\end{aligned}
$$


The reversibility indexes are compared to the threshold indexes for the purpose of determining the aggregated severity, namely the level of irreversibility, of impacts of altemative projects in each of the three categories. Alternatively, the category indexes can be standardized using the threshold values. The minimum and maximum reversibility values can also be used to identify acceptable levels of imeversibility for various projects. For example, the reversibility index of a large reservoir development project can be specified not to exceed $75 \%$ of the maximum threshold limit so that altemative designs are automatically rejected if their reversibility index exceeds this value.

The analytical format of the $R$-metric enables its repetitive application. This is useful for obtaining reversibility indexes that correspond to different project stakeholders, for example, community council, various levels of govemment, and residents, who may specify different impact values and weights. The repetitive application of the distance metric is also necessary in Stage IV of the framework for determining the sensitivity of the indexes to changes in various parameters.

\subsubsection{Stage IV}

This is an important stage of the reversibility framework. It is important to determine the sensitivity of the indexes to changes in impact values or weights as a significant portion of the impact quantification stage (Stage II) is subjective. Typically, a decision maker would prefer to consider a sensitivity analysis of the information upon which important decisions are based before committing monetary and natural resources to a project.

The distance metric formulation can be programmed in a spreadsheet for easy manipulation of the parameters. A sensitivity analysis is different from determining threshold values in that the parameters are tested separately for sensitivity whereas they are varied simultaneously for calculating threshold limits. A sensitivity analysis is particularly useful for determining the effect of changes in highly subjective impact values on the indexes. The decision maker needs to specify the extent of a sensitivity analysis. A complete and exhaustive sensitivity analysis would require that each impact value be changed individually, 
the distance metric be applied and the change in reversibility indexes be recorded, and the impact value be changed to its original value before the process is repeated with the next impact value. This can be a tedious task if the list of impacts is large. However, a systematic elimination of some parameters, for example, those parameters that were measurable and easily quantified, from the sensitivity analysis would considerably simplify the scale of the sensitivity analysis. This point is demonstrated in the application of the reversibility framework to the case study in Chapter 4. Furthermore, the $R$-metric can be translated into computer code, for example, $C_{+}$, FORTRAN, or BASIC, or programmed in a spreadsheet macro to facilitate a sensitivity analysis of large lists.

\subsubsection{Aggregation of Category Indexes}

Methods for combining the three category indexes (social, ecological, economic) in order to obtain one aggregated index were not investigated. As pointed out in Chapter $\mathrm{l}$, it is reasonable to assume that the number of feasible altematives for most development projects are few (less than ten), and that the decision makers would most likely prefer to observe a measure of performance in each category. Therefore, having three indexes per alternative does not complicate the use of the framework or reduce its efficacy. The only advantage of aggregating the three category indexes into one index per alternative is that it provides one criterion, instead of three, on which the final selection of an alternative can be based. A meaningful method for combining the three indexes will require consideration of complex social, ecological, and economic issues, as well as the connections between these issues. For example, in poor countries more weight may be placed on the social and economic categories as minimizing ecological degradation can be achieved by reducing poverty and increasing social status (see section 2.1.4.1 for a discussion of poverty from a sustainable development point of view). However, based on this example, an effective way of combining the indexes is to specify category weights based on some specific criteria and calculate a weighted average of the three category indexes. Examples of applicable criteria for this purpose include the physical distance between the local communities and the project area for the social category, the expected duration of the project for the ecological category, and the current 
unemployment rate for the economic category. Recommendations for future research in this direction are contained in Chapter 5.

\subsection{Utilization of Sustainability Principles}

As noted in Chapter 1, the ultimate goal of the reversibility framework is sustainable project selection. Sustainability goals and principles are inherently considered in the framework, particularly in the process of defining and quantifying individual impacts. When assessing health and safety impacts of a development plan, poor health conditions is considered undesirable, consistent with one of the main goals of sustainable development identified by the United Nations Environment Program [Tolba, 1984]. Improved water quality is desirable, consistent with priority number eight for achieving sustainable development identified by Palmer [1992]. Disturbance of wildlife, other than regulated hunting, and damage to wildlife habitat are considered unsustainable, another priority for sustainable development listed by Palmer [1992]. Sustaining natural aesthetic amenities in an area is preferable to altering them by man-made structures. These examples are indicative of the rationale for identifying and quantifying impacts within the reversibility framework, which is consistent with the mainstream objectives of sustainability and sustainable development summarized in Section 2.1.4. Therefore, there is a strong connection between sustainability and the proposed reversibility framework. 


\section{APPLICATION OF REVERSIBILITY FRAMEWORK}

The application of the reversibility framework to a detailed electrification project is discussed in this chapter. A background to the selected case study is given in the first main section. Section 4.2 describes the process of application of the reversibility framework. The last main section in this chapter contains a general discussion of the results.

\subsection{The Case Study}

A large-scale electrification project in northeastern Manitoba was selected for evaluating the effectiveness of the proposed reversibility framework. The need for this project has already been established, and some work has already been completed to date.

\subsubsection{Background}

Between 1967 and 1972 Manitoba Hydro constructed independent local diesel generating plants and distribution systems for seven of the north central communities: St. Theresa Point, Garden Hill, Wasagamack, God's Lake Narrows, Oxford House, Red Sucker Lake, and God's River. Since then, the North Central (NC) communities and affiliated Indian organizations have requested improved electric service on numerous occasions for various reasons, including population growth and high expectations for a reliable power supply that were not met by the diesel plants. The general perception was that these communities were paying the highest cost in terms of the level and quality of service, risk to personal safety, and personal convenience, as well as the highest cost in monthly bills.

The most recent forecasts based on estimated number of houses anticipated that demand for electricity would increase in the NC communities by an average $4.0 \%$ per year in the next two decades. To continue to supply the expected energy growth, significant additions to the existing diesel facilities would be required. Continued operation of the 
existing diesel facilities, however, would entail rising costs due to projected increases in the cost of diesel fuel and its transportation, increasing surcharges to government customers, and the requirement for more land for expansion of the facilities and fuel storage tanks. Furthermore, the "restricted" service provided by diesel generation which limits the ability of NC residents to enjoy the same level of use of electrical appliances as that provided to other comparable rural communities would not change significantly. Manitoba Hydro, as mandated in The Manitoba Hydro Act, is responsible for providing reliable, low-cost electricity to all Manitoba customers. Therefore, there is a need for a more reliable source of energy capable of providing unrestricted electric service to the NC communities.

To determine the viability of power supply altematives, a number of load growth, feasibility, and cost-benefit analyses were carried out [Manitoba Hydro, 1983; IDE, 1984; Hildebrand Young, 1986]. In these studies, a wide range of energy supply alternatives for the electrification of the NC communities were evaluated, including: connection to Manitoba Hydro's central system; development of small, local water power sites; enhanced diesel generation; generation by wood-fired boiler-steam turbines, wood gasification dual-fuel engines, and peat-fired steam turbines; solar energy generation; wind energy generation; and several hybrid methods. On economic and technological grounds only the central system supply and the local hydro generation alternatives were considered feasible. Based on further economic analysis, however, the central system supply option proved to be the most viable. A preliminary environmental evaluation and socio-economic assessment, contained in a 1984 report by IDE, concluded that potential environmental impacts of the two principal altematives were similar, except that the small hydro generation option appeared to have more serious potential impacts on brook trout habitat and fish passage. The overall conclusion of the initial study was that on economic, environmental, and social grounds a connection from the Manitoba Hydro central grid at Kelsey to the communities is the preferred option. The proposed central system is now known as the North Central Project, NCP. A description of the NCP is contained in the following section. 


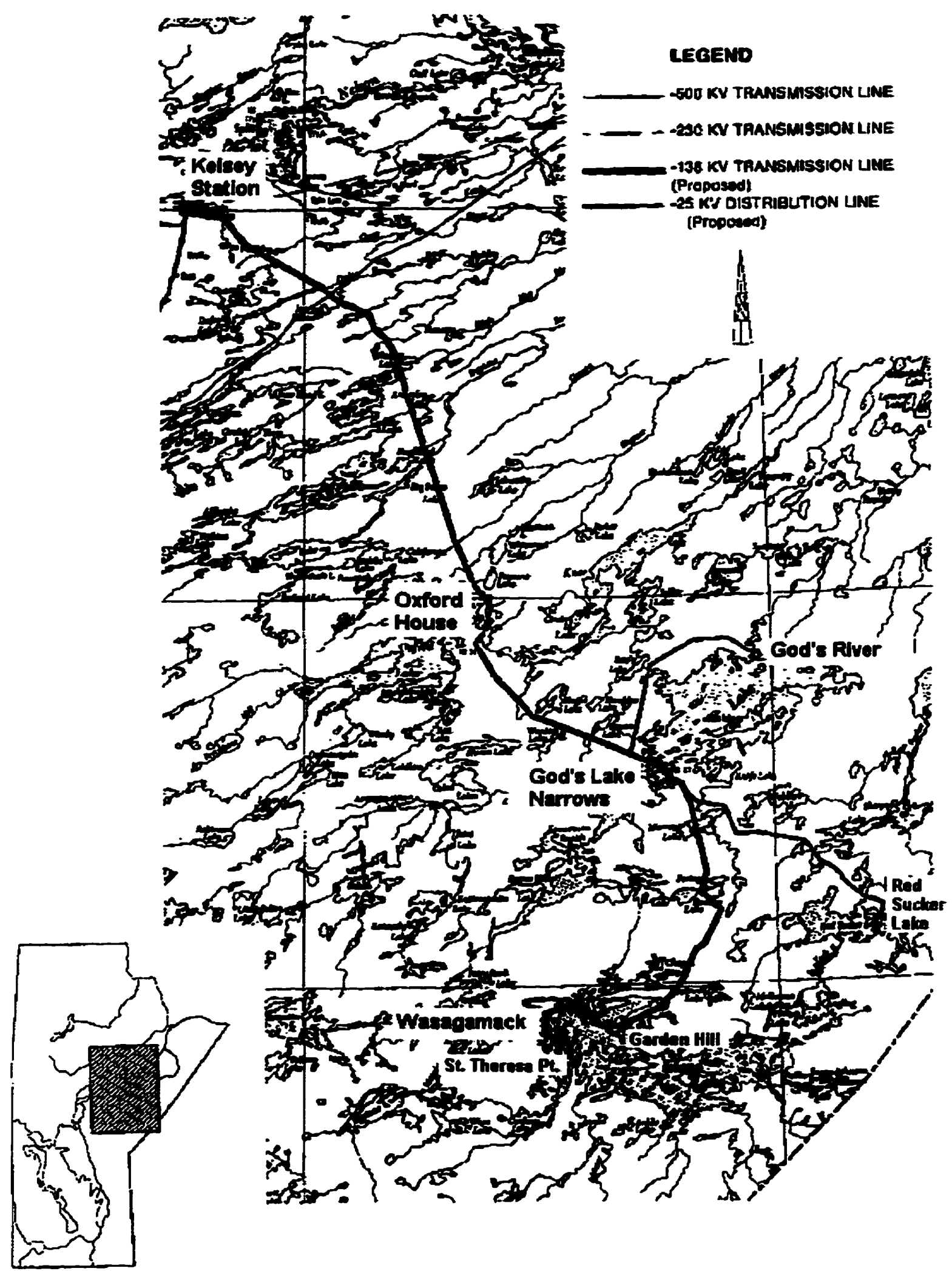

Key Map

Figure 4.1 NCP Transmission and Distribution Lines 


\subsubsection{The North Central Project (NCP)}

The North Central Project (NCP) is an electric transmission and distribution system designed by Manitoba Hydro (MH) to link nine aboriginal communities in northeastern Manitoba to the provincial electric power system, as requested by the Government of Canada and the Province of Manitoba. The existing Kelsey generating station will serve as the NCP connection point. The nine communities include the seven First Nations of Oxford House, God's Lake, God's River, Red Sucker Lake, Garden Hill, Wasagamack, and St. Theresa Point, and two non-status Community Council communities of Island Lake and God's Lake Narrows (and three other non-status populations at Oxford House, Red Sucker Lake, and St. Theresa Point). Figure 4.1 contains a map of the NCP study area and the proposed transmission and distribution routes. The NCP involves four principal activities:

1. construction of about 518 kilometers of transmission and distribution lines to the communities from Kelsey Station on the Nelson River (see Figure 4.1);

2. constructing four transformer stations at Oxford House, God's Lake Narrows, Garden Hill, and Wasagamack;

3. rebuilding and upgrading the power distribution networks within all nine communities; and

4. removing the existing local diesel plants and returning the use of all sites, after any needed clean-up, to the communities.

The base capital cost of the NCP was estimated to be $\$ 97.8$ million in April 1993. By February 28, 1993, expenditures had reached approximately $\$ 9.56$ million on various components of $\mathrm{NCP}$, including route and site investigation and selection; construction of the Wasagamack to St. Theresa feeder line; preliminary transmission and distribution systems, and communications design; and, community consultation and liaison services. Actual project costs will be shared $75 \%$ by the federal government, $15 \%$ by the provincial government, and $10 \%$ by Manitoba Hydro. 


\subsubsection{Community Support and Concerns}

In 1990, after a proposed project funding agreement was negotiated among the federal government, provincial government, and Manitoba Hydro, full formal support for the NCP central supply system altemative was given by the Bands and Communities. Residents were excited by the prospect of improved morale, health and living conditions potentially attainable through modem water and sewer systems, improved housing and related amenities, improved recreational facilities, and other such developments.

Some residents and leaders, especially the elders, initially raised concems regarding the NCP effects on the natural resources and traditional values. But these concerns were based on the misconception that the NCP involved flooding of land, and have been alleviated through various information programs and community open-house meetings. Basically, a high level of participation (Section 2.1.4.2) has been maintained throughout the phases of the NCP.

\subsection{Application of Reversibility Framework}

The purpose of conducting this case study of the NCP is to demonstrate the application of the reversibility framework and to evaluate its effectiveness based on the results. Therefore, due to the availability of information, only the central supply system alternative (the NCP) and maintenance of the existing diesel generating facilities are considered. As a full investigation of all the energy supply altematives (described in Section 4.1.1) would require collection of relevant data for each alternative, it is beyond the scope of this thesis. It should be noted, however, that this does not affect the results of the reversibility framework. The four stages of application of the framework, described in Section 3.2, are demonstrated in the sections that follow. 
Table 4.1 List of NCP Impacts and Corresponding Values and Weights

\begin{tabular}{|c|c|c|c|c|c|c|}
\hline i Impact Name & Units & $\boldsymbol{M}_{e i}$ & $m_{a i}$ & $w_{a i}$ & NCP & Diesel \\
\hline \multicolumn{7}{|c|}{ Social } \\
\hline I Hunting & Scale & 0 & 10 & 0.85 & $\overline{1}$ & $\overline{0}$ \\
\hline 2 Trapping & RTL sq. km & $\mathbf{0}$ & 1.35 & 0.85 & 0.7 & 0 \\
\hline 3 Visual and aesthetic & Scale & $\mathbf{0}$ & 10 & 0.90 & 9 & $\mathbf{0}$ \\
\hline 4 Roads & Scale & 10 & $\mathbf{0}$ & 0.65 & 6 & $\mathbf{0}$ \\
\hline 5 Health and hygiene & Scale & 10 & 0 & 0.95 & 9 & $\mathbf{0}$ \\
\hline 6 Nutrition and diet & Scale & 10 & 0 & 0.90 & 9 & 0 \\
\hline 7 Safety & Scale & 0 & 10 & 0.40 & 9 & 0 \\
\hline 8 Water quality/quantity & Scale & 10 & 0 & 1.00 & 10 & $\mathbf{0}$ \\
\hline 9 Outside workers & No. / comm. & $\mathbf{0}$ & 20 & 0.35 & 15 & 0 \\
\hline 10 Air quality & Scale & 10 & $\mathbf{0}$ & 0.80 & 10 & 0 \\
\hline 11 Traffic, short-term & Scale & 0 & 10 & 0.35 & 6 & I \\
\hline 12 Traffic, long-term & No. loads & 294 & 0 & 0.70 & 294 & 0 \\
\hline 13 Noise & Scale & 0 & 10 & 0.30 & 2 & $\mathbf{l}$ \\
\hline 14 Fire safety & R. Scale & 10 & $\mathbf{0}$ & 0.95 & 9 & $\mathbf{0}$ \\
\hline I5 Improved facilities & Scale & 10 & $\mathbf{0}$ & 0.45 & 9 & 0 \\
\hline 16 Heritage resources & R. Scale & 0 & 10 & 0.95 & 10 & $\mathbf{0}$ \\
\hline I7 Appliance and equipment & R. Scale & 0 & 10 & 0.50 & I & 7 \\
\hline 18 Criminal behavior & R. Scale & 10 & 0 & 0.60 & 5 & 0 \\
\hline \multicolumn{7}{|c|}{ Ecological } \\
\hline I Rights-of-way & ha & 0 & 2352 & 0.50 & 2352 & 0 \\
\hline 2 Rare plants & R. Scale & 0 & 10 & 0.95 & 7 & 0 \\
\hline 3 Wildlife habitat & sq. $\mathbf{k m}$ & 0 & 50000 & 0.80 & 27.4 & 0 \\
\hline 4 Diesel fuel & $\mathbf{M} \mathbf{k g}$ & 7 & 0 & 1.00 & 7 & 0 \\
\hline 5 Water crossings & No. & 0 & 164 & 0.95 & 23 & 0 \\
\hline 6 Fish and aquatic resources & Scale & 0 & 10 & 0.35 & 2 & 0 \\
\hline 7 Hazardous materials & R. Scale & 0 & 10 & 0.45 & 3 & 8 \\
\hline 8 Wild rice & R. Scale & 0 & 10 & 0.85 & 4 & 0 \\
\hline \multicolumn{7}{|c|}{ Economic } \\
\hline I Training and employment & Scale & 10 & 0 & 1.00 & 10 & 0 \\
\hline 2 Direct business opportunities & M\$ & 25 & 0 & 0.80 & 25 & 0 \\
\hline 3 Monthly bills & $\$ /$ month & 0 & 230 & 0.85 & 110 & 41 \\
\hline 4 Federal Government savings & $\mathbf{M} \$$ & 2 & 0 & 0.95 & 2 & 0 \\
\hline 5 Provincial Government savings & M\$ & 0.44 & 0 & 0.95 & 0.44 & 0 \\
\hline 6 Retrofitting & \$/ unit & 0 & 2700 & 0.65 & 2400 & 0 \\
\hline 7 Large businesses & M \$ & 0.5 & 0 & 0.90 & 0.5 & 0 \\
\hline 8 Rates savings & cents / kWh & 6 & 32.4 & 0.75 & 6 & 32.4 \\
\hline
\end{tabular}

\subsubsection{Stage I: Impact Identification}

In 1993, Manitoba Hydro prepared an EIS containing a discussion of NCP impacts and management techniques designed to reduce adverse effects of NCP. Critical impacts of NCP and the diesel alternative were extracted from the EIS. Table 4.1 contains a list of the 
identified and categorized impacts. A full description of these impacts is combined with the impact quantification stage (Stage II) of the framework so as to achieve continuity in the discussion and justification for the selection of each impact and its associated value and weight.

\subsubsection{Stage II: Impact Quantification}

Table 4.1 contains a list of all identified impacts and corresponding values for the parameters of the $R$-metric. The impacts are described in detail in the following subsections. Some of these impacts were readily quantifiable while other impacts required a subjective scale (Scale) or a "risk scale" (R. Scale) to evaluate their magnitude. For some of the impacts, a risk scale was used to indicate the subjective level of the risk of observing that impact from undertaking the project. For example, the impact of the NCP on fire safety was evaluated on a risk scale. For each impact, the justification for assigning values and weights is discussed in the context of the reversibility framework presented in Chapter 3 with reference to the concepts of resilience, option value, time preferences, and cumulative effects, where applicable.

\subsubsection{Social Impacts}

Hunting

The added pressures on local wildlife populations during or after NCP clearing and construction are expected to be minimal. Even though about $70 \%$ of all NCP right-of-way (ROW) provide new access routes to previously remote areas that were only accessible by air (the remaining $30 \%$ parallel winter roads and, therefore, do not provide alternative access), over the longer term, travel along the ROW will not always be possible. Some concerns were raised regarding disturbance of moose and caribou movement (discussed under ecological impacts). But harvest of these animals will not be significantly affected by the NCP ROW clearing and construction, and any change in movement and distribution patterns will be of short duration. Therefore, on a subjective scale of 0 to 10 , a low value of 1 is assigned to 
NCP impacts on hunting in the area. A high weight of 0.85 represents the importance of hunting to the traditional way of life in the NC communities (a large option value will always be attached to hunting opportunities). The diesel altemative will not affect hunting opportunities, thus a value of 0 is assigned.

\section{Trapping}

Trapping is a source for fur production and, therefore, a source of income. It also represents a component of the traditional way of life in the North Central communities, a social activity. The economic aspects of trapping are not considered here. Only the social aspects of the effect of NCP on trapping opportunities are considered. Forty-three (43) Registered Trap Lines (RTLs) are crossed by the NCP transmission and distribution lines. Within any given RTL, the area that would be affected by the ROW clearing ranges from 0.05 $\mathrm{km}^{2}$ to $1.35 \mathrm{~km}^{2}$, the mean value being $0.70 \mathrm{~km}^{2}$. Assuming that the average area $\left(0.70 \mathrm{~km}^{2}\right)$ is affected in each RTL, the worst amount that could be affected is $1.35 \mathrm{~km}^{2}$, and the best value is $0 \mathrm{~km}^{2}$. Although the total area affected is a small portion of the total RTL area, a quasi-option value is attached to trapping opportunities in the area assuming information regarding effects of NCP on trapping will accumulate as the project proceeds. A high weight is assigned as the effects are permanent and trapping represents a significant part of the traditional economy and contributes to the quality of traditional life within the NC communities.

\section{Visual and Aesthetic Effects}

Visual impacts of the NCP transmission and distribution lines are permanent. Measures will be taken by Manitoba Hydro to reduce adverse visual impacts (for example, locating structures $30-50 \mathrm{~m}$ from the shoreline, or setting them back from high-walled river channels, high vegetated banks, and obscuring them from canoe routes). However, these changes are unavoidable. The level of resilience of the system for adapting to future changes, for example, future tourist sites, is low. Therefore, a high scale value is assigned. Visual effects will persist over the longer term even if they are accepted as part of the natural surroundings and there are no lingering apprehensions on the part of community residents. 
Therefore, a high weight is used to represent the importance of visual effects of NCP relative to other impacts.

\section{Roads}

Substantial wear and tear of local roads may occur during construction work within the communities. However, regular maintenance and upgrading will minimize damage to these roads. Also, new all-season access routes will be constructed to connect the four transformer stations to their host communities, which will also provide alternative routes between some of these communities. This is a positive effect of NCP. A scale value of 6 out of 10,0 being worst, is assigned. The worst scale value is assigned to the diesel alternative as it does not provide the opportunity for improvement. A relatively low weight is assigned as changes in existing roads are not considered to have a significant effect on the social setting in the NCP area.

\section{Health and Hygiene}

NCP will increase the resilience of NC communities to overcome health problems that would otherwise accumulate without improved electrical service as a result of cumulative effects of population growth and unreliable power source (diesel). Improved personal hygiene and cleanliness of homes, businesses, and community facilities will be easier to achieve once $\mathrm{NC}$ residents have easy access to modem plumbing and electrical appliances which will also be expandable to accommodate population growth. This is considered a substantial, positive impact with long term benefits. Therefore, a high scale value and a high weight are assigned.

\section{Nutrition and Diet}

NCP will create the ability for NC residents to store a larger variety and quantity of fresh food. This could improve nutrition by encouraging use of more fresh and frozen foodstuffs, and a greater variety of ways in which foods can be preserved. This impact is evaluated on a scale representing the potential for improvement in nutrition and diet created by the NCP or the diesel facilities. The positive effects of the NCP will be realized in the long term while enhancement of the existing diesel facilities will not have a significant long term 
effect on nutrition and diet. Furthermore, improvements in nutrition and diet are one of the major changes that have been anticipated by the NC communities from the beginning stages of the NCP. Therefore, a relatively high weight of 0.90 is assigned.

\section{Safety}

Many north central residents, especially elders and children, are unprepared for the increased risk of accidents involved in their use of, and access to, unfamiliar and more dangerous electrical equipment and appliances. Past experience from projects similar to NCP (such as a land line for Pukatawagan) has prepared MH for better safety education and training programs that will begin before and continue past the construction period. Therefore, though potential safety impacts could be substantial (high scale value), safety education and training increases the resilience of residents within the communities to prevent or overcome safety threats and hazards. Therefore, a low weight is assigned.

\section{Water Quality and Quantity; Water and Sewer Systems}

Water quality and quantity can only improve as a result of NCP. Improved water supply, in turn, has other cumulative effects such as improved health and hygiene. Central supply power will: (I) enable use of larger sized motors, pumps and electric heat tape to prevent water and sewer lines from freezing, and (2) reduce the possibility of motor failure due to voltage fluctuations; features which have not been feasible with the limited supply of the existing diesel generating plants. North central households that haul their water supply from a nearby lake or river may use on average 23 liters of water per person each day, which amounts to $12 \%$ to $25 \%$ of the per capita consumption in households with indoor plumbing. Linkages between sanitation, water quality and quantity, and health status are well established particularly in relation to the incidence of infectious and parasitic diseases. Research has shown that the incidence of intestinal and skin diseases can be reduced where people have access to at least 60 liters of water per day. Options such as gravity systems and community or individual septic fields have been ruled out because of population density and growth, prevailing community layout, topography, soil, bedrock, and other biophysical limitations. A piped water system, feasible with the NCP, will improve water availability in the north central 
communities, and is easily expandable. An improved sewer system will reduce risks of poor health due to poorly constructed or maintained pit privies. Installation of these systems is considered to be one of the most significant, long term benefits to follow the NCP. The rate of time preference for improved sewer and water systems is very high with a scale value of 9; immediate availability of such improved systems is highly preferred to their availability after, for example, five years. All factors considered, the best scale value and the highest weight in the social category are assigned.

\section{Outside Workers}

The influx of non-resident workers into the community during station construction and community distribution rebuilding and construction could create adverse impacts. These could occur as a result of interaction and opposition with local residents. An average of 15 workers (estimated from employment tables contained in the NCP EIS documents) is taken as the value for this impact. At worst, a maximum of 20 outside workers can be expected in each community during peak construction periods. The influx of workers can have positive economic effects, but only the potentially negative social impacts are addressed in the social category. Adverse impacts should be easily manageable with proper preparation, and can be minimized because of past experience of $\mathrm{MH}$ with similar projects (for example, Pukatawagan and Split Lake). Therefore, a low weight of 0.35 is assigned.

\section{Air Quality}

Air quality can only improve as a direct result of NCP. Even though pollution levels are considered to be minimal in at least four of the seven communities, cumulative effects of future expansions to diesel (in the absence of NCP) combined with population growth and expansion of the communities can create undesirable amounts of air emissions from the buming of diesel at the stations and buming of wood and fuel oil in many homes. Therefore, $\mathrm{NCP}$ is assigned the best scale value (10 out of 10 ) for improving air quality. However, air quality impacts are not as substantial as water quality impacts. Therefore, a lower weight of 0.8 is assigned to represent the importance of air quality impacts of the two alternatives relative to impacts on the quality and quantity of water. 


\section{Traffic, Short-Term}

One year prior to and during NCP construction seasons, MH and contractor shipments of materials along different segments of the road network will significantly increase movement of traffic. Increased traffic volume may lead to accidents (vehicles and pedestrians). There is also a risk of temporary disnuption of local traffic pattems due to construction vehicles and during line stringing. This impact is evaluated on a subjective risk scale. As the size of the NCP is significantly larger that the size of the diesel altemative, its short-term adverse effects on traffic and related accidents are also potentially larger. This is represented in the assigned impact scale values for the two altematives. Past experience, use of "rider poles" to prevent accidents during line stringing, and other measures will minimize potential hazards. As there is no risk of cumulative effects, and the adverse impacts on traffic movement will end with the completion of NCP, a very low weight is assigned.

\section{Traffic, Long-Term}

A longer term benefit of NCP in terms of traffic and related hazards (accidents, fuel spills) is an overall reduction in annual diesel fuel loads hauled to the station sites, and fuel oil loads hauled to the communities; this does not account for the negative economic impacts of reduction of fuel loads. In 1991, based on freight haul statistics, a total of 294 loads were made to the NC area for the transport of diesel fuel for MH's facilities. This value is used to quantify the long-term social benefit of reduced traffic volume. A relatively high weight of 0.7 reflects the importance of this long-term benefit and other positive cumulative effects, such as reduced wear and tear of winter roads.

Noise

No significant increase in noise levels is expected from all phases of the NCP. Short term increase in noise levels may be experienced during construction of community distribution lines and decommissioning of diesel sites. The level of noise generated by existing diesel sites is subjectively rated at 1 , while the short term impact of NCP on noise levels is assigned a magnitude of 2 out of 10; 10 being the worst possible increase in noise levels beyond tolerable limits that could lead to disturbance of residents. A low weight of 0.3 
reflects the insignificance of this impact relative to other social impacts, as well as its shortterm duration.

\section{Fire Safety}

The effectiveness of any attempt in recent years to upgrade the fire fighting capacity in the north central region has been constrained by the lack of pressurized water supply. Improved household fire safety will follow NCP as a result of: (1) installation of piped water systems; (2) less reliance on old wood-fired cooking and heating stoves; and (3) improved residential wiring. $\mathrm{NCP}$ will increase the resilience of communities to prevent, reduce, or contain residential fires. The use of less flammable insulating oil (compared to diesel fuel used at existing sites) and improved fire breaks reduce the risk of fire at the new transformer stations. An "improvement scale" is used to quantify this impact. NCP is assigned a 9 (out of 10) while the existing diesel service is rated at 0 in terms of their potential for improvement. This is a positive and potentially long-term effect of NCP. Therefore, a high weight is assigned.

\section{Improved Recreational Facilities}

The potential for improvement in community facilities or establishment of new ones is generated by NCP. On a scale of 0 to 10,10 representing the highest potential for improvement, NCP is rated at 9. Residents and Band members prefer to possess the option of improving recreational facilities or building new ones as soon as possible since lack of recreation is believed to be one of the causes of substance abuse, violence, thefts, and other illegal activities in the region. This positive rate of time preference for improved facilities is evaluated at 7. However, as development of recreational facilities is not a direct result of $\mathrm{NCP}$, and the positive effects are constrained by high operating costs, a low weight of 0.45 is assigned relative to other social impacts.

\section{Heritage Resources}

Provincially registered heritage sites, known areas of local cultural importance, and new sites identified during field studies along the proposed ROW have been identified and 
avoided during the route selection process. Regardless of these efforts, however, NCP creates a definite risk of damaging these and other, as yet unidentified, sites. Some areas could contain unidentified heritage resources. Cultural resources can be disturbed when land surfaces are altered by vehicle use or by excavation. Inappropriate construction practices at water crossings may contribute to site erosion or slumping that can result in submersion of important artifacts. In short, there is a relatively high risk that heritage resources are damaged inadvertently. As they are unique and irreplaceable, the option value attached to retaining and protecting heritage resources is very high. Those who value such resources tend to exhibit strong aversity towards the risk of damaging the resources. Potential effects on heritage resources are quantified on a risk scale. A high weight of 0.95 is assigned as any damage, whether inadvertent or deliberate, is irreversible. In other words, the resilience of heritage resources to overcome accidental damage is very low.

\section{Damage to Appliances and Equipment}

Accidental damage to household appliances and other equipment with the existing diesel service was typically encountered when too many units were plugged in simultaneously causing overload tripping of service main breakers. NC residents most likely have a high rate of time preference for the opportunity to eliminate the risk of damage to their appliances and equipment. NCP reduces risk of damage by enabling improvements to household electrical wiring. $N C P$ is assigned a value of 1 , and the diesel alternative a value of 7 , on a risk scale of 0 to 10. As this is not a substantial impact of NCP or diesel relative to other impacts, a low weight is assigned.

\section{Criminal Behavior}

NC communities may experience a short term increase in criminal activities, such as break-ins and thefts, if there is a sudden increase in consumer purchases of new appliances, power tools, and entertainment equipment; as was experienced in Pukatawagan. However,

experience from communities that received land line power such as Pukatawagan indicates that residents are likely to obtain a greater sense of well-being and satisfaction as a result of positive changes associated with improved power supply. Coupled with improvements in 
community infrastructure and economic conditions, this may increase the resilience of residents and community leaders to deal with crime, violence, substance abuse, and social tension that now exist. Therefore, in the longer term, there is potential for decreasing the level of criminal behavior and improving the psychological well-being within the NC communities. NC residents most likely have a high rate of time preference for the opportunity to have a greater sense of well-being. This impact is rated on a subjective scale based on the above discussion. The diesel alternative will have insignificant effect, whereas the NCP will produce an average potential for improvement (scale value of 5) of the psychological wellbeing of NC residents

\subsubsection{Ecological Impacts}

\section{Rights-of-Way Clearing}

An estimated $458 \mathrm{~km}$ of the total $518 \mathrm{~km}$ of transmission and distribution line segments cross treed land, including bogs, mineral soils, and bedrock controlled uplands. The 2,352 ha of required clearing for NCP is significant if taken relative to the insignificant amount required for expanding the existing diesel sites, the alternative to NCP. However, the total amount of required clearing is not considered a cumulative effect as it amounts to an area totaling less than $0.01 \%$ of the boreal forest in the study area. The effect on the resilience of the natural forest to withstand shocks, such as forest fires, is insignificant. Therefore, an assigned impact weight of 0.5 is sufficiently low to account for the insignificant percentage of the forest area affected, and is high enough to also account for the significance of the impact when comparing the two alternatives (NCP and diesel expansion).

\section{Rare Plants}

The types and distribution of plants in general, and rare plants in particular, in the NCP study area are not fully known. Even if the rare plants that have been identified are available in abundance elsewhere, damage or destruction at any one location reduces the natural biodiversity of the affected area. Three out of five rare plant habitats crossed by the proposed NCP routes are unique to the area. Therefore, the NCP could potentially jeopardize their 
survival. Potential damage to a rare plant species can significantly reduce the resilience of that species to natural environmental and other pressures. On a risk scale of 0 to 10,0 representing a no-risk scenario, the risk of potential damage to rare plants is evaluated at 7. The high weight assigned represents the importance of this type of risk as well as the uncertainty regarding the presence of other, as yet unknown, rare plant species in the NCP right-of-way (ROW) that could be affected.

\section{Wildlife and Wildlife Habitat}

According to the EIS documents and various exhibits of the NCP study area, $27.4 \mathrm{~km}^{2}$ of wildlife habitat is directly affected by NCP. This amount is spread over a very large area in excess of $50,000 \mathrm{~km}^{2}$, thus the resilience of wildlife and their habitat is not likely affected. Disturbance of wildlife and their habitat is considered in itself a significant impact. However, woodland caribou are sensitive to disturbances in their habitat. Clearing of vegetation on raised bogs and ridges that support vegetation cover favored by caribou may make wintering habitat less attractive to the animals. The residents of NC communities have also expressed some concern regarding disturbance of caribou movement pattems affecting their distribution, and possibly making them more accessible to hunters or less available in traditional hunting areas. This could increase pressure on the caribou population and reduce their resilience to withstand harvesting pressure. Therefore, a high impact weight which reflects the importance of wildlife, especially caribou, and their habitat is warranted. However, the weight is adjusted (lowered) to reflect the mitigative measures taken by Manitoba Hydro to minimize potential adverse effects. These measures include an environmental information program to discourage or restrict construction workers from approaching, feeding, hunting, trapping, or otherwise disturbing wildlife; local provincial Natural Resources Officers that will monitor worker conduct; proper disposal of waste generated at camp sites and work sites to avoid attracting scavengers, such as red fox, black bear, and wolf, and control of recreational travel via snowmobiles. 


\section{Diesel Fuel}

The 1991 winter road freight haul statistics indicated that a total of 7 million $\mathrm{kg}$ of diesel fuel ( $46 \%$ of all fuels), equivalent to 294 loads ( $28 \%$ of total loads) or $31 \%$ of all freight, was transported to the communities in that year. This 7 million $\mathrm{kg}$ per year is considered a low but typical amount of diesel fuel that could be saved as a result of NCP. Diesel fuel is a non-renewable resource. Regardless of the actual amount, any reduction in use of diesel is considered to be beneficial to the environment. Therefore, the highest category weight is assigned to this impact.

\section{Water Crossings}

A total of 164 water courses are crossed by the NCP transmission and distribution lines. Twenty-three (23) of these water crossings are at locations where the upstream drainage area is greater than $30 \mathrm{~km}^{2}$. Water courses of this size are likely to contain important feeding, spawning, and overwintering habitat for resident fish populations. A high weight is assigned as the adverse effects can persist in the long term creating the potential for future adversities, such as erosion around important habitat and increased turbidity of spawning waters. Such complications can occur during routine inspection and maintenance procedures.

\section{Fish and Aquatic Resources}

Adverse impacts on fish and their habitat are expected to be virtually undetectable. However, local populations of pike, walleye, and longnose sucker, for example, could be affected during one out of a total of six spawning seasons due to blasting and other construction activities. A very low value of 2 on a risk scale of 0 to 10 is assigned to represent potential adverse impacts. Any adverse effects will be minimized through mitigative measures, for example proper timing of explosions. Contingency plans to prevent and/or minimize potential erosion, drainage alteration and permafrost damage at stream crossings and along water bodies, and other impacts that could affect fish and aquatic resources have been considered by MH. As the NCP does not jeopardize the resilience of fisheries and fish habitat to overcome unforeseen natural pressures, no cumulative effects are expected. Therefore, a very low weight is assigned. 


\section{Hazardous Materials}

The risk of contamination of soils and ground water by diesel spills will continue to exist as long as the diesel sites are operational. Accidental spills of fuels, lubricants, and other chemicals during clearing, facility installation, and operation and maintenance phases of NCP also create the risk of contamination of soil, ground water, permafrost areas, water bodies, and wetlands. All factors considered, the two altematives are evaluated on a risk scale. A value of 8 is assigned for the risk level of the existing diesel facilities, and a value of 3 is assigned to the NCP, as the transmission line altemative eliminates risk of contamination by eliminating the need for large amounts of diesel fuel. A very low weight is assigned as the risk of contamination by hazardous materials is in itself not substantial, and adequate mitigative measures and plans for dealing with spills have been developed.

\section{Wild Rice}

Segments of the transmission line route cross many minor streams and pass by lakes of size greater than 50 ha. Streams and lakes of this size may have future potential for production of wild rice. Some experimental seeding has taken place in the NCP study area. Since adverse effects could be discovered after project implementation, and continued operation and maintenance procedures after the transmission line has been completed could impede future production capacity, a high weight is assigned. However, the magnitude of the inpact, evaluated on a risk scale, is minimal.

\subsubsection{Economic Impacts}

\section{Training and Employment}

Regardless of the actual amount of employment opportunities, the NCP is $100 \%$ better than the existing diesel service in terms of providing short-term employment, as well as contracts that can be potentially beneficial for ongoing regional economic development. The local company, Wapanuk, would gain important management and work force experience plus the opportunity to build its capital base. Over the intermediate and longer term, therefore, Wapanuk could become an effective competitor for future construction and maintenance 
contracts with $\mathrm{MH}$, or for local development of sewer and water installation, road work, housing and community facilities. NC companies, especially Wapanuk, would prefer to obtain training and employment opportunities as soon as possible, so their rate of time preference for

these opportunities is very high. A scale value of 10 , the best possible value, is assigned to impacts of NCP on training and employment. Enhancement of the existing diesel facilities will not produce such training and employment opportunities, thus a value of 0 is assigned to the diesel alternative. In the economic category of impacts, this is considered to be the most important impact of NCP. Therefore, the highest weight of 1 is assigned.

\section{Direct Business Opportunities; Wapanuk}

Three contracts have been set aside. These have been estimated at $\$ 25$ million, and include: clearing of all transmission and distribution line ROW; construction of the transmission line; and, selected civil construction work on the four transformer stations. This is a substantial but short-term economic benefit gained directly from NCP, as reflected in the assigned impact weight of 0.8 .

\section{Monthly Bills}

The impact of new land line service on monthly electrical bills will depend on basic residential consumption which will vary depending on the number of appliances and electrical equipment and the rate at which these are used in each household. The present average of $\$ 41$ per month (quantifies the effect of the diesel altemative on monthly bills) could increase to between $\$ 100$ and $\$ 120$ per month, the average of which quantifies the impact of NCP on monthly bills. Households that choose 200 amp service with electric heat could experience average monthly bills of up to $\$ 230$ (used as the worst value in the $R$-metric). However, residents are free to choose the type of service they desire, and are not compelled to upgrade at any time during or after construction of NCP. As increases in monthly bills are permanent, a high weight should be assigned to this impact. However, MH is prepared to help community leaders educate residents about how to understand rates and billings, and how much more electricity they are likely to consume after they are connected to land line power. Therefore, an adjusted weight of 0.85 is assigned, which represents the importance of the 
impact of NCP (the diesel alternative will not significantly affect consumption rates) on monthly electric bills relative to other economic impacts, but also accounts for the mitigative measures as well as the discretion regarding type of service

\section{Savings to Federal Government}

Federal government facilities, including federal departments, crown corporations, federally funded schools, nursing and health stations, and the RCMP will collectively benefit from annual cost savings of approximately $\$ 2.0$ million (1992\$) at their north central operations. This is a long term benefit that will be realized after completion of NCP. Therefore, a high weight of 0.95 is assigned.

\section{Savings to Provincial Government}

In total, provincial government facilities, including provincial departments, crown corporations, and the Provincially funded Frontier School Division will benefit from annual cost savings of approximately $\$ 450,000$ (1992\$). This is a direct long term benefit of NCP. Therefore, a high weight of 0.95 is assigned.

\section{Retrofitting and Conversions}

The cost of residential rewiring and upgrading to 200 amp all-electric service, including electric heat, is $\$ 2,700$ (1992\$) per housing unit. It is expected that the most common residential conversion will be to a 100 amp service, which will cost $\$ 2,400$ (1992\$) per housing unit. This value is taken as the average cost of upgrading, and the 200-amp conversion as the worst possible value. A low weight, relative to other economic impacts, of 0.65 was assigned as upgrading costs are one-time costs and the residents are not compelled to convert and upgrade at any time during or after construction of NCP.

Operating Cost Savings to Large Businesses

Projected annual reductions in electrical costs for large businesses is estimated at $\$ 500,000$ (1992\$) per year. In addition to the monetary aspects, this is a long term benefit 
that will increase the resilience of large businesses, namely their ability to adapt to changes in regional markets. Therefore, a high weight of 0.9 is assigned.

\section{Rates Savings: Small Businesses and Full Cost Customers}

Small businesses with greater than 15 amp service now face a Full Cost rate of $32.4 \notin / \mathrm{kWh}$. With the completion of NCP all Full Cost commercial customers will pay average energy charges of 5 to $6 \notin / \mathrm{kWh}$. This is a significant decrease that will open up new options for various types of businesses that may be viable in the region and influence existing and future business development. A weight of 0.75 reflects the relative importance of this impact, but also takes into account the fact that the substantial reduction in Full Cost energy rate only applies to Full Cost customers.

\subsubsection{Stage III: Application of R-Metric}

The $R$-metric presented in Chapter 3 was applied to the data (Table 4.1). The resulting reversibility indexes and threshold limits are summarized in Table 4.2. The analysis was carried out using Microsoft Excel; see Appendix A for a detailed list.

Table 4.2 Results of $R$-metric

\begin{tabular}{|l|ccc|}
\hline \multirow{2}{*}{ Index } & \multicolumn{3}{|c|}{ Category } \\
\cline { 2 - 4 } & $\begin{array}{c}c=1 \\
\text { (Social) }\end{array}$ & $\begin{array}{c}c=2 \\
\text { (Ecological) }\end{array}$ & $\begin{array}{c}c=3 \\
\text { (Economic) }\end{array}$ \\
\hline$T c_{\min }$ & 0.00 & 0.00 & 0.00 \\
$T c_{\max }$ & 3.13 & 2.18 & 2.44 \\
$R_{c l}$ (NCP) & 1.53 & 0.92 & 0.71 \\
$R_{c 2}$ (Diesel) & 2.45 & 0.97 & 2.20 \\
Scaled $R_{c 1}$ (NCP) & 0.49 & 0.42 & 0.29 \\
Scaled $R_{c 2}$ (Diesel) & 0.78 & 0.49 & 0.90 \\
\hline
\end{tabular}

The "scaled" indexes are calculated by simply dividing the actual $R$-metric by $T c_{\max }$ in each category. In the social category, the diesel altemative is $78 \%$ irreversible whereas the NCP is $49 \%$ irreversible. A comparison of these values shows that the NCP is the least irreversible, hence the most preferred altemative in all three categories. The economic 
impacts of NCP, aside from the capital costs and operation and maintenance costs, are mainly positive impacts (Table 4.1 ) such that their combined degree of irreversibility of $29 \%$ is very low compared to $90 \%$ for the diesel alternative. In the ecological category, the irreversibility of NCP is only $7 \%$ less than the diesel altemative. Clearly, the decision maker responsible for selecting the best alternative would desire more information pertaining to the ecological impacts and their quantified values and weights before making a selection.

\subsubsection{Stage IV: Sensitivity Analysis}

\subsubsection{1/mpact Weights}

The first parameter tested for sensitivity was the set of weights. This was done by generating a different set of weights and applying the $\boldsymbol{R}$-metric. A total of ten sets were generated each containing a random value between 0.30 and 1.00 for each impact in all three categories. The lower bound of this range (0.30) corresponds to the lowest weight assigned; a weight less than 0.30 is not likely to be assigned to an impact as it implies that the impact is not considered to be significant and should, therefore, be excluded from the list. Thus, ten sets of reversibility indexes were obtained. This approach was used only to demonstrate the procedure of conducting a sensitivity analysis on impact weights. Specifying a range of weights for each impact which represent the level of confidence (the shorter the range the higher the confidence in assigning the original weight) would produce more meaningful results. The results of the random analysis are summarized in Table 4.3 (see Appendix B for the complete sensitivity results obtained using Microsoft Excel).

Table 4.3 Category Indexes Calculated for Ten Sets of Randomly Generated Weights

\begin{tabular}{|c|c|c|c|c|c|c|c|c|c|c|c|}
\hline \multirow[b]{2}{*}{ Category } & \multirow[b]{2}{*}{$R_{g i}^{\dagger}$} & \multicolumn{9}{|c|}{ Category Indexes Corresponding to Random Weight Sets } & \multirow{2}{*}{$\begin{array}{l}\text { No. of Times } \\
\text { Ranked First }\end{array}$} \\
\hline & & 2 & 3 & 4 & 5 & 6 & 7 & 8 & 9 & 10 & \\
\hline Social & $\begin{array}{l}R_{11} \\
R_{12}\end{array}$ & $\begin{array}{ll}0.49 & 0.56 \\
0.74 & 0.66\end{array}$ & $\begin{array}{l}0.47 \\
0.74\end{array}$ & $\begin{array}{l}0.50 \\
0.65\end{array}$ & $\begin{array}{l}0.52 \\
0.71\end{array}$ & $\begin{array}{l}0.53 \\
0.69\end{array}$ & $\begin{array}{l}0.46 \\
0.67\end{array}$ & $\begin{array}{l}0.49 \\
0.76\end{array}$ & $\begin{array}{l}0.43 \\
0.76\end{array}$ & $\begin{array}{l}0.45 \\
0.75\end{array}$ & $\begin{array}{c}10 \\
0\end{array}$ \\
\hline Ecological & $\begin{array}{l}R_{21} \\
R_{22}\end{array}$ & $\begin{array}{ll}0.59 & 0.47 \\
0.32 & 0.40\end{array}$ & $\begin{array}{l}0.49 \\
0.47\end{array}$ & $\begin{array}{l}0.61 \\
0.37\end{array}$ & $\begin{array}{l}0.62 \\
0.28\end{array}$ & $\begin{array}{l}0.34 \\
0.46\end{array}$ & $\begin{array}{l}0.53 \\
0.39\end{array}$ & $\begin{array}{l}0.48 \\
0.23\end{array}$ & $\begin{array}{l}0.41 \\
0.42\end{array}$ & $\begin{array}{l}0.45 \\
0.46\end{array}$ & $\begin{array}{l}3 \\
7\end{array}$ \\
\hline Economic & $\begin{array}{l}R_{31} \\
R_{32}\end{array}$ & $\begin{array}{ll}0.44 & 0.27 \\
0.86 & 0.94\end{array}$ & $\begin{array}{l}0.37 \\
0.84\end{array}$ & $\begin{array}{l}0.29 \\
0.93\end{array}$ & $\begin{array}{l}0.32 \\
0.87\end{array}$ & $\begin{array}{l}0.50 \\
0.80\end{array}$ & $\begin{array}{l}0.34 \\
0.91\end{array}$ & $\begin{array}{l}0.56 \\
0.71\end{array}$ & $\begin{array}{l}0.49 \\
0.76\end{array}$ & $\begin{array}{l}0.39 \\
0.89\end{array}$ & $\begin{array}{c}10 \\
0\end{array}$ \\
\hline
\end{tabular}


The last column in Table 4.3 indicates the number of times that each alternative is ranked best in each category. In both the social and economic categories the NCP has the lowest category index for all ten sets of weights indicating that the range of indexes corresponding to changes in category weights does not significantly affect the selection of the least irreversible altemative in these two categories. In the ecological category, however, the range of indexes for the two alternatives overlap so that the diesel altemative is ranked best in 7 of the 10 sets of weights while the NCP is ranked best only 3 times. An immediate observation is that the ecological category indexes are sensitive to changes in the weights assigned to ecological impacts.

Table 4.4 Results of Sensitivity Analysis of Impact values

\begin{tabular}{|c|c|c|c|c|c|c|c|c|c|c|}
\hline$c$ & $i$ & $\begin{array}{c}\text { Parameter } \\
\text { Tested } \\
f_{a i}\end{array}$ & $\begin{array}{c}\text { Original } \\
\text { Impact } \\
\text { Value } \\
\end{array}$ & $\begin{array}{l}\text { Changed } \\
\text { Impact } \\
\text { Value }\end{array}$ & $\begin{array}{l}\text { Percent } \\
\text { Change }\end{array}$ & $\begin{array}{c}\text { Index } \\
\text { Affected } \\
R_{f}{ }^{\prime} \\
\end{array}$ & $\begin{array}{l}\text { Original } \\
\text { Index } \\
\text { Value }\end{array}$ & $\begin{array}{l}\text { Changed } \\
\text { Index } \\
\text { Value } \\
\end{array}$ & $\begin{array}{l}\text { Percent } \\
\text { Change }\end{array}$ & $\begin{array}{c}\text { Least } \\
\text { Irreversible } \\
\text { Altemative }\end{array}$ \\
\hline I & $\begin{array}{c}1 \\
2 \\
3 \\
4 \\
7 \\
9 \\
11 \\
14 \\
17 \\
17 \\
18 \\
\end{array}$ & $\begin{array}{l}f_{111} \\
f_{121} \\
f_{131} \\
f_{1+1} \\
f_{171} \\
f_{191} \\
f_{1(11) !} \\
f_{1(1+1)} \\
f_{1(17) !} \\
f_{1(17) 2} \\
f_{1(18) 1}\end{array}$ & $\begin{array}{c}1 \\
0.7 \\
9 \\
6 \\
9 \\
15 \\
6 \\
9 \\
1 \\
7 \\
5 \\
\end{array}$ & $\begin{array}{c}10 \\
1.35 \\
10 \\
0 \\
10 \\
20 \\
10 \\
0 \\
10 \\
10 \\
0 \\
\end{array}$ & $\begin{array}{l}+900 \\
+93 \\
+11 \\
-100 \\
+11 \\
+33 \\
+67 \\
-100 \\
+900 \\
+43 \\
-100 \\
\end{array}$ & $\begin{array}{l}R_{11} \\
R_{11} \\
R_{11} \\
R_{11} \\
R_{11} \\
R_{11} \\
R_{11} \\
R_{11} \\
R_{11} \\
R_{12} \\
R_{11}\end{array}$ & $\begin{array}{l}0.49 \\
0.49 \\
0.49 \\
0.49 \\
0.49 \\
0.49 \\
0.49 \\
0.49 \\
0.49 \\
0.78 \\
0.49 \\
\end{array}$ & $\begin{array}{l}0.56 \\
0.54 \\
0.50 \\
0.52 \\
0.49 \\
0.49 \\
0.50 \\
0.54 \\
0.50 \\
0.79 \\
0.55 \\
\end{array}$ & $\begin{array}{l}+14.3 \\
+10.2 \\
+2.0 \\
+6.1 \\
+0.0 \\
+0.0 \\
+2.0 \\
+10.2 \\
+2.0 \\
+1.3 \\
+12.2 \\
\end{array}$ & $\begin{array}{l}\text { NCP } \\
\text { NCP } \\
\text { NCP } \\
\text { NCP } \\
\text { NCP } \\
\text { NCP } \\
\text { NCP } \\
\text { NCP } \\
\text { NCP } \\
\text { NCP } \\
\text { NCP }\end{array}$ \\
\hline 2 & $\begin{array}{l}2 \\
3 \\
4 \\
5 \\
6 \\
7 \\
7 \\
8 \\
\end{array}$ & $\begin{array}{l}f_{221} \\
f_{231} \\
f_{241} \\
f_{251} \\
f_{251} \\
f_{271} \\
f_{272} \\
f_{281} \\
\end{array}$ & $\begin{array}{c}7 \\
27.4 \\
7 \\
23 \\
2 \\
3 \\
8 \\
4 \\
\end{array}$ & $\begin{array}{c}8.96 \\
54.8 \\
3.4 \\
46 \\
10 \\
10 \\
3 \\
7.41 \\
\end{array}$ & $\begin{array}{r}+28 \\
+100 \\
-50 \\
+50 \\
+400 \\
+233 \\
-63 \\
+85 \\
\end{array}$ & $\begin{array}{l}R_{21} \\
R_{21} \\
R_{21} \\
R_{21} \\
R_{21} \\
R_{21} \\
R_{22} \\
R_{21} \\
\end{array}$ & $\begin{array}{l}0.42 \\
0.42 \\
0.42 \\
0.42 \\
0.42 \\
0.42 \\
0.49 \\
0.42 \\
\end{array}$ & $\begin{array}{l}0.49 \\
0.42 \\
0.48 \\
0.44 \\
0.45 \\
0.47 \\
0.46 \\
0.49 \\
\end{array}$ & $\begin{array}{l}+26.2 \\
+0.0 \\
+14.3 \\
+4.8 \\
+7.1 \\
+11.9 \\
-6.1 \\
+16.7 \\
\end{array}$ & $\begin{array}{c}\text { NCP/Diesel } \\
\text { NCP } \\
\text { NCP } \\
\text { NCP } \\
\text { NCP } \\
\text { NCP } \\
\text { NCP } \\
\text { NCP/Diesel }\end{array}$ \\
\hline 3 & $\begin{array}{l}3 \\
4 \\
5 \\
6 \\
7 \\
8\end{array}$ & $\begin{array}{l}f_{331} \\
f_{341} \\
f_{351} \\
f_{361} \\
f_{372} \\
f_{381}\end{array}$ & $\begin{array}{c}110 \\
2 \\
0.44 \\
2400 \\
0.5 \\
6\end{array}$ & $\begin{array}{c}230 \\
1 \\
0.22 \\
2700 \\
0.25 \\
12\end{array}$ & $\begin{array}{r}+109 \\
-50 \\
-50 \\
+13 \\
-50 \\
+50\end{array}$ & $\begin{array}{l}R_{31} \\
R_{31} \\
R_{31} \\
R_{31} \\
R_{31} \\
R_{31}\end{array}$ & $\begin{array}{l}0.29 \\
0.29 \\
0.29 \\
0.29 \\
0.29 \\
0.29\end{array}$ & $\begin{array}{l}0.42 \\
0.35 \\
0.35 \\
0.31 \\
0.34 \\
0.30\end{array}$ & $\begin{array}{r}+44.8 \\
+20.7 \\
+20.7 \\
+6.9 \\
+17.2 \\
+3.4\end{array}$ & $\begin{array}{l}\mathrm{NCP} \\
\mathbf{N C P} \\
\mathrm{NCP} \\
\mathrm{NCP} \\
\mathrm{NCP} \\
\mathrm{NCP}\end{array}$ \\
\hline
\end{tabular}




\subsubsection{Impact Values}

Using the original set of weights, the sensitivity of the category indexes of the two alternatives to changes in impact values was analyzed. The approach taken was to first determine which impact values were quantified with a high level of confidence in Stage II of the reversibility framework. For example, it can be said, with a high level of confidence, that the diesel altemative will not have a significant effect on health and hygiene (social impact number 5), rare plants (ecological impact number 2), or provide direct business opportunities (economic impact number 2); note that the use of the term "confidence" has no statistical connotation here. These impact values were then excluded from the sensitivity analysis. This approach is particularly useful for larger applications of the reversibility framework. The impacts that were tested for sensitivity and corresponding results of the sensitivity analysis are summarized in Table 4.4.

The value of each impact tested for sensitivity was changed to its worst value or a percentage of its original value and the $\boldsymbol{R}$-metric was applied with all other parameters held at their original value. The "changed index value" column in Table 4.4 is compared to the original index value to determine whether the selection of the least irreversible alternative in the corresponding category is affected. For example, a significant change in parameter $f_{\mathrm{II}}$ (value of impact number $I$ for NCP in the social category) did not affect the original selection of the NCP as the least irreversible alternative in the social category; the changed index value for the NCP $\left(R_{11}=0.56\right)$ remains less than the index value for the diesel alternative $\left(R_{12}=\right.$ 0.78). Similarly for the other parameters tested, the change in the indexes corresponding to changes in the parameters tested did not affect the selection of the least irreversible alternative (the NCP) except in the case of ecological impacts $f_{221}$ (rare plants) and $f_{281}$ (wild rice). As indicated in Table 4.4, the ecological category index for the NCP, $R_{21}$, exceeds the ecological category index for the diesel alternative, $R_{22}$, if the original subjective value for $f_{221}$ is increased by $28 \%$ or more. The same occurs with an increase of $85 \%$ or greater from the original value of $f_{281}$. This observation suggests that further investigation of the potential impact of the NCP on the rare plants in the area and the potential for production of wild rice in the future is required. 


\subsection{Discussion}

The outcome of the application of the reversibility framework to the selected case study indicates that the NCP is the least irreversible alternative when compared to the option of maintaining the existing diesel facilities. The level of confidence in quantifying impact values and weights was high in all three categories due to the abundance of available information. Most of the identified impacts were not applicable to the diesel option so that the best value, $M_{i}$, was appropriately assigned. Accordingly, the sensitivity analysis carried out in Stage IV was simplified by excluding most of the parameters $f_{c i 2}$ (impact values for alternative 2 ) from the analysis. If the level of available information is scarce, most of the impact values and weights would be quantified with a low level of confidence and, therefore, a more rigorous sensitivity analysis would be required.

There are no temporal restrictions on the application of the reversibility framework. The analytical stages of the framework, Stage III and Stage IV, facilitate the application of the framework at different times during project implementation, for example when new information regarding certain impacts becomes available. The impacts can be adjusted according to the new information, and Stage III repeated to obtain a new set of indexes.

The reversibility framework can be applied at various stages of the decision making process, including project reconnaissance [Pal and Rajappa, 1993] or appraisals which are carried out for the purpose of determining whether the project should be pursued, design and engineering of feasible alternatives, initial screening of feasible alternatives, or the final selection of the least irreversible alternative. The framework can be used for predicting what type of mitigation measures would be required for certain impacts in order to reduce the irreversibility of the alternatives. The framework can also be used for assessing project location, proposed construction or operation.

The role of stakeholders or interest groups was not discussed. An important characteristic of the reversibility framework is its flexibility in terms of its potential users. The reversibility framework can be applied by different groups of stakeholders to obtain a set of category indexes corresponding to each group. The category indexes for different interest groups would be comparable as all groups would apply the framework systematically, though 
with slightly varying levels of subjectivity. The stakeholders involved in the NCP case study include NC residents, Manitoba Hydro, NC Community Councils, government facilities in the area, and the local businesses. The preferences of these groups can be expressed in the impact values and weights, and their respective indexes compared to determine the most preferred alternative in each group, or to determine the level of consensus or discordance among the groups.

The issue of dependence between impacts was discussed in Section 3.2.1. Through the process of identifying, categorizing, and classifying impacts of a particular development project, dependence could be detected. A very strong dependence between two impacts would indicate that the impacts are similar and represent different dimensions of the same effect of the project under consideration. In that case, the two impacts would be combined into one impact. In most cases, however, such as the examples discussed in Section 3.2.1, dependence would be accounted for through the assignment of weights and values. First, since a single word or phrase is used for each impact in the list, the impacts must be discussed and analyzed in detail so as to prevent misconceptions. In Table 4.1, for example, it appears that there is dependence between water crossings and fish and aquatic resources, two impacts listed separately in the ecological category. However, as explained in Section 4.2.2.2, water crossings represent a long-term effect whereas fish and aquatic resources represent a shortterm effect of the NCP. Second, values and weights are appropriately assigned; a relatively high weight of 0.95 is assigned to water crossings while the impact on fish and aquatic resources is weighted at a low value of 0.35 . After carefully following the systematic procedure outlined herein, possible dependence between impacts, in the same category or in different categories, would be fully reflected in the procedures used. 


\section{CONCLUSIONS AND RECOMMENDATIONS}

The reversibility framework is proposed as a combined theoretical and analytical tool for implementing reversibility as one of many viable sustainability criteria in the decision making process. The integration of theoretical aspects of sustainability into the framework has increased its validity and effectiveness for application as a tool for sustainable project selection. Therefore, the framework is an appropriate tool for implementing reversibility as one of many possible criteria for achieving sustainable project selection. In addition, the proposed framework has provided an expanded view of development projects, the construction of electrical transmission and distribution lines in particular, that involve use of natural ecological resources and affect social and economic factors.

Environmental impact statements (EIS), discussed in Chapter 1, can be used as a reference point for evaluating the efficacy of the proposed reversibility framework. Environmental impact statements, which summarize the findings of the process of environmental impact assessments (EIA), contain a great amount of information about potential social, ecological and economic impacts. This information is presented in a variety of formats of text and tables which are acceptable and follow regulated government guidelines. As indicated in Chapter 1, the most significant attempt at establishing and regulating goals of sustainability has been the incorporation of EIA guidelines into legislation. However, even though the ultimate goal of EIA is to achieve sustainability, it does not address a specific sustainability issue. Comprehensive frameworks, such as the one proposed herein for measuring reversibility, are more efficient for achieving sustainability at the project selection level. Furthermore, the reversibility framework, because of the fact that it is based on sustainability criteria, increases awareness of the existing state of natural resources and instigates a moral obligation to act so that protecting natural resources and achieving sustainability becomes more than a set of government regulations.

An additional advantage gained from using the reversibility framework is that the required information can be obtained from as many sources as are available, and compiled in a systematic form. The framework is sufficiently transparent so as to facilitate presentation of 
the material to various interest groups or to higher authorities who may lack the relevant expertise.

The results of the application of the reversibility framework in the case study of the North Central Project showed that the least irreversible altemative is the central supply system (the NCP) when compared to the option of maintaining the exisiting diesel generating facilities. The irreversibility index of the NCP alternative in each of the three categories (social, ecological, economic) was lower than that of the diesel altemative. In a sensitivity analysis, changes in impact weights did not affect the selection of NCP as the least irreversible alternative in the social and economic categories. The ecological index was found to be sensitive to changes in the weights assigned to ecological impacts. Further observations, made in the sensitivity analysis of category indexes to changes in impact values, suggested that further investigation of the impact of NCP on the rare plants and on the potential for production of wild rice is required. Based on the high level of confidence in quantifying impact values and weights, it was concluded that the selection of NCP as the least irreversible alternative did not change.

When the NCP was initiated by Manitoba Hydro, the selection of the central supply alternative was essentially based on economic feasibility. Once the decision to implement the central supply system was made, an environmental impact assessment was carried out according to specific guidelines in order to ensure minimal social and ecological impacts and to devise mitigative plans for minimizing certain effects. The credibility of sustainable project decisions would significantly increase if these decisions were based on sustainability criteria such as reversibility, rather than first selecting an altemative based on some economic criteria and then attempting to meet sustainability objectives. An environmental impact assessment, or any other process of identifying project effects, can precede a sustainability framework such as the proposed reversibility framework, and the final project selection can be based on the outcome of the framework. Such an approach would also allow modifications to be made to project alternatives during the project design phase for the purpose of minimizing the irreversibility, namely for optimizing the sustainability criteria.

The observations based on the outcome of the case study have clarified some inherent attributes of the reversibility framework. These attributes are: the identification of impacts 
(rare plants and wild rice) which are relatively sensitive and more significant than others in terms of their effect on the reversibility indexes and, therefore, require further investigation; the temporal flexibility of the framework, namely its potential application during project reconnaissance, design of alternatives, evaluation of the alternatives, selection of the "best" alternative, and during project implementation; and the ability of the framework to incorporate various sources of expertise in the social, ecological and economic categories.

Several suggestions for expansions to the reversibility framework or for future work in a similar direction are included in the following paragraphs.

The exponent in the $L_{p}$-metric (Chapter 3) was fixed at a value of 2 for deriving the proposed $R$-metric. The selection of the value of $p$ could be explored further. Changing the exponent $p$ would most likely result in changes in the category indexes, and possibly in the decision regarding the least irreversible alternative. The effect of changes in the value of $p$ on the indexes can also be tested in the sensitivity analysis.

It was noted that the role of various interest groups or stakeholders in the NCP case study was not discussed. Game theoretic models [Hipel et al., 1993; Shubik, 1983] could be used to analyze conflicts between the interest groups involved in a project. The impact weights could be defined separately by each stakeholder, and game theory could be applied in order to determine the "best" set of weights to be used in the framework for the selection of the least irreversible alternative. Alternatively, game theoretic models could be applied to sets of indexes obtained for each stakeholder using a set of criteria (for example, the physical distance of stakeholders from affected area, number of people represented by each group, level of capital invested by each group) in order to find the best combination of indexes. Another useful method for representing the preferences of stakeholders is discussed in Bender [1996].

Methods for combining the three category indexes into one index per alternative should be explored. This could simplify the final project selection phase as it would replace the three criteria, namely the category indexes, on which the final selection is based by one criterion, namely one index. A simple method of combining the three indexes is to calculate a weighted average. This would require the selection of category weights based on some 
criteria, for example, the physical scale of each project alternative or the total invested capital which has a high degree of irreversibility versus operating costs which can be altered and are therefore more reversible. 


\section{REFERENCES}

Alfsen, K. H. (1991), "Some Comments on a Report on Canada's Progress Towards a National Set of Environmental Indicators," Mimeo, Central Bureau of Statistics, Oslo.

Alfsen, K. H., and H. V. Sæbø (1993), "Environmental Quality Indicators: Background, Principles and Examples from Norway," Environmental and Resources Economics, 3, 415435, Kluwer Academic Publishers, Netherlands.

Anderson, R. J. (1981), "A Note on Option Value and the Expected Value of Consumer's Surplus," J. Environ. Econ. Mangmt., 8, 187-191.

Arrow, K. J. (1968), "Optimal Capital Policy with Irreversible Investment." in Value, Capital, and Growth, J. N. Wolfe (ed.), Adine-Atherton, Chicago.

Arrow, K. J., and A. C. Fisher, (1974), "Environmental Preservation, Uncertainty, and Irreversibility." Quart. J. Econ., 88(2), 312-319.

Barbier, E. B. (1987), "The Concept of Sustainable Economic Development." Environ. Conservation, 14(2), 101-110.

Barbier, E. B. (1989), Economics, Natural Resource Scarcity and Development, Earthscan, London.

Bartelmus, P. (1986), Environment and Development, Allen \& Unwin, London.

Batie, S. S., (1989), "Sustainable Development Challenges to the Profession of Agricultural Economics," Americal Journal of Agricultural Economics, 71, 1083-1101.

Bedau, H. G. "Ethical Aspects of Environmental Decision Making," in Chechile, R. A., and S. Carlisle (eds.), (1991), Environmental Decision Making: A Multidisciplinary Perspective, Van Norstrand Reinhold, New York.

Bender, M., and S. P. Simonovic (1996), "Collaborative Planning Support System: An Approach for Determining Evaluation Criteria," J. Hydrology, 177, 273-251.

Bernanke, B. S. (1983), "Irreversibility, Uncertainty, and Cyclical Investment." Quart. J. Econ., 98, 85-106.

Bishop, R. C. (1982), "Option Value: An Exposition and Extention." Land Economics, 58(1), 1-15.

Bohm, P. (1972), “Option Demand and Consumer's Surplus: Comment," Amer. Econ. Rev., $65,233-236$.

Boyce, J. K. (1994), "Inequality as a cause of environmnetal degradation," Ecological Economics, 11, 169-178.

Brookshire, D. S., L. S. Eubanks, and A. Randall (1983), "Estimaing Option Prices and Existence Values for Wildlife Resources," Land Economics, 59, 1-15.

Brown, L. R., (1981), Building a Sustainable Society, W.W. Norton, New York. 
Cernea, M. M., (1993), "The Sociologist's Approach to Sustainable Development," Finance \& Development, December, 11-13.

Cicchetti, C. J., and A. M. Freemann III, (1971), "Option Demand and Consumer Surplus: Further Comment." Quart.J. Econ., 85(3), 528-539.

Cobb, J. (1993), "Ecology, Ethics, and Theology," in H.E. Daly and K.N. Townsend (eds.), Valuing the Earth: Economics, Ecology, Ethics, MIT Press, Cambridge, Massachusetts.

Cohen, J., and N. Uphoff, (1980), "Participation's place in rural development: Seeking to clarify through specificity," World Development, 8, 213-235.

Conrad, J. M. (1980), “Quasi-Option Value and the Expected Value of Information." Quart. J. Econ., 94, 813-820.

Cook, P. J., and D. A. Graham (1977), "The Demand for Insurance and Protection: The Case of Irreplaceable Commodities," Quart. J. Econ., 91, 143-156.

Cummings, R., and V. Norton, (1974), "The Economics of Environmental Preservation: Comment." Amer. Econ. Rev., 64(6), 1021-1024.

Dirschl, H. J., N. S. Novakowski, and M. Hosain Sadar (1993), "Environmental Auditing: Evolution of Environmental Impact Assessment as Applied to Watershed Modification Projects in Canada," Environmental Management, 17(4), 545-555.

Dovers, S. R., and J. W. Handmer, (1993), "Contradictions in Sustainability," Environmental Conservation, 20(3), 217-222.

Duckstein, L. and S. Opricovic (1980), "Multi-objective Optimization in River Basin Development," Water Resources Research, 16(1), 14-20.

Environment Canada (1991), “A Report on Canada's Progres Towards a National Set of Environmental Indicators," State of the Environment Report no. 91-1.

Erickson, P.A. (1994). A Practical Guide To Environmental Impact Assessment. Academy Press, Boston.

FEARO (1978), Federal Environmental Review Process, Bulletin No. 3, Federal Environmental Assessment Review Office, Hull, Quebec.

Feldstein, M. S. (1964), "The Social Time Preference Discount Rate in Cost-Benefit Analysis." Econ. J., 74, 360-379.

Field, B. C. (1994), Environmental Economics: An Introduction, McGraw Hill Inc., New York.

Field, B. C., and N. D. Olewiler, (1995), Environmental Economics, First Canadian Edition, McGraw-Hill Ryerson Limited, Toronto.

Fiering, M. B. (1967), Streamflow Synthesis, Harvard University Press, Cambridge, Massachusetts.

Fiering, M. B. (1969), "Forecasts with Varying Reliability," J. Sanit. Eng. Div., ASCE, 95(4), 629-644. 
Fiering, M. B. (1982a), "A Screening Model to Quantify Resilience." Water Resources Research, 18(1), 27-32.

Fiering, M. B. (1982b), "Altemative Indices of Resilience." Water Resources Research, 18(1), 33-39.

Fiering, M. B., and C. S. Holling (1974), "Management and Standards for Perturbed Ecosystems, Agro-Ecosystems, 1, 30 l-321.

Fisher, A. C., and J. V. Krutilla, (1974), "Valuing Long Run Ecological Consequences and Irreversibility." J. Environ. Econ. Mangmt., 1, 96-108.

Fisher, A. C., and W. M. Hanemann, (1987), "Quasi-Option Value: Some Misconceptions Dispelled." J. Environ. Econ. Mangmt., 14, 183-190.

Fisher, A.C., J. V. Krutilla, and C. J. Cicchetti, (1972), "The Economics of Environmental Preservation: A Theoretical and Empirical Analysis." Amer. Econ. Rev., 62, 605-619.

Fisher, A.C., J. V. Krutilla, and C. J. Cicchetti, (1974), "The Economics of Environmental Preservation: Further Discussion." Amer. Econ. Rev., 64(6), 1030-1039.

Freeman III, A. M. (1984a), "The Quasi-Option Value of Irreversible Development." J. Environ. Econ. Mangmt., 11, 292-295.

Freeman III, A. M. (1984b), "The Sign and Size of Option Value." Land Econ., 60(1), 1-13.

Freeman III, A. M. (1985), "Supply Uncertainty, Option Price, and Option Value." Land Economics, 61(2), 176-181.

Ghai, D. (1992), "Conservation, Livelihood, and Democracy: Social Dynamics of Environmental Changes in Africa," United Nations Research Institute for Social Development, Discussion Paper 33.

Goicoechea, A. D. R. Hansen, and L. Duckstein (1982), Multiobjective Decision Analysis with Engineering and Business Applications, John Wiley \& Sons.

Gordon, I. M., and J. L. Knetsch, (1979), "Consumer Surplus Measures and the Evaluation of Resources." Land Econ., 55(1), 1-10.

Gray, E. D. (1994), "Come Inside the Circle of Creation," in F. Frederick and P. Hartel (eds.), Ehtics and Environmental Policy: Theory Meets Practice, The University of Georgia Press, Athens and London.

Haimes, Y. Y., and W. A. Hall, (1977). "Sensitivity, Responsivity, Stability and Irreversibility as Multiple Objectives in Civil Systems." Advan. Water Resources, 1(2), 71-81.

Hanemann, W. M. (1989), "Information and the Concept of Option Value." J. Environ. Econ. Mangmt., 16, 23-37.

Hashimoto, T., D. P. Loucks, and J. R. Stedinger (1982b), "Robustness of Water Resources Systems." Water Resources Research, 18(1), 21-26.

Hashimoto, T., J. R. Stedinger, and D. P. Loucks, (1982a), "Reliability, Resiliency, and Vulnerability Criteria For Water Resource System Performance Evaluation." Water Resources Research, 18(1), 1420. 
Henry, C. (1974a), "Investment Decisions under Uncertainty: The Irreversibility Effect." Amer. Econ. Rev., 64(6), 1006-1012

Henry, C. (1974b), "Option Values in the Economics of Irreplacable Assets." Review of Economic Studies: Symposium on the Economics of Exhaustible Resources, 89-104.

Hildebrandt Young and Associates Ltd (1986), Northeastern Manitoba Electrification Benefits and Costs Land Line vs Diesel. Prepared for the Island Lake Tribal Council, Winnipeg.

Hipel, K. W., L. Fang, and D. M. Kilgour (1993), "Game Theoretic Models in Engineering Decision Making," J. Infrastructure Plan. and Man., 20(470), 1-16.

Hogendorn, Jan S. (1992), Economic Development, Harper Collins.

Holling, C. S. (1973), "Resilience and Stability of Ecological Systems." Ann. Rev. Ecol. Systems, 4, 1-23.

Holling, C. S. (1986), "The Resilience of Terrestrial Ecosystems: Local Surprise and Global Change," in W.C. Clark and R.E. Munn (eds.), Sustainable Development of the Biosphere, Cambridge University Press, Cambridge, MA.

IDE (1984), (1984), North Central Electrification Study, I.D. Engineering Company, Montreal Engineering Company Ltd., and Teshmont Consultants Inc., Winnipeg.

IUCN, (1980), World Conservation Strategy. International Union for the Conservation of Nature and Natural Resources, Gland, Switzerland.

Jacobs, M. (1993). The Green Economy. UBC Press, Vancouver.

Jacobs, P., J. Gardner, and D. Munro, (1987), "Sustainable and equitable development: An emerging paradigm," in P. Jacobs and D. A. Munro (eds.), Conservation with Equity: Strategies for Sustainable Development, Intemational Union for Conservation of Nature and Natural Resources, Cambridge.

Jordaan, J., E. J. Plate, E. Parins, and J. Veltrop (1993), "Water in our common future," UNESCO Committee on Water Research COWAR, UNESCO International Hydrological Program, Paris.

Kay, J. J. (1991). "The Concept of Ecological Integrity, Altemative Theories of Ecology, and Implications for Decision-Support Indicators." In: Economic, Ecological, and Decision Theories: Indicators of Ecologically Sustainable Development, 23-58, Canadian Environmental Advisory Council, Ottawa.

Kroeger, H. (1996), "Risk as a Project Selection Criterion for Sustainable Development," Proceedings of the North American Water and Environment Congress '96, ASCE.

Lele, S. M. (1991). "Sustainable Development: A Critical Review." World Development, 19(6), 607-621.

Linsay, C. M. (1969), "Option Demand and Consumer Surplus." Quart. J. Econ., 83, 344 346. 
Long, M. F. (1967), "Collective Consumption Services of Individual Consumption Goods: Comment," Quart. J. Econ., 81, 351-352.

Manitoba Hydro (1983), A Comparison of the Financial Impact of Diesel and Central Supply of Electric Power to the Northeastern Manitoba Area, Unpublished Report \#83-4, Corporate Planning Division, Manitoba Hydro, Winnipeg.

Mannion, Antoinette M. (1992), "Sustainable Development and Biotechnology," Environmental Conservation, 19(4), 297-306.

Matalas N. C., and M. B. Fiering (1977), "Water Resources Systems Planning," in Climate, Climate Change, and Water Supply, 99-1 10, National Academy of Sciences, New York.

Matheson, S. (1996), "Equity Measures for Selection of Sustainable Projects," Proceedings of the North American Water and Environment Congress '96, ASCE.

McPeak, John (1994), "Summary of Major Writings on Sustainable Development," Unpublished, drafted as a research assistant for Professor Daniel Bromley, Department of Agricultural Economics, University of Wisconsin-Madison, Madison, WI.

Miller, J. R., and F. Lad, (1984), "Flexibility, Learning, and Irreversibility in Environmental Decisions: A Bayesian Approach." J. Environ. Econ. Mangmt., 11, 161-172.

Moy, W. S., J. L. Cohon, and C. S. ReVelle, (1986), "A Programming Model for Analysis of the Reliability, Resilience, and Vulnerability of a Water Supply Reservoir," Water Resources Research, 22(4), 489-498.

Munasinghe, M., (1993), "The Economist's Approach to Sustainable Development," Finance \& Development, December.

Munda, G., P. Nijkamp and P. Rietveld. (1994), "Fuzzy Multigroup Conflict Resolution for Environmental Management." in John Weiss (ed.), The Economics of Project Appraisal and the Environment, Edward Elgar Publishing Lid., Cheltenham, England.

O'Riordan, T. (1985), "Futrure Directions in Environmental Policy," Journal of Environmental Planning, 17, 1431-1446.

OECD, (199l), Environmental Indicators. A Preliminary Set, Organization for Economic Cooperation and Development, Paris.

Onta, P. R., A. Das Gupta, and H. Ricardo, (1991), "Multistep Planning Model for Conjunctive Use of Surface- and Ground-Water Resources." Journal of Water Resources Planning and Management, 117(6), 662-678.

Page, T. (1977a), "Equitable use of the resource base," Environment and Planning, Ser. A 9, 15-22.

Page, T. (1977b), Conservation and Economic Efficiency, Johns Hopkins University Press, Baltimore, Md.

Pal, K. and R. Rajappa (1993), "EIA Guidelines for Water Resources Development Projects," Water Resources Development, 9(2), 189-204. 
Palmer, J. A. (1992), "Towards a sustainable future," In Cooper, D. E., and J. A. Palmer (eds), The Environment in Question, Routledge, London, England, UK.

Palmer, M. and N. Rising, (1996). "The Development of an Environmental Sustainability Parameter for Agriculture." Canadian Water Resources Journal, 21(1), 13-25.

Pearce, D. W. and J. J. Warford (1993). World Without End: Economics, Environment, and Sustainable Development. Oxford University Press.

Pearce, D. W., (1991), "Economics of The Environment" In Greenway, D., M. Bleaney, and I.M.T. Stewart (eds.), Companion to Contemporary Economic Thought, Routledge, London.

Pearce, D. W., and R. K. Turner, (1990), Economics of Natural Resources and the Environment, Johns Hopkins University Press, Baltimore.

Pearce, D., A. Markandya, and E. Barbier, (1989), Blueprint for a Green Economy, Earthscan, London.

Pearce, D., E. Barbier, and A. Markandya, (1990), Sustainable Development. Aldershot: Edward Elgar.

Pendergast, J. (1993), “Engineering Sustainable Development." Civil Engineering, 12, 39-42.

Pindyck, R. S. (1991), "Irreversibility, Uncertainty, and Investment." Journal of Economic Literature, 29, $1110-1148$.

Rawls, J. (1971), A Theory of Justice, Harvard University Press, Cambridge, MA.

Rawls, J. (1972), A Theory of Justice, Oxford University Press, Oxford.

Redclift, M., (1987), Sustainable Development: Exploring the Contradictions, Methuen, London, England, UK.

Reddy, A. K. N. (1994), "Technology, Development and the Environment: An Analytical Framework." in Guha, Ramachandra (ed.), Social Ecology, Oxford University Press, Bombay.

Rees, C. (1992), "The Ecologist's Approach to Sustainable Development," Finance \& Development, December, 14-15.

Repetto, R. (1986), World Enough and Time, Yale University Press, New Haven, Conn.

Robinson, J., G. Francis, R. Legge, and S. Lemer, (1990), "Defining a Sustainable Society," Alternatives, 17(2), 37-46.

Ryding, S. O., (1981), "Reversibility of Man-Induced Eutrophication. Experiences of a Lake Recovery Study in Sweden." Int. Revue ges. Hydrobiol., 66, 449-503.

Schmalensee, R. (1972), “Option Demand and Consumer's Surplus: Valuing Price Changes under Uncertainty." Amer. Econ. Rev., 62(5), 813-824.

Serageldin, I., (1993), "Making Development Sustainable," Finance \& Development, December, 6-10.

Shubik, M. (1983), Game Theory in the Social Sciences, MIT Press, Cambridge. 
Simonovic, S. P. (1989), "Application of Water Resources Systems Concept to the Formulation of a Water Master Plan," Water International, 14, 37-50.

Singh, N. C., and V. Titi, (1995), Empowerment for Sustainable Development: Towards Operational Strategies, Decision-Makers Summary, International Institute for Sustainable Development, Winnipeg, Manitoba.

Smith, V. K. (1983), "Option Value: A Conceptual Overview." Southern Economics Journal, $49,654-668$.

Smith, V. K. (1984), “A Bound for Option Value." Land Econ., 60(3), 292-296.

Smith, V. K. (1987), "Uncertainty, Benefit-Cost Analysis, and the Treatment of Option Value." J. Environ. Econ. Mangmt., 14, 283-292.

Solow, R. M. (1978), "Intergenerational Equity and exhaustible resources," Review of Economic Studies, 41, 29-45.

Solow, R. M. (1986), "On the intergenerational allocation of natural resources," Scandinavian Journal of Economics, 88, 141-149.

Tisdell, C. (1993), Environmental Economics: Policies for Environmental Management and Sustainable Development. Aldershot: Edward Elgar.

Tisdell, C., (1988), "Sustainable development: Differing perspectives of ecologists and economists, and relevance to LDCs," World Development, 16(3), 373-384.

Tolba, M. K., (1984), The Premises for Building a Sustainable Society - Address to the World Commission on Environment and Development, United Nations Environment Program, Nairobi.

Turner, R. K. (ed.) (1988), Sustainable Environmental Management, Belhaven Press, London.

UNESCO, (1995), The Development and Management of Sustainable Water Resource Systems: Decision Support Methods and Experiences.

Usategui, J. M. (1990), "Uncertain Irreversibility, Information, and Transformation Costs." J. Environ. Econ. Mangmt., 19, 73-85.

Viscusi, W. K. (1985), "Environmental Policy Choice with an Uncertain Chance of Irreversibility." J. Environ. Econ. Mangmt., 12, 28-43.

Viscusi, W. K. (1988), "Irreversible Environmental Investment with Uncertain Benefit Levels." J. Environ. Econ. Mangmt., 15, 147-157.

Vivian, Jessica M. (1991), "Greening at the grassroots: people's participation in sustainable development," United Nations Research Institute for Social Development, Discussion Paper 22, Geneva.

Weeden, R. B. (1989), “An Exchange of Sacred Gifts." Alternatives, 16(1), 41-49.

Weisbrod, B. (1964), "Collective-Consumption Services of Individual-Consumption Goods." Quart.J. Econ., 78, 47 I-477. 
World Commission on Environment and Development (WCED), (1987), Our Common Future, Oxford University Press, Oxford.

Young, M. D. (1992), Sustainable Investment and Resource Use: Equity, Environmental Integrity, and Economic Efficiency," Man and the Biosphere Series, The Partheson Publishing Goup Inc., New Jersey.

Zeleny, M. (1973), "Compromise Programming," in Cochrane, J. L., and M. Zeleny (eds.), Multiple Criteria Decision Making, University of Carolina Press, Columbia, 262-301.

Zeleny, M. (1982), Multiple Criteria Decision Making, McGraw-Hill Book Co., New York, N.Y. 


\section{APPENDIX A}

Detailed Results of $\boldsymbol{R}$-Metric Application 
Detailed Calculations of Category Reversibility Indexes

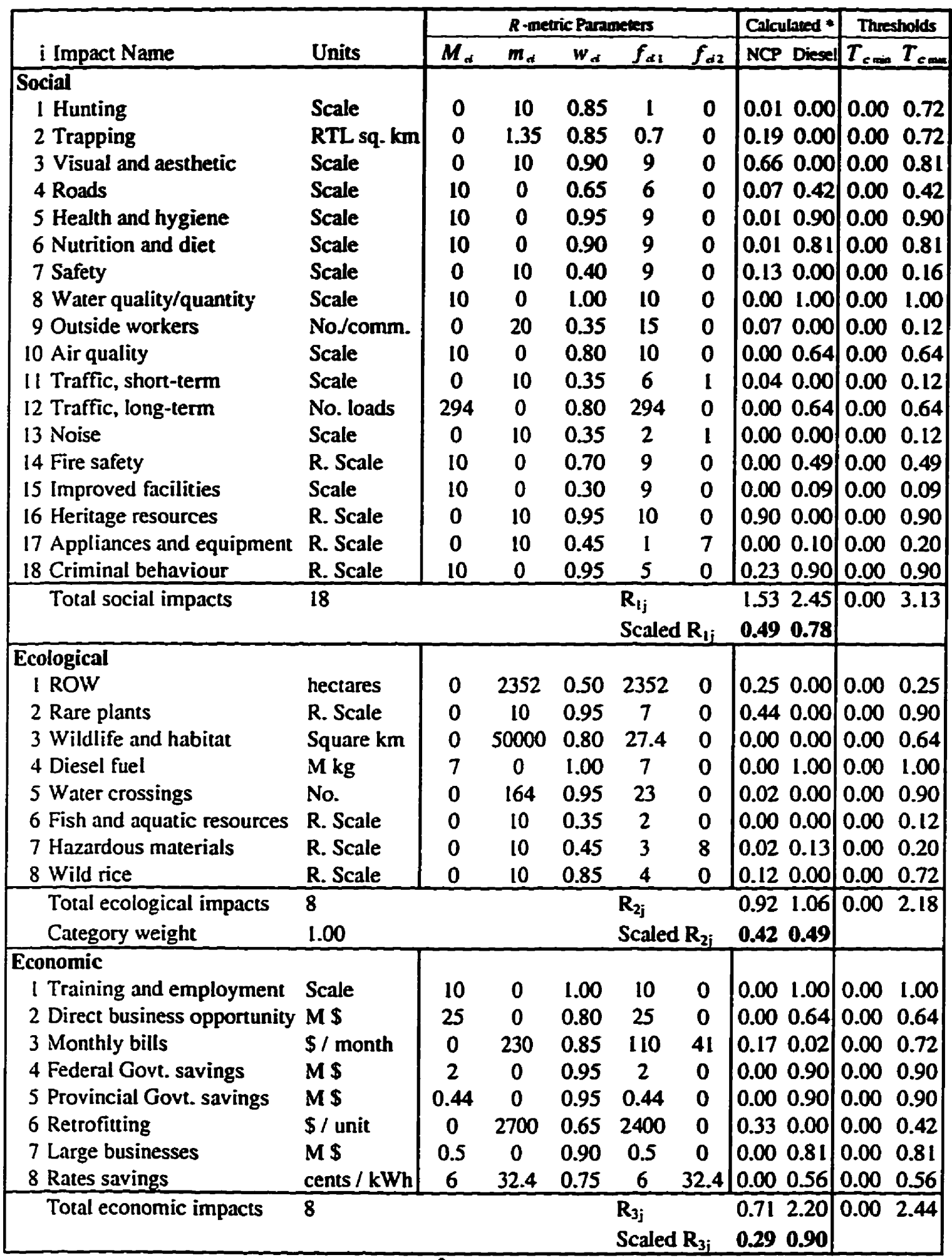

* Each value calculated as: $w_{c i}^{2}\left|\frac{M_{c i}-f_{c i j}}{M_{c i}-m_{c i}}\right|^{2}$ 


\section{APPENDIX B}

Detailed Results of Sensitivity Analysis 


\section{Sensitivity Analysis of Impact Weights}

Ten sets of impact weights were randomly generated between a value of 0.30 and 1.00 , in all three categories simultaneously and the corresponding category indexes were recorded (Table 4.3)

\begin{tabular}{|c|c|c|c|c|c|c|c|c|c|c|}
\hline \multirow[b]{2}{*}{ i Impact Name } & \multirow[b]{2}{*}{ Units } & \multicolumn{5}{|c|}{$R$-metric Parameters } & \multicolumn{2}{|c|}{ Calculated } & \multirow{2}{*}{\multicolumn{2}{|c|}{\begin{tabular}{|l} 
Thresholds \\
$T$ \\
\end{tabular}}} \\
\hline & & $M_{d}$ & $m_{r}$ & $w_{d}$ & $f_{d 1}$ & $f_{\text {in }}$ & NCP & Diesel & $T_{c \min }$ & \\
\hline \multicolumn{11}{|l|}{ Social } \\
\hline I Hunting & Scale & 0 & 10 & 0.48 & 1 & 0 & 0.00 & 0.00 & 0.00 & 0.23 \\
\hline 2 Trapping & RTL sq. $\mathrm{km}$ & 0 & 1.35 & 0.49 & 0.7 & 0 & 0.06 & 0.00 & 0.00 & 0.24 \\
\hline 3 Visual and aesthetic & Scale & 0 & 10 & 0.53 & 9 & 0 & 0.23 & 0.00 & 0.00 & 0.28 \\
\hline 4 Roads & Scale & 10 & $\mathbf{0}$ & 0.30 & 6 & 0 & 0.01 & 0.09 & 0.00 & 0.09 \\
\hline 5 Health and hygiene & Scale & 10 & 0 & 0.45 & 9 & 0 & 0.00 & 0.21 & 0.00 & 0.21 \\
\hline 6 Nutrition and diet & Scale & 10 & 0 & 0.51 & 9 & 0 & 0.00 & 0.26 & 0.00 & 0.26 \\
\hline 7 Safety & Scale & 0 & 10 & 1.00 & 9 & 0 & 0.80 & 0.00 & 0.00 & 0.99 \\
\hline 8 Water quality/quantity & Scale & 10 & 0 & 0.75 & 10 & 0 & 0.00 & 0.56 & 0.00 & 0.56 \\
\hline 9 Outside workers & No/comm. & 0 & 20 & 0.30 & 15 & 0 & 0.05 & 0.00 & 0.00 & 0.09 \\
\hline 10 Air quality & Scale & 10 & 0 & 0.30 & 10 & 0 & 0.00 & 0.09 & 0.00 & 0.09 \\
\hline II Traffic, short-term & Scale & 0 & 10 & 0.30 & 6 & 0 & 0.03 & 0.00 & 0.00 & 0.09 \\
\hline 12 Traffic, long-term & No. loads & 294 & 0 & 0.30 & 294 & 0 & 0.00 & 0.09 & 0.00 & 0.09 \\
\hline 13 Noise & Scale & 0 & 10 & 0.32 & 2 & 1 & 0.00 & 0.00 & 0.00 & 0.10 \\
\hline 14 Fire safety & Scale & 10 & 0 & 0.60 & 9 & 0 & 0.00 & 0.36 & 0.00 & 0.36 \\
\hline 15 Improved facilities & Scale & 10 & 0 & 0.91 & 9 & 0 & 0.01 & 0.83 & 0.00 & 0.83 \\
\hline 16 Heritage resources & R. Scale & 0 & 10 & 0.30 & 10 & 0 & 0.09 & 0.00 & 0.00 & 0.09 \\
\hline 17 Appliances and equipment & R. Scale & 0 & 10 & 0.94 & I & 7 & 0.01 & 0.43 & 0.00 & 0.88 \\
\hline 18 Criminal behaviour & Scale & 10 & 0 & 0.48 & 5 & 0 & 0.06 & 0.23 & 0.00 & 0.23 \\
\hline \multirow[t]{2}{*}{ Total social impacts } & \multirow{2}{*}{\multicolumn{4}{|c|}{18}} & \multicolumn{2}{|l|}{$\mathbf{R}_{\mathbf{l j}}$} & 1.17 & 1.77 & \multirow{2}{*}{\multicolumn{2}{|c|}{$0.00 \quad 2.39$}} \\
\hline & & & & & Scaled & $\mathbf{R}_{\mathbf{l i}_{j}}$ & 0.49 & 0.74 & & \\
\hline \multicolumn{11}{|l|}{ Ecological } \\
\hline I ROW & hectares & 0 & 2352 & 0.75 & 2352 & 0 & 0.56 & 0.00 & 0.00 & 0.56 \\
\hline 2 Rare plants & R. Scale & 0 & 10 & 0.61 & 7 & 0 & 0.18 & 0.00 & 0.00 & 0.37 \\
\hline 3 Wildlife and habitat & Square km & 0 & 50000 & 0.62 & 27.4 & 0 & 0.00 & 0.00 & 0.00 & 0.38 \\
\hline 4 Diesel fuel & $M \mathrm{~kg}$ & 7 & 0 & 0.42 & 7 & 0 & 0.00 & 0.18 & 0.00 & 0.18 \\
\hline 5 Water crossings & No. & 0 & 164 & 0.40 & 23 & 0 & 0.00 & 0.00 & 0.00 & 0.16 \\
\hline 6 Fish and aquatic resources & R. Scale & 0 & 10 & 0.49 & 2 & 0 & 0.01 & 0.00 & 0.00 & 0.24 \\
\hline 7 Hazardous materials & R. Scale & 0 & 10 & 0.30 & 3 & 8 & 0.01 & 0.06 & 0.00 & 0.09 \\
\hline 8 Wild rice & R. Scale & 0 & 10 & 0.55 & 4 & 0 & 0.05 & 0.00 & 0.00 & 0.30 \\
\hline \multirow[t]{2}{*}{ Total ecological impacts } & \multirow[t]{2}{*}{8} & & & \multicolumn{3}{|c|}{$\overline{\mathbf{R}_{\mathbf{2 j}}}$} & 0.90 & 0.49 & \multirow[t]{2}{*}{0.001} & \multirow[t]{2}{*}{1.51} \\
\hline & & & & & Scal & $\mathbf{2}_{2 j}$ & 0.59 & 0.32 & & \\
\hline \multicolumn{11}{|l|}{ Economic } \\
\hline I Training and emplos & Scale & 10 & 0 & 0.75 & 10 & 0 & 0.00 & 0.56 & 0.00 & 0.56 \\
\hline 2 Direct business opportunity & MS & 25 & 0 & 0.78 & 25 & 0 & 0.00 & 0.62 & 0.00 & 0.62 \\
\hline 3 Monthly bills & \$/month & 0 & 230 & 0.30 & 110 & 41 & 0.02 & 0.00 & 0.00 & 0.09 \\
\hline 4 Federal Govt. savings & M\$ & 2 & 0 & 0.30 & 2 & 0 & 0.00 & 0.09 & 0.00 & 0.09 \\
\hline 5 Provincial Govt. savings & M\$ & 0.44 & 0 & 0.56 & 0.44 & 0 & 0.00 & 0.32 & 0.00 & 0.32 \\
\hline 6 Retrofitting & \$/ unit & 0 & 2700 & 0.90 & 2400 & 0 & 0.63 & 0.00 & 0.00 & 0.80 \\
\hline 7 Large businesses & M\$ & 0.5 & 0 & 0.63 & 0.5 & 0 & 0.00 & 0.40 & 0.00 & 0.40 \\
\hline 8 Rates & cents / & 6 & 32.4 & 0.67 & 6 & 32.4 & 0.00 & 0.45 & 0.00 & 0.45 \\
\hline \multirow[t]{2}{*}{ Total economic impacts } & 8 & & & & $\overline{\mathbf{R}_{3 j}}$ & & 0.81 & 1.56 & \multirow{2}{*}{\multicolumn{2}{|c|}{$0.00 \quad 1.82$}} \\
\hline & & & & & Scal & & 0.44 & 0.86 & & \\
\hline
\end{tabular}


Weight Set 2

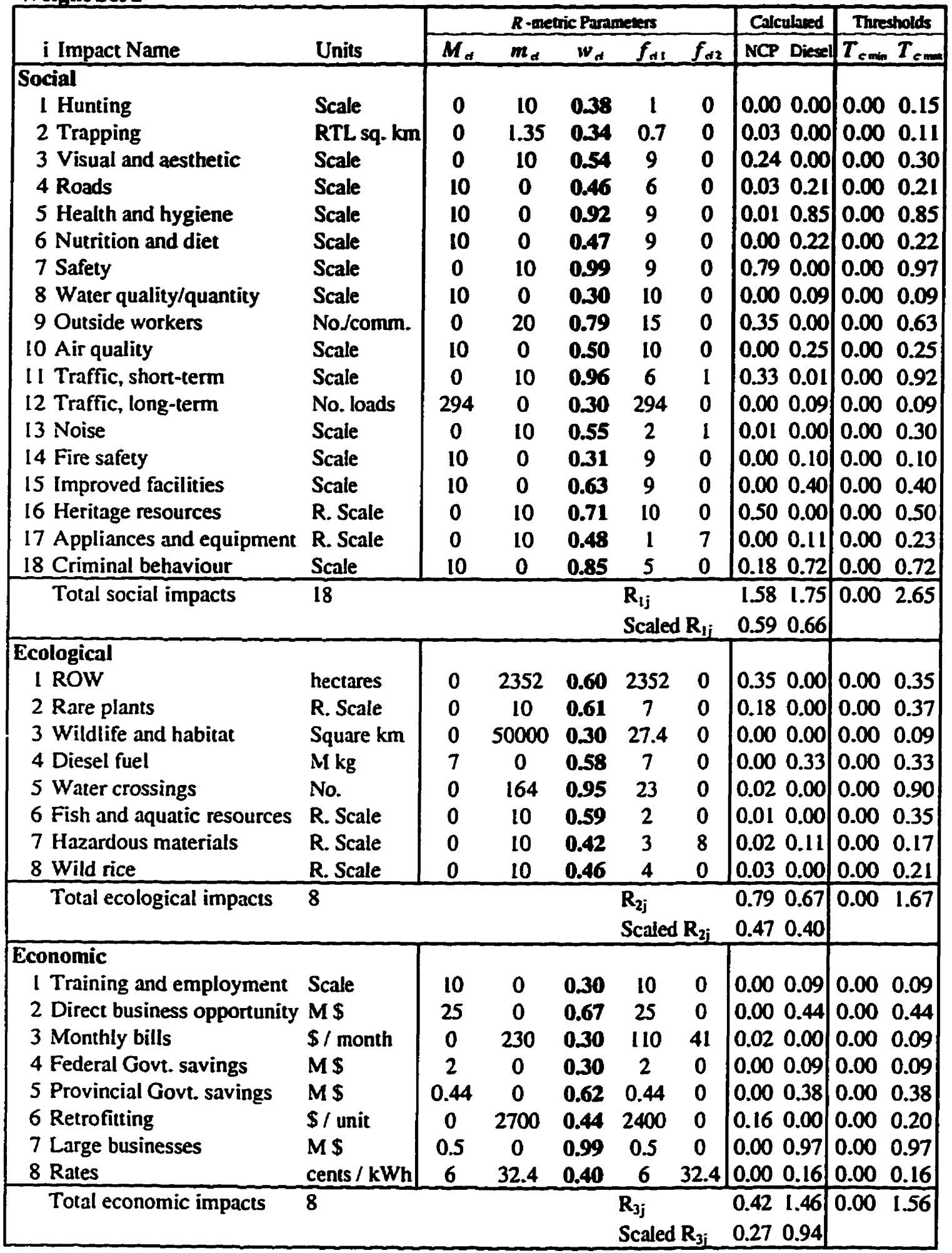


Weight Set 3

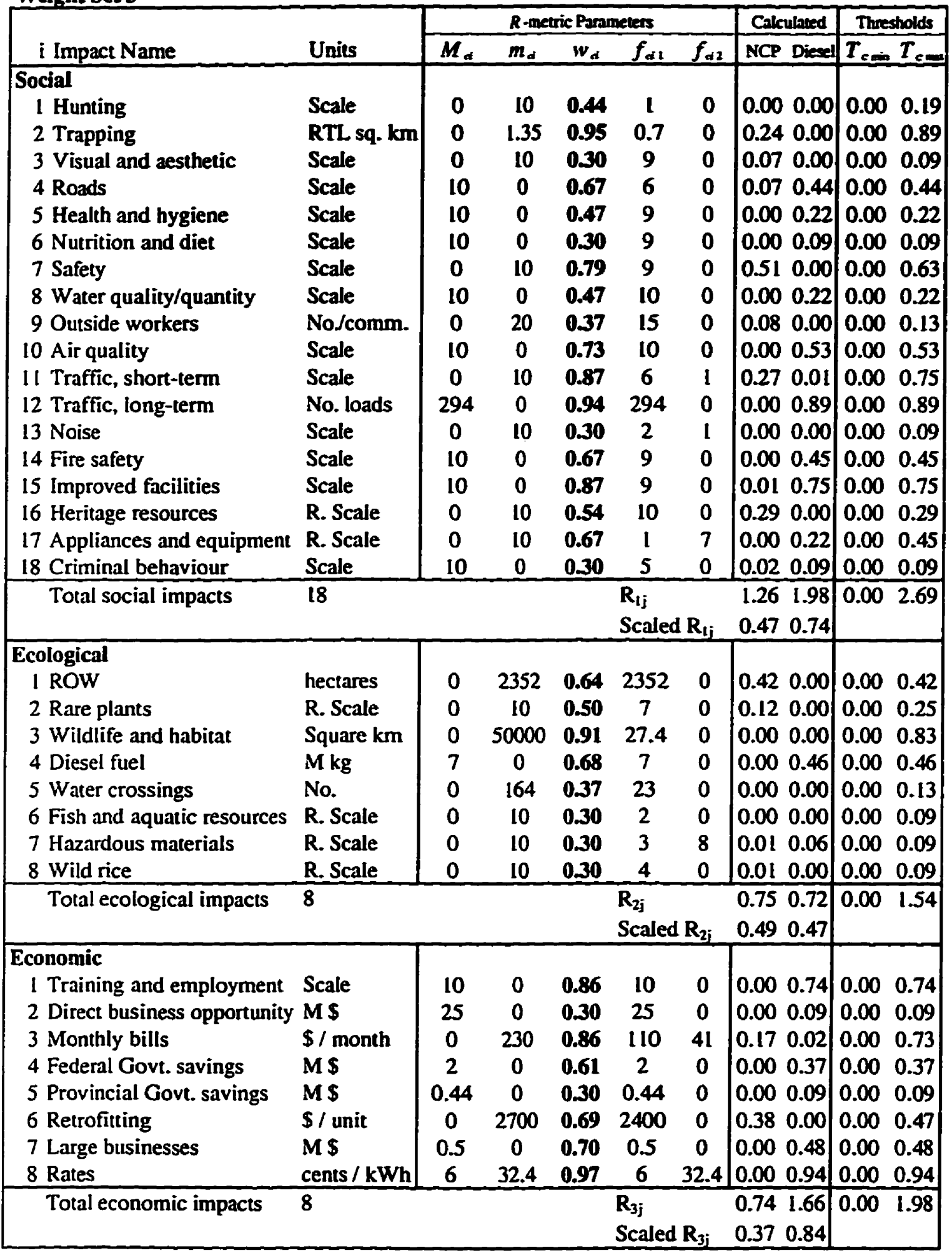




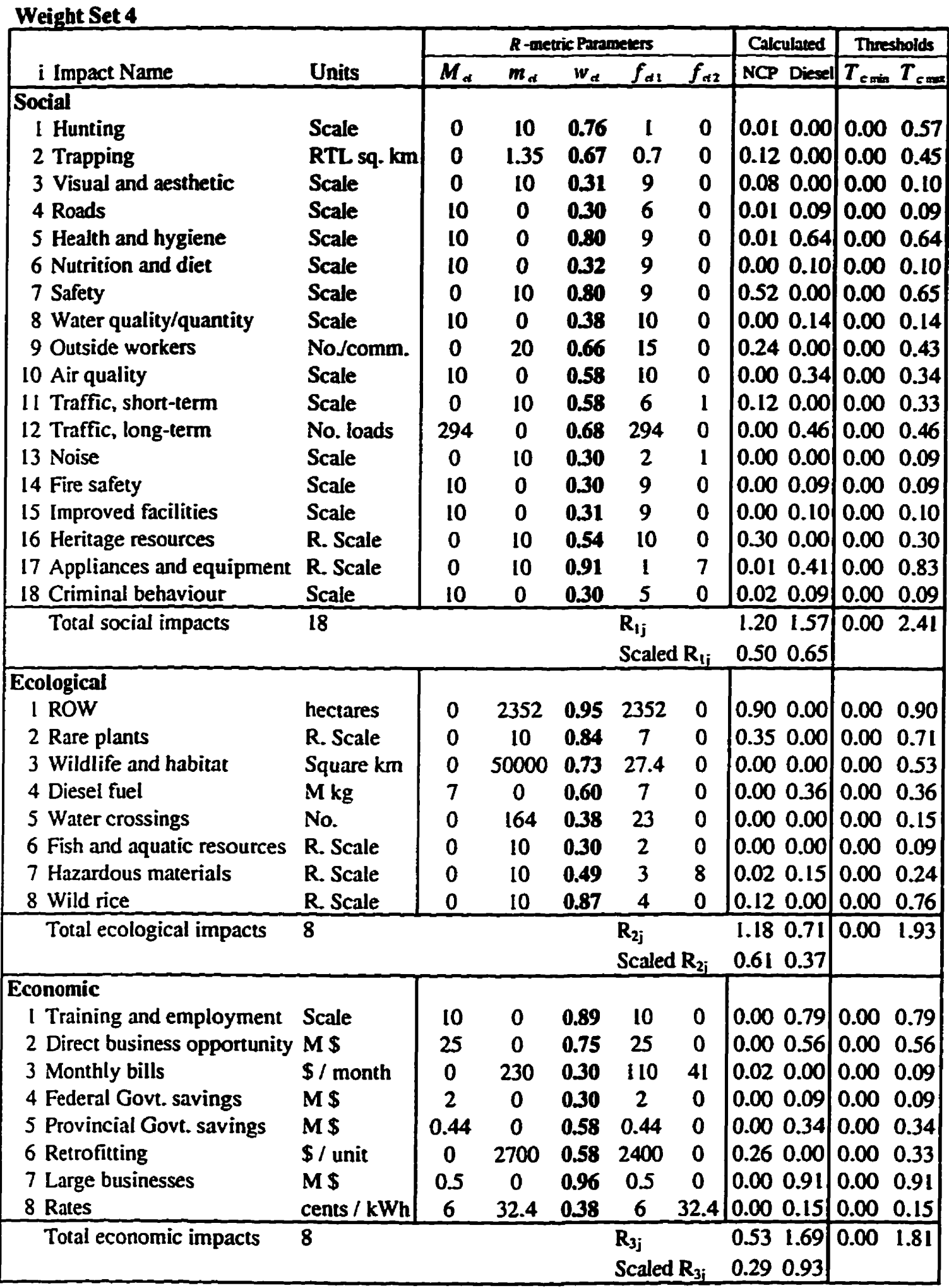




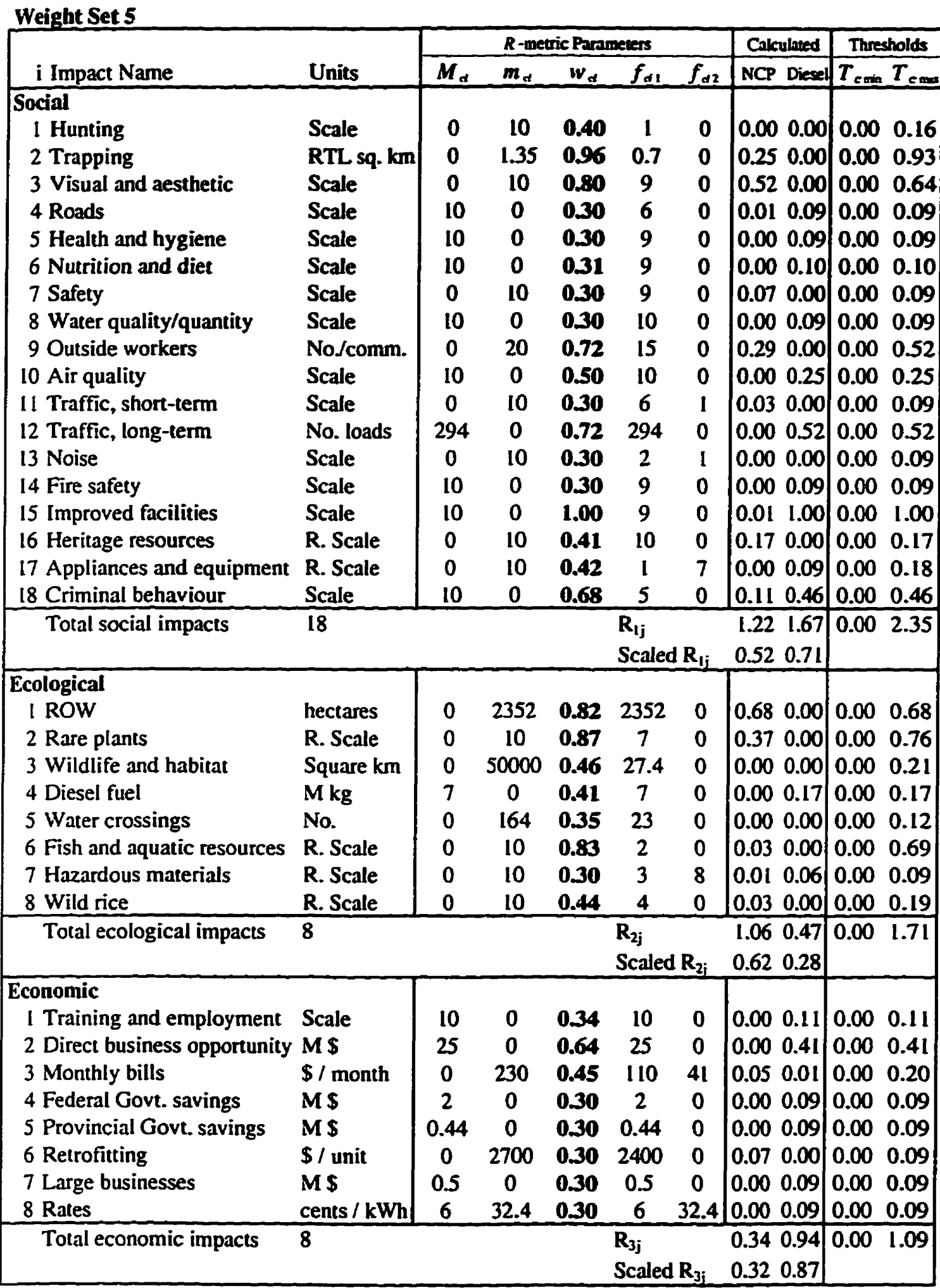


Weight Set 6

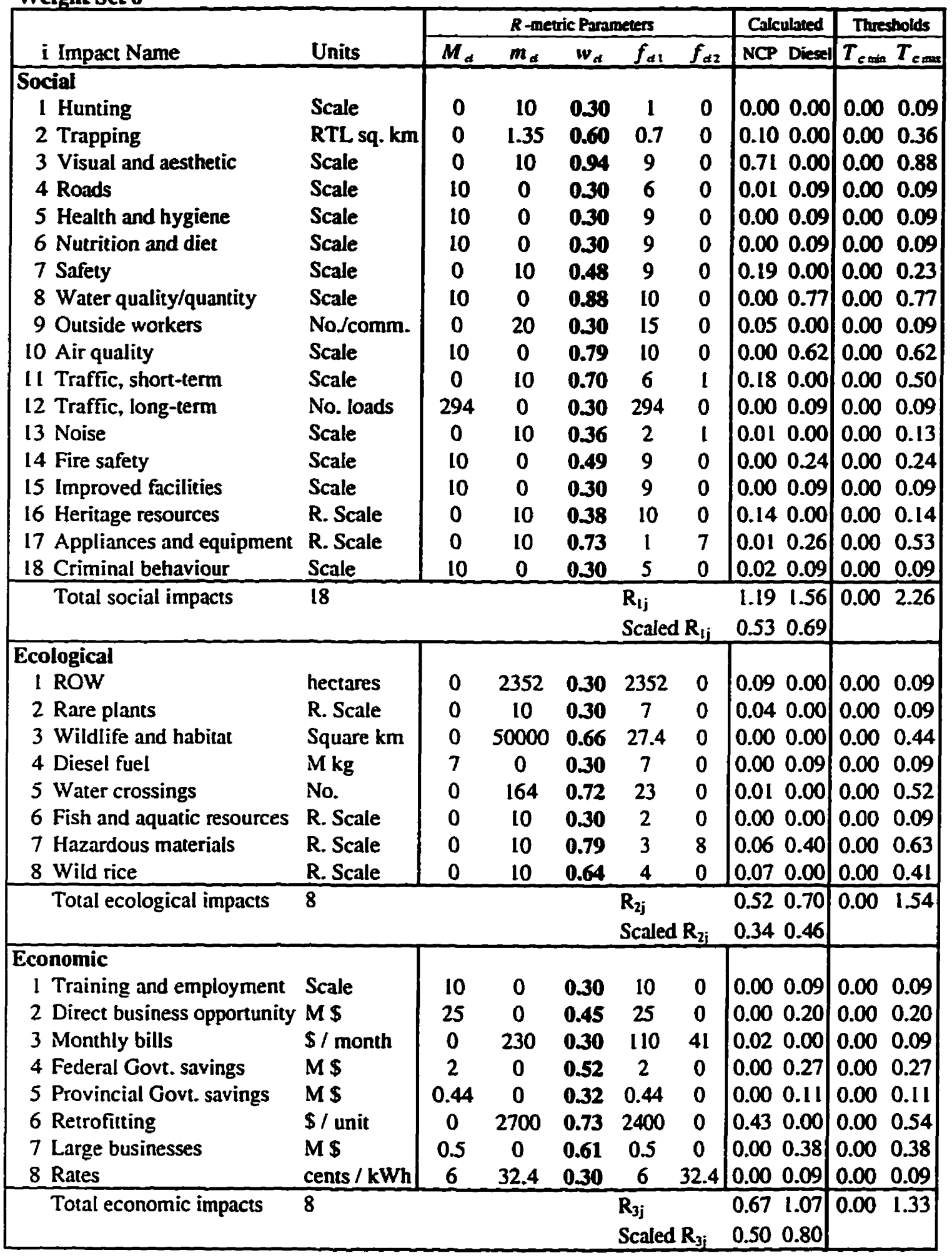


Weight Set 7

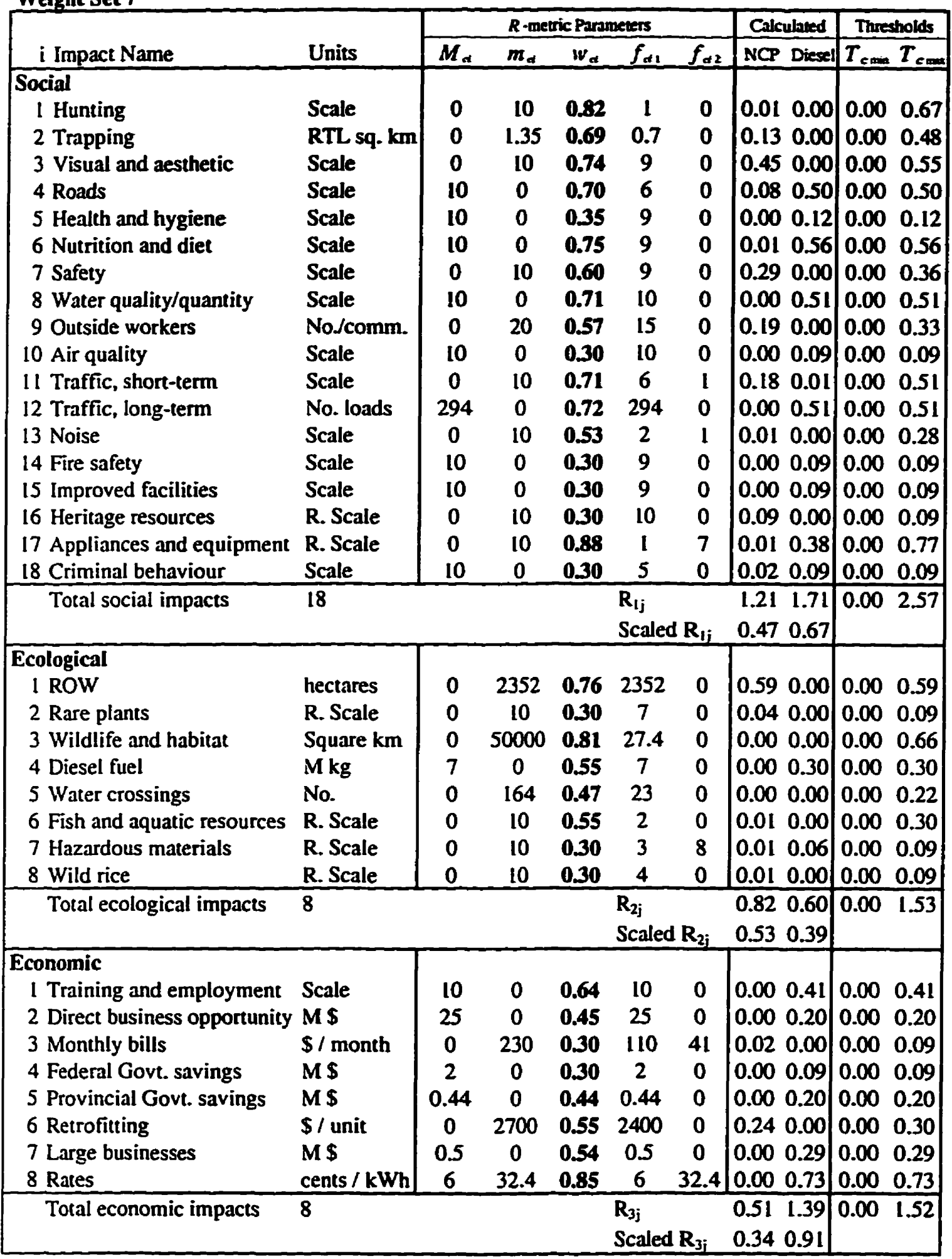




\begin{tabular}{|c|c|c|c|c|c|c|c|c|c|c|}
\hline \multirow[b]{2}{*}{ i Impact Name } & \multirow[b]{2}{*}{ Units } & \multicolumn{5}{|c|}{$R$-meric Parmmeters } & \multicolumn{2}{|c|}{ Calculored } & \multicolumn{2}{|c|}{ Thresholds } \\
\hline & & $M_{d}$ & $m_{a}$ & $w_{d}$ & $f_{d l}$ & $f_{d 2}$ & NCP & Diesel & $T_{c \operatorname{man}}$ & $T_{e \max }$ \\
\hline \multicolumn{11}{|l|}{ Social } \\
\hline I Hunting & Scale & 0 & 10 & 0.47 & $\mathbf{I}$ & 0 & 0.00 & 0.00 & 0.00 & 0.22 \\
\hline 2 Trapping & RTL sq. $\mathbf{k m}$ & $\mathbf{0}$ & 1.35 & 0.30 & 0.7 & 0 & 0.02 & 0.00 & 0.00 & 0.09 \\
\hline 3 Visual and aesthetic & Scale & 0 & 10 & 0.36 & 9 & 0 & 0.11 & 0.00 & 0.00 & 0.13 \\
\hline 4 Roads & Scale & 10 & 0 & 0.36 & 6 & 0 & 0.02 & 0.13 & 0.00 & 0.13 \\
\hline 5 Health and hygiene & Scale & 10 & 0 & 0.30 & 9 & 0 & 0.00 & 0.09 & 0.00 & 0.09 \\
\hline 6 Nutrition and diet & Scale & 10 & 0 & 0.51 & 9 & 0 & 0.00 & 0.26 & 0.00 & 0.26 \\
\hline 7 Safety & Scale & $\mathbf{0}$ & 10 & 0.74 & 9 & 0 & 0.45 & 0.00 & 0.00 & 0.55 \\
\hline 8 Water quality/quantity & Scale & 10 & 0 & 0.68 & 10 & 0 & 0.00 & 0.46 & 0.00 & 0.46 \\
\hline 9 Outside workers & No./comm. & $\mathbf{0}$ & 20 & 0.93 & 15 & $\mathbf{0}$ & 0.48 & 0.00 & 0.00 & 0.86 \\
\hline 10 Air quality & Scale & 10 & $\mathbf{0}$ & 0.99 & 10 & $\mathbf{0}$ & 0.00 & 0.98 & 0.00 & 0.98 \\
\hline 11 Traffic, short-term & Scale & 0 & 10 & 1.00 & 6 & I & 0.36 & 0.01 & 0.00 & 0.99 \\
\hline 12 Traffic, long-term & No. loads & 294 & 0 & 0.33 & 294 & $\mathbf{0}$ & 0.00 & 0.11 & 0.00 & 0.11 \\
\hline 13 Noise & Scale & 0 & 10 & 0.30 & 2 & 1 & 0.00 & 0.00 & 0.00 & 0.09 \\
\hline 14 Fire safety & Scale & 10 & 0 & 0.88 & 9 & $\mathbf{0}$ & 0.01 & 0.77 & 0.00 & 0.77 \\
\hline IS Improved facilities & Scale & 10 & 0 & 0.56 & 9 & $\mathbf{0}$ & 0.00 & 0.31 & 0.00 & 0.31 \\
\hline 16 Heritage resources & R. Scale & 0 & 10 & 0.30 & 10 & 0 & 0.09 & 0.00 & 0.00 & 0.09 \\
\hline 17 Appliance: & R. Scale & 0 & 10 & 0.50 & 1 & 7 & 0.00 & 0.12 & 0.00 & 0.25 \\
\hline 18 Criminal b & Scale & 10 & 0 & 1.00 & 5 & 0 & 0.25 & 1.00 & 0.00 & 1.00 \\
\hline Total social impacts & \multirow{2}{*}{\multicolumn{3}{|c|}{18}} & \multicolumn{3}{|c|}{$R_{\mathbf{i j}}$} & 1.34 & 2.06 & 0.00 & 2.72 \\
\hline & & & & \multicolumn{3}{|c|}{ Scaled $\mathbf{R}_{\mathbf{i j}}$} & 0.49 & 0.76 & & \\
\hline \multicolumn{11}{|l|}{ Ecological } \\
\hline I ROW & hectares & 0 & 2352 & 0.30 & 2352 & $\mathbf{0}$ & 0.09 & 0.00 & 0.00 & 0.09 \\
\hline 2 Rare plants & R. Scale & $\mathbf{0}$ & 10 & 0.89 & 7 & 0 & 0.39 & 0.00 & 0.00 & 0.79 \\
\hline 3 Wildlife and habitat & Square km & 0 & 50000 & 0.69 & 27.4 & 0 & 0.00 & 0.00 & 0.00 & 0.48 \\
\hline 4 Diesel fuel & M kg & 7 & 0 & 0.30 & 7 & 0 & 0.00 & 0.09 & 0.00 & 0.09 \\
\hline 5 Water crossings & No. & 0 & 164 & 0.30 & 23 & 0 & 0.00 & 0.00 & 0.00 & 0.09 \\
\hline 6 Fish and aquatic resources & R. Scale & 0 & 10 & 0.48 & 2 & 0 & 0.01 & 0.00 & 0.00 & 0.23 \\
\hline 7 Hazardous materials & R. Scale & $\mathbf{0}$ & 10 & 0.30 & 3 & 8 & 0.01 & 0.06 & 0.00 & 0.09 \\
\hline 8 Wild rice & R. Scale & 0 & 10 & 0.98 & 4 & $\mathbf{0}$ & 0.15 & 0.00 & 0.00 & 0.97 \\
\hline \multirow[t]{2}{*}{ Total ecological impacts } & \multirow{2}{*}{\multicolumn{3}{|c|}{8}} & \multicolumn{3}{|c|}{$\mathbf{R}_{\mathbf{2 j}}$} & 0.81 & 0.38 & \multirow[t]{2}{*}{0.001} & 1.68 \\
\hline & & & & & Scal & & 0.48 & 0.23 & & \\
\hline \multicolumn{11}{|l|}{ Economic } \\
\hline I Training and employment & Scale & 10 & $\mathbf{0}$ & 0.66 & 10 & 0 & 0.00 & 0.44 & 0.00 & 0.44 \\
\hline 2 Direct business opportunity & $\mathbf{M} \$$ & 25 & 0 & 0.48 & 25 & $\mathbf{0}$ & 0.00 & 0.23 & 0.00 & 0.23 \\
\hline 3 Monthly bills & \$/ month & 0 & 230 & 0.61 & 110 & 41 & 0.09 & 0.01 & 0.00 & 0.37 \\
\hline 4 Federal Govt. savings & M\$ & 2 & 0 & 0.30 & 2 & $\mathbf{0}$ & 0.00 & 0.09 & 0.00 & 0.09 \\
\hline 5 Provincial Govt. savings & M\$ & 0.44 & 0 & 0.30 & 0.44 & 0 & 0.00 & 0.09 & 0.00 & 0.09 \\
\hline 6 Retrofitting & $\$ /$ unit & $\mathbf{0}$ & 2700 & 0.94 & 2400 & $\mathbf{0}$ & 0.70 & 0.00 & 0.00 & 0.88 \\
\hline 7 Large businesses & M\$ & 0.5 & $\mathbf{0}$ & 0.55 & 0.5 & $\mathbf{0}$ & 0.00 & 0.30 & 0.00 & 0.30 \\
\hline 8 Rates & cents / kWh & 6 & 32.4 & 0.30 & 6 & 32.4 & 0.00 & 0.09 & 0.00 & 0.09 \\
\hline Total economic impacts & 8 & & & & $\overline{\mathbf{R}_{\mathbf{3 j}}}$ & & 0.89 & 1.12 & 0.00 & 1.58 \\
\hline & & & & & Scal & $\mathbf{R}_{3 \mathbf{j}}$ & 0.56 & 0.71 & & \\
\hline
\end{tabular}




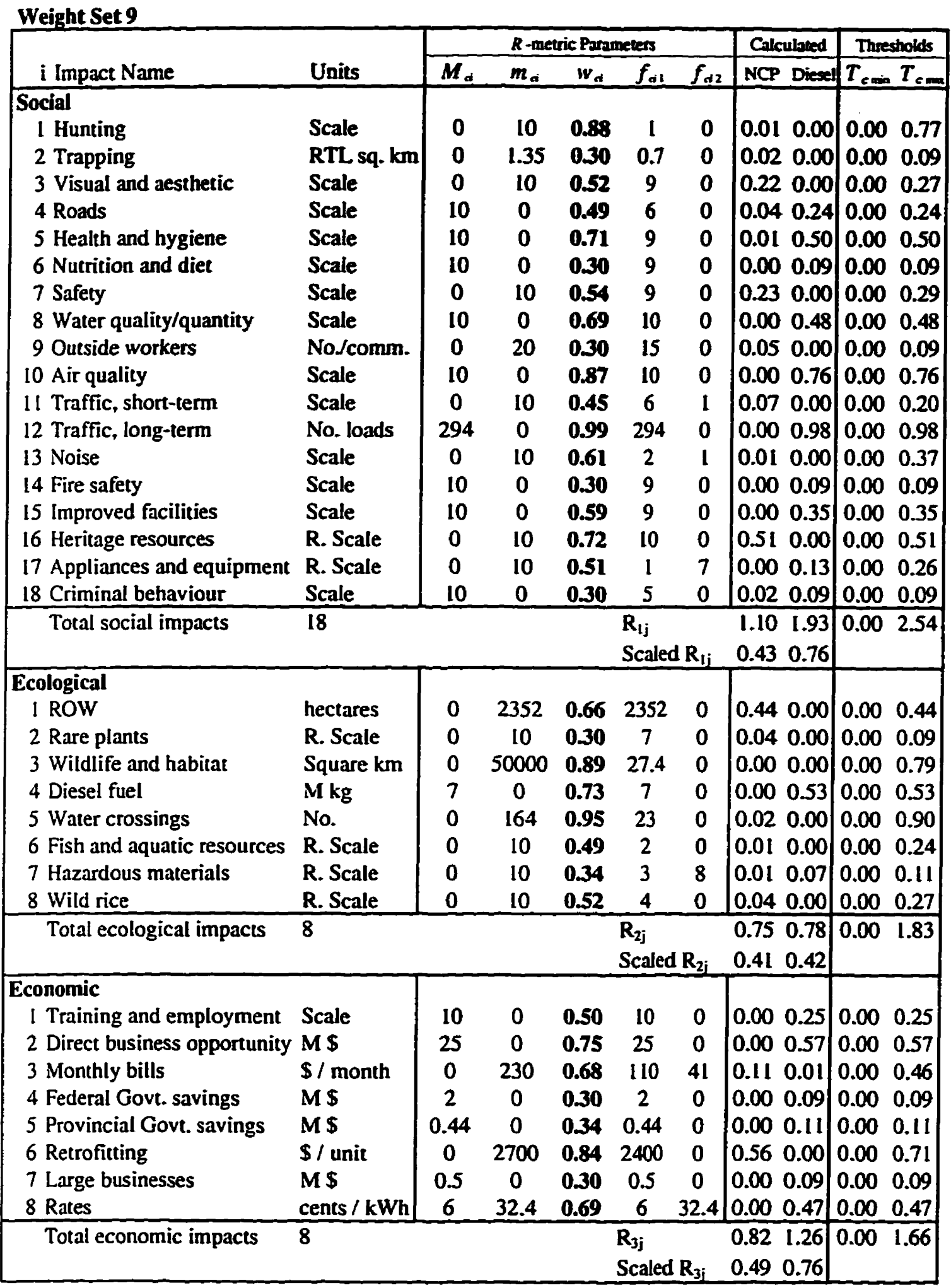


Weight Set 10

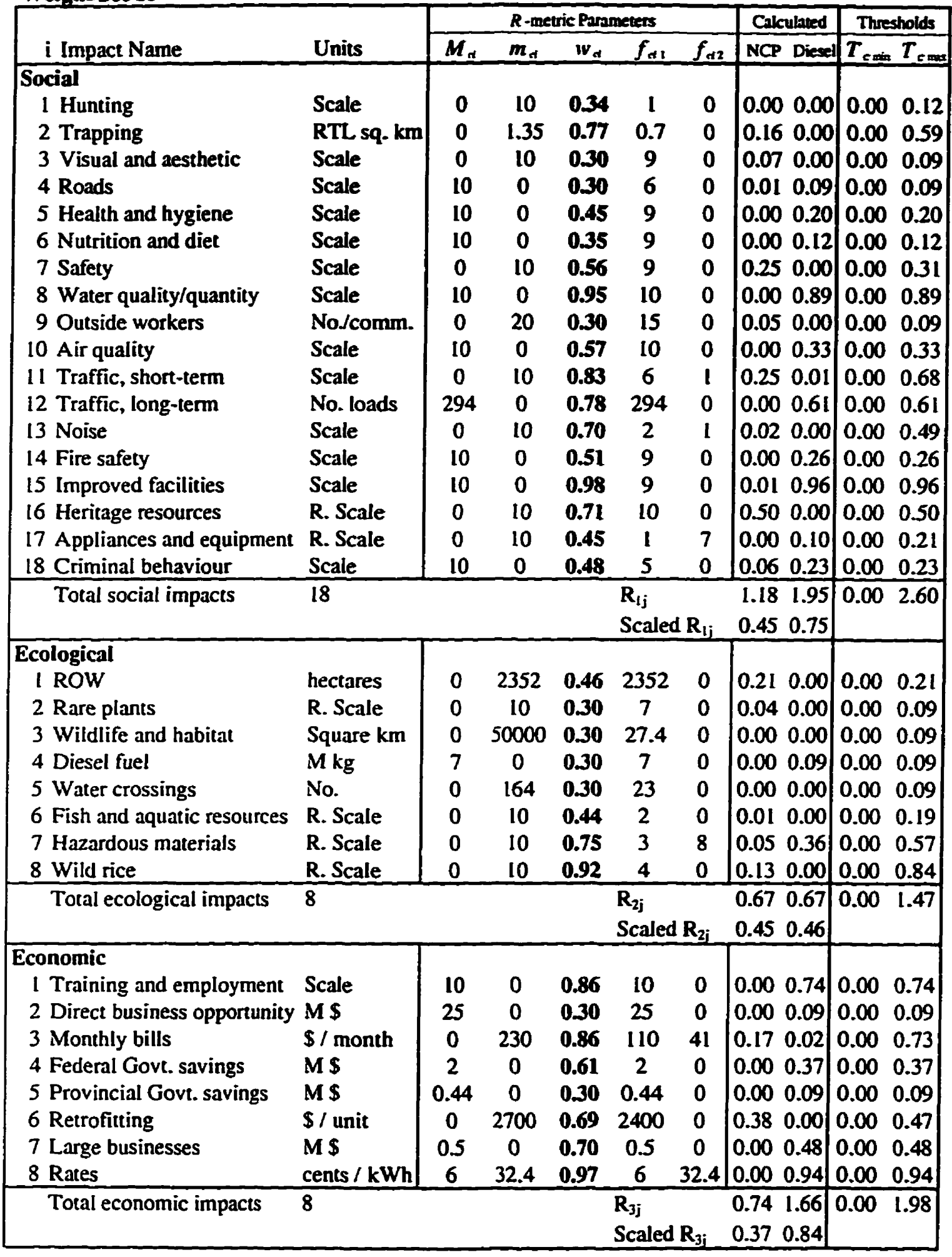




\section{Sensitivity Analysis of Impact Values}

The values shown in bold were individually altered in order to determine the corresponding category indexes (Table 4.3)

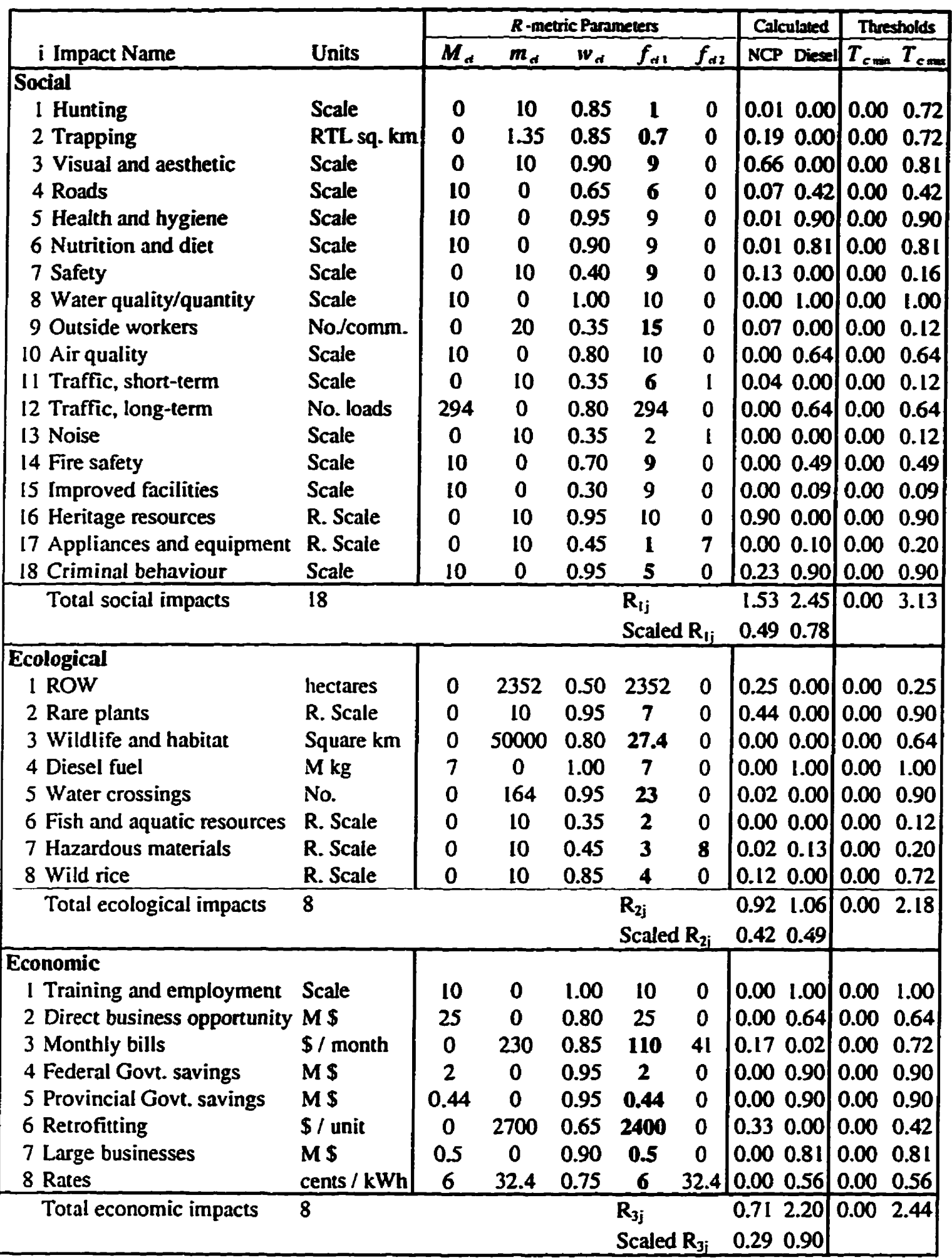

